\title{
Pharmacologically controlled neurotrophic factor gene therapy for Parkinson's disease
}

\author{
Dissertation \\ for the award of the degree \\ "Doctor of Philosophy (PhD)" \\ Division of Mathematics and Natural Sciences of the \\ Georg-August-Universität Göttingen \\ within the doctoral program CMPB \\ of the Georg-August University School of Science (GAUSS)
}

submitted by

Shi Cheng

from Changchun, China

Göttingen, 2019 


\section{Thesis Committee}

Dr. Sebastian Kügler (Referee)

Department of Neurology

Georg-August-University Göttingen

Prof. Dr. Markus Zweckstetter (Referee)

Research Group Protein Structure Determination Using NMR

Max Planck Institute for Biophysical Chemistry

\section{Prof. Dr. André Fischer}

Department for Psychiatry and Psychotherapy

University Medical Center Göttingen

Other Members of the Examination Board:

Prof. Dr. mult. Thomas Meyer

Department of Molecular Psychocardiology

University Medical Center Göttingen

Prof. Dr. Thomas Dresbach

Department of Anatomy and Embryology

University Medical Center Göttingen

Prof. Dr. Michael Müller

Department of Neurophysiology and Sensory Physiology

University Medical Center Göttingen

Date of oral examination: $25^{\text {th }}$ June 2019 


\section{Declaration}

Hereby, I declare that I prepared the PhD Thesis "Pharmacologically controlled neurotrophic factor gene therapy for Parkinson's disease" on my own and with no other sources and aids than quoted.

Göttingen, 30.03.2019 



\section{Contents}

1. Introduction 1

1.1 Parkinson's disease 1

1.1.1 Pathophysiology, symptoms and diagnosis of PD 1

1.1.2 Current treatments for Parkinson's disease 4

1.2.1 Gene therapy clinical trials 10

1.2.2 Gene therapy for Parkinson's disease 11

1.2.3 AAV vectors and regulated gene expression system 13

1.3 Mifepristone metabolism in rats or human 18

$\begin{array}{ll}\text { 1.3.1 Mifepristone pharmacokinetics } & 19\end{array}$

1.3.2 CYP3A enzymes and their inhibitors $\quad 20$

1.3.3 Alpha-1 acid glycoprotein and its binding affinity for Mfp 21

1.4 Aim of the project $\quad 22$

2. Materials $\quad 24$

2.1 Animals and cells 24

2.1.1 Ethical approval of animal experimentations 24

2.1.2 Rats $\quad 24$

2.2 Chemicals and drugs $\quad 25$

2.3 Solutions 26

$\begin{array}{ll}2.4 \text { Kits } & 27\end{array}$

2.5 Enzymes 28

3. Methods $\quad 29$

3.1 Stereotaxic injection of AAV vectors into rat striatum 29

3.2 Drugs application to rats 30

3.3 Transcardial perfusion and processing on rats brains 31

3.4 Tissue preparation for dopamine and GDNF quantification 31

3.5 Fluorescence microscopy 32

3.6 Motor functional test 33

3.7 Molecular biology 34

3.7.1 PCR amplification 34

3.7.2 Digestion by restriction enzymes 35

3.7.3 Agarose gel electrophoresis $\quad 35$

3.7.4 Gel extraction kit for DNA 36

3.7.5 PCR purification 36

$\begin{array}{ll}\text { 3.7.6 Ligation } & 37\end{array}$

3.7.7 Transformation 37

3.8 Building hAAG rat model, plasma collection and hAAG quantification 38 
4.2 Kinetics of induced GDNF expression 39

4.3 Evaluations of Mfp dosages and application routes 42

4.4 Gender-dependent mifepristone pharmacokinetics and GDNF expression 47

4.5 Evalutation of the GS-GDNF vector in the partial striatal 6-OHDA model of PD 50

4.5.1 Functional evaluation of AAV-5-GS-GDNF in the apomorphine - induced motor imbalance test

4.5.2 Reactivation of the GS-GDNF vector after long-term inactivation

4.5.3 Effects of GDNF expression from AAV-GS-GDNF on dopamine metabolism 57

4.6 Effect of CYP3A inhibition on Mfp pharmacokinetics

4.7 Generation of a humanized rat model to study pharmacokinetics of Mfp

4.8 Evaluation of the GS-GDNF system in the hAAG rats model

5. Discussion

5.1 Neurotrophic factor gene therapy for PD: failures and prospects 70

5.2 Precise control of the GeneSwitch system 71

5.3 Treatment effect of the developed gene therapy method 73

5.4 Optimization of pharmacodynamics: CYP3A inhibition $\quad 74$

5.5 Optimizing the application route of Mfp

5.6 Comparison of GS-GDNF with other systems for regulated GDNF expression 76

5. 7 Evaluation of the GS-GDNF system in a "humanized" rat model (hAAG expressing rats).

5.8 Outlook 


\section{Introduction}

\subsection{Parkinson's disease}

Parkinson's disease (PD) is the most common ageing-related motoric neurodegenerative disease, initially described in 1817 by James Parkinson (Mhyre et al., 2012). It affects 2 - 3\% of the population older than 65 years. Neuronal loss in the substantia nigra, which causes striatal dopamine deficiency, and intracellular inclusions containing aggregates of $\alpha$-synuclein are the neuropathological hallmarks of Parkinson disease (Poewe et al., 2017). Patients suffering from Parkinson's disease (PD) will typically experience a range of motor and non-motor symptoms during the course of their illness (Politis et al., 2010).

\subsubsection{Pathophysiology, symptoms and diagnosis of PD}

The primary pathologic hallmarks of PD are loss of dopaminergic neurons in the substantia nigra pars compacta, and the aggregation of $\alpha$-synuclein in neurons in substantia nigra pars compacta. The deposition of $\alpha$-synuclein in neurons and the loss of pigmented dopaminergic neurons in the substantia nigra together can be used to specify PD, one of these symptoms is not sufficient for specifying PD (Dickson et al., 2009; Halliday et al., 2011).

The abnormal deposition of $\alpha$-synuclein in the axons and neurites of neurons in several different brain regions is one of the important neuropathological features of PD (Braak et al, 2003; Volpicelli-Daley et al., 2014). Aggregated $\alpha$-synuclein associated with other proteins, such as ubiquitin, neurofilament proteins, and alpha $B$ crystalline, consists a dense core surrounded by a halo of 10-nm-wide radiating fibrils, which is named Lewy bodies. Lewy body is considered to contribute to PD (Jellinger et al., 2007; Engelender, 2008), although its exact contribution to the disease is still unknown. Histological examination of 
post-mortem brains reveals the presence of alpha-synuclein in cranial nerve nuclei, premotor oculomoter, precerebellar and vestibular brainstem nuclei (Seidel et al., 2015). In patients with Alzheimer pathology, there is a different pattern of a-synuclein pathology that concentrates mainly in limbic brain region (lacono et al., 2015).

The other required neurological feature of $P D$ is neuronal degeneration in certain types of neurons within particular brain regions. In early-stage disease, loss of dopaminergic neurons is restricted to the ventrolateral substantia nigra with relative sparing of other midbrain dopaminergic neurons, but becomes more widespread by end-stage disease (Poewe et al., 2017) (Fig. 1.1). The dramatic loss of these dopaminergic neurons even early in the disease suggests that the degeneration in this region starts before the onset of motor symptoms (Poewe et al., 2017; Halliday et al., 2010).
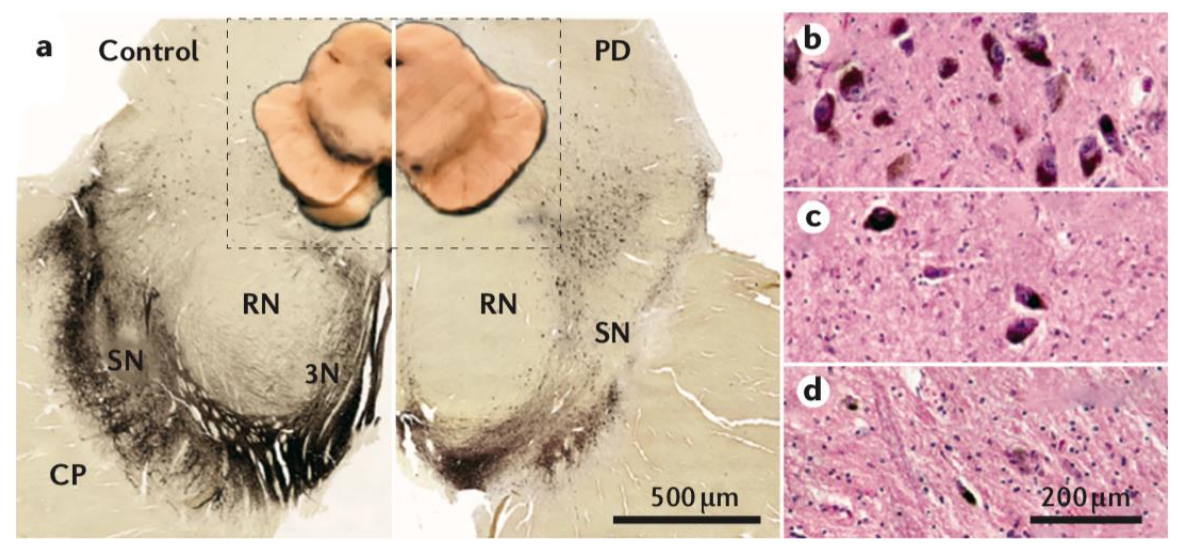

Figure 1.1 The main diagnostic neuropathologies for Parkinson disease.

a, PD is defined by depigmentation of the substantia nigra (SN) compared with control. Macroscopical and transverse sections of the midbrain upon immunohistochemical staining for tyrosine hydroxylase, the rate limiting enzyme for the synthesis of dopamine, are shown. Selective loss of the ventrolateral parts of the $\mathrm{SN}$ with sparing of the more medial and dorsal regions is evident in the histological section. $\mathbf{b}-\mathbf{d}$, Haematoxylin and eosin staining of the ventrolateral region of the SN showing a normal distribution of pigmented neurons in a healthy control (part $\mathbf{b}$ ) and diagnostically significant moderate (part c) or severe (part d) pigmented cell loss in PD. REF: Poewe et al., 2017. 
Except dopaminergic neuron loss in $\mathrm{SN}$ and $\alpha$-synuclein aggregation, several further mechanisms take part in the ethiology of PD. Scientists suggested the mitochondrial dysfunction as a key element in the pathogenesis of PD (Schapira, 2007; Bose and Beal, 2016). A vicious cycle was suggested, that $\alpha$-synuclein aggregation and mitochondrial dysfunction exacerbate each other. Oxidative stress is considered as a consequence of mitochondrial dysfunction. Oxidative stress is increased in the brain tissue of PD patients, however it is still debatable whether it occurs early or late during the demise of neurons (Dias et al., 2013).

The clinical manifestations and symptoms can be different for individuals. Early symptoms may be mild and go unnoticed. Symptoms often begin on one side of the patient's body and usually remain worse on that side, even after symptoms begin to affect both sides. Common movement symptoms of PD include tremor, bradykinesia, rigid muscles, impaired posture and balance, loss of automatic movements, speech changes and writing changes (Jankovic, 2008; Jankovic et al., 2012; Poewe et al., 2017). Parkinson's disease not only affects motor function of patients, but also induced mental and visceral problems. Other symptoms of PD also need to be noticed and to be treated such as thinking difficulties, depression, swallowing problem, eating problem, sleep disorders, bladder problems and constipation (Chaudhuri et al., 2006).

Diagnosis of Parkinson's disease is depending on clinical criteria which are not unified in the world. Generally, the criteria are based on the presence of a combination of cardinal motor features, associated and exclusionary symptoms, and the relief of motor symptoms as response to L-DOPA (Rao et al., 2003). Specifically, PD patients can be diagnosed by their family medical history, static tremor and slow moving, development of motor defect from unilateral side to the opposite side and exclusion of atypical Parkinson's disease-like symptoms (Olanow et al., 2009). Treatment effects by L-DOPA provide powerful support for the diagnosis of PD (Chaudhuri et al., 2006). Although several criteria are available worldwide, none of them can diagnose PD absolutely accurate. Taking the criteria developed by the UK Parkinson's Disease Society Brain Bank for example, 76 PD patients were diagnosed from 100 potential patients at the 
clinical diagnosis by the pathologic criteria, but later neuropathological examination suggested ten from them were misdiagnosed. Assessment of the clinical features suggested that an accuracy of roughly ninety percent may be the highest that can be expected using current diagnostic criteria (Hughes et al., 1992; Hughes et al., 2001). Except diagnosis by clinical criteria, molecular neuroimaging is being developed to distinguish PD from clinical mimics. In 1980s, a breakthrough in molecular neuroimaging was made by visualization of striatal dopamine depletion in PD patients using ${ }^{18} \mathrm{~F}$-labelled L-DOPA and PET (Garnett et al., 1983). Since then, ${ }^{125}$-ioflupane single-photon emission CT (SPECT) was approved for differentiating PD from several clinical mimics in clinical use, and structural MRI was used for PD diagnosis as well (Mahlknecht et al., 2010; Politis et al., 2014; Stoessl et al., 2014).

Although formation of Lewy bodies is considered as one of the important pathological symptoms of PD, little or no correlation exists between Lewy body burden and severity of clinical manifestation (Outeiro et al., 2019). PD is not only a disease of the motor system, but come along with a variety of visceral and psychiatric problems, a multi-methods diagnosis of PD is more accurate to respond the divergent symptomatics of PD.

\subsubsection{Current treatments for Parkinson's disease}

Striatal dopamine depletion induced by dopaminergic neurons loss in substantia nigra pars compacta is considered as the major pharmacological target in PD treatments. L-DOPA, the precursor to dopamine, was tested to substitute the loss of striatal dopamine. The positive treatment effect achieved by L-DOPA represented a revolutionary breakthrough in the treatment of PD, and promoted the development of multiple treatment methods targeting the nigrostriatal dopaminergic transmission (Tomlinson et al., 2010).

The PD treatment by L-DOPA was developed and clinically approved by George Cotzias in 1969 (Cotzias et al., 1969). Until now, L-DOPA remains the gold 
standard for PD treatments, and is always the first choice for PD patients. L-DOPA crosses the blood-brain barrier, whereas dopamine cannot, and is converted into dopamine by the enzyme DOPA decarboxylase in the central nervous system to substitute the loss of striatal dopamine (Simuni et al., 2008). However, L-DOPA only provides temporary medical relief of the motor symptoms. It cannot prevent disease development due to the lack of protection of the dopaminergic projection. Following the temporary medical relief, most PD patients have to suffer the development of motor complications, such as motor response oscillations and dyskinesias, as side effects of L-DOPA (Olanow et al., 2006; Cenci et al., 2014). The mechanisms of L-DOPA induced side effects are not completely understood. Some scientists suggested that the side effects of L-DOPA are induced by the discontinuous L-DOPA delivery caused by its short half-life and its variable blood-brain barrier transport and gastro-intestinal absorption (Poewe et al., 2015). Thus, continuous L-DOPA deliveries have been developed against L-DOPA induced dyskinesias. For instance, continuous delivery of L-DOPA was performed by intestinal gel infusion. Pre-existing dyskinesia was reduced by the continuous L-DOPA delivery. The treatment effect of continuous L-DOPA delivery in pre-existing dyskinesias supports the conjecture that development of motor complications in many cases of treatment with L-DOPA can be ascribed to discontinuous delivery of L-DOPA (Poewe et al., 2015).

Except re-uptaken into the synapse by dopamine transporter, synaptically released dopamine is mainly cleared by monoamine oxidase type $B$ (MAOB) in glial cells. Inhibitors of MAOB (e.g. selegiline, safinamide) are usually used as an adjunct to L-DOPA to prolong the half-life of dopamine and to increase synaptic dopamine concentrations (Birkmayer et al., 1977; Schapira et al., 2011). Selegiline was frequently used as a MAOB inhibitor for PD patients since the 1970s, however the clinical application of selegiline was limited by its irreversible MAOB inhibiting effect. Selegiline was recently replaced by a reversible MAOB inhibitor, safinamide (Birkmayer et al., 1977; Schapira et al., 2017). The treatment effect of PD by monotherapy with MAOB inhibitors has also been demonstrated (Fox et al., 2011). 
Except MAOB inhibitors, catechol-O-methyltransferase (COMT) inhibitors and aromatic amino acid decarboxylase (AADC) inhibitors are also usually used together with L-DOPA to increase bioavailability and the half-life of L-DOPA by inhibiting L-DOPA metabolism in the periphery. Not only the central nervous system but also the peripheral nervous system converses L-DOPA to dopamine, and the excessive peripheral dopamine signaling is responsible for low systolic blood pressure and abnormal gastrointestinal motility (Rubi et al., 2010). To avoid the excessive levels of dopamine in the peripheral nervous system and to extend the duration of therapeutic effects of single L-DOPA dose, L-DOPA is usually given in combination with peripheral inhibitors of AADC to block the primary metabolic pathway of L-DOPA, and COMT inhibitors are used to prevent secondary metabolic pathway as ortho-methylation of L-DOPA (Fox et al., 2011; Ferreira et al., 2016). Carbidopa and Opicapone are the representatives of AADC inhibitors and COMT inhibitors, respectively (Olanow et al., 2014; Ferreira et al., 2016).

Except enhancing the level of dopamine in the nigro-striatal system, stimulation of dopamine receptors with dopamine agonists is another strategy to treat PD. As a dopamine agonist targeting the D2 dopamine receptor family, ergot alkaloid bromocriptine was first used in PD therapy in the 1970s (Connolly et al., 2014). Since then, ergoline derivatives became an important medicine in PD treatment, however, currently, they have been disused due to safety concerns by its undesired binding with 5-hydroxytryptamine receptors. Nowadays, dopamine agonists used in PD therapy are all non-ergoline drugs (Fox et la., 2011). Advantages of dopamine agonists in PD therapy include markedly reduced risk to induce motor complications by their less pulsatile stimulation to striatal dopamine receptor and the longer half-life of dopamine agonists than L-DOPA, which makes them more attractive in motor fluctuation treatment (Jankovic et al., 2012; Connolly et al., 2014). Disadvantages of dopamine agonists include their relatively limited treatment effect compared to L-DOPA and the potential to induce impulse dyscontrol and drowsiness, which is considered to be induced by their preferential stimulation to D3 receptors in the ventral striatum (Calne et al., 1984; 
Paus et al., 2003). Apomorphine stands out among the other dopamine agonists by its roughly equal treatment effect with L-DOPA to motor fluctuations, and it is being used against L-DOPA induced dyskinesias (Frankel et al., 1990; Katzenschlager et al., 2005).

All therapies mentioned before are related to dopaminergic pharmacology. Few methods with non-dopaminergic pharmacology have been used in clinical treatment of PD also. High-frequency $(100-200 \mathrm{~Hz})$ electrical stimulation to subthalamic nucleus was developed as a treatment method to PD, and was named as deep brain stimulation (DBS) (Limousin et al., 1995). The dramatic antiparkinsonian efficacy of DBS has been confirmed by lots of clinical trials, and now DBS becomes an established evidence-based therapy in severe PD patients to treat their dyskinesia and motor fluctuation (Fox et al., 2011). As a complex therapy, high level of interdisciplinary expertise is required for DBS, such as accurate placement of the electrode, postoperative programing and performing correct frequency of the electrical stimulation (Bronstein et al., 2011). The common adverse events are intracranial bleedings and infections (Voges et al., 2007). Even though the exact underlying physiological mechanism of DBS remains unclear, studies confirmed that idiopathic PD patients with a good response to L-DOPA are the ideal candidates for DBS therapy. In contrast, PD patients who do not respond to L-DOPA are unlikely to respond to DBS (Bronstein et al., 2011). Except DBS, exercise-based treatment is also widely used as a non-dopaminergic method in PD therapy. Exercise-based treatment is a valid supplement for the dopaminergic therapies or DBS with good safety and almost no adverse effect. Epidemiologic evidence suggests that moderate to vigorous exercise may protect against PD (Xu et al., 2010).

In addition to the the clinically available PD treatments mentioned above, several experimental therapies are under development. Two highly experimental treatments that focused on achieving neurochemical or structural brain repair in PD have attracted great interest recently: cell transplantation and gene therapy. In 1990, the first open-label trial of cell transplantation in PD treatment had been published. Immature dopaminergic neurons were prepared from fetuses or 
aborted embryos and were transplanted into brains of PD patients. Curative effect on motor symptoms was suggested in the trials. The effect of restoration in striatal dopamine transmission and connectivity was confirmed upon autopsy (Lindvall et al., 1990; Piccini et al., 1999). However, the cell transplantation method did not show any clinical benefit in the following double-blinded, placebo-controlled trails. As a severe complication, graft-induced dyskinesias was observed in some patients (Freed et al., 2001; Olanow et al., 2003). Although the clinical trials were halted, PD treatment by cell transplantation is still developed further in preclinical studies.

Another strategy of PD treatment was designed with glial cell line-derived neurotropic factor (GDNF). The theoretical basis of the strategy is that GDNF protects nigral dopaminergic neurons from death and promotes regeneration of their axons following damage (Kordower et al., 2013). In 2003, an open-label trial was performed with GDNF peptide injections into the putamen in PD patients, and treatment effect to the symptoms of PD was observed in the patients (Gill et al., 2003). However, a double-blind trial with intraputamenal infusion of GDNF failed to demonstrate clinical benefit, and severe, device-related adverse events occurred in three out of thirty-four PD patients. The failure was ascribed to the low dosage of GDNF which can not deliver clinical benefit to PD patients (Lang et al., 2006). Thus, gene therapy is considered as a potential method to continuously deliver high-level of GDNF in putamen.

\subsection{Gene therapy treatments}

Generally, gene therapy is performed by the delivery of a specific nucleic acid into patients' cells, and the treatment effect is achieved by protein expression from the nucleic acid. Comparing with protein-based drugs, the potential advantage of gene therapy is its consecutive clinical benefit by a single treatment. Gene therapy was firstly tested in 1980s, in therapy of inherited disease (Rosenberg et al., 1990). Recent studies were applying gene therapy to non-inherited disease (e.g. cancer) either (Sadelain et al., 2017). 
Nontoxic gene transfer into human cells was firstly achieved by recombinant, replication-defective viral vectors (Kotterman et al., 2015). By their clinical promise, adeno-assciated virus (AAV) and lentivirus were widely used in studies concerning gene therapy in various diseases (Flotte et al., 1995; Bloemer et al., 1997). AAV vectors are engineered from a naturally occurring parvovirous, adeno-associated virus. The replication of wild-type AAV requires assistance from another virus (e.g. herpesvirus or adenovirus) (Asokan et al., 2012). AAV itself is not associated with any known diseases in human. A gene expression cassette of interest can be inserted into the AAV vector, allowing the frecombinant vector genome to express the therapeutic facor in its target cells. Advantages of AAV to be used as the tool in gene therapy are their persistent expression in non-dividing cells and asence of significant adverse consequences for the host. Disadvantages of AAV are the limited DNA capacity, in that AAV only can accommodate DNA less than $5.0 \mathrm{~kb}$, and relative short-term expression in dividing cells due to their non-integrating episomal state (Flotte et al., 1995). Lentivirus is another important tool in gene therapy. The large DNA capacity of lentivirus lets it be widely used in studies concerning hemoglobinopathies (May et al., 2000). Even though lentivirus showed low immunogenicity in human, its proinflammatory risk is obviously higher than AAV, in accordance with ability of lentivirus to efficiently interact with the innate immune system (Vandendriessche et al., 2007). Lenti- or retroviral vectors can integrate randomly into the host genome, which has caused adverse activation of proto-oncogenes. Occurrence of leukemia following retroviral gene therapy has been reported (Kohn et al., 2003). A self-inactivating SIN design performed by removal of endogenous strong enhancer elements decreases the genotoxicity of lentivitus, and this design is usually used in current clinical trials (Baum et al., 2011).

Another strategy in gene therapy is performed by genome editing, which not only can process gene addition like viral vectors, but also can mediate gene ablation, gene correction and other highly targeted genome modifications. "Molecular scissors", engineered nucleases, are used to create site-specific double-strand breaks (DSBs) at specific target locations of the genome, and the breaks are 
repaired to desired mutations by homologous recombination $(\mathrm{HR})$ or nonhomologous end-joining (NHEJ). Clustered regularly interspaced short palindromic repeats (CRISPR/Cas9) system, zinc finger nucleases (ZFNs), meganucleases and transcription activator-like effector-based nucleases (TALEN) are commonly used as the "molecular scissors" in genome editing studies (Urnov et al., 2010; Zhang et al., 2010; Silva et al., 2011; Ran et al., 2013).

\subsubsection{Gene therapy clinical trials}

Since the statistics of gene therapy clinical trials for 2018 has not been published yet, until 2017, more than 2600 gene therapy clinical trials have been completed, are waiting for or have been approved worldwide (Ginn et al., 2018). In the 2600 clinical trials, the overwhelming majority $(76.1 \%)$ has addressed cancer $(65 \%)$ and inherited monogenic disease (11.1\%), trials targeting neurological disease are the fifth-most common indication (1.8\%) (Ginn et al., 2018).

Clinical trials of gene therapy in monogenic diseases increased from $8.7 \%$ in 2012 to $11.1 \%$ in 2017 (Ginn et al., 2013; Ginn et al., 2018). In the field of non-viral gene therapy trials, a gene therapy method delivered plasmid DNA encoding the CFTR cDNA complexed with a cationic liposome to lung of patients of cystic fibrosis has been proven efficient to improve lung function in a phase $2 b$ trial (Alton et al., 2015). Using gamma-retroviral or lentiviral-based gene transfer, a remarkable clinical benefit was demonstrated in primary immune deficiencies treatment (Thrasher et al., 2017). In such an attempt, more than $70 \%$ disease-free survival rate (not requiring re-introduction of polyethylene-glycol-conjugated adenosine deaminase or hematopoietic stem cell transplantation) was demonstrated in 40 treated patients of adenosine deaminase deficiency (ADA-SCID) (Thrasher et al., 2017). The first gene therapy commercial product against ADA-SCID, Strimvelis, was approved by European Marketing Authorization (EMA) in 2016 (Aiuti et al., 2017; table 1.1). AAV is also showing impressive results to be used as a vector in gene therapy for retinal diseases 
(Allocca et al., Lebherz et al., 2008; Surace et al., 2008), haemophilia (Kay et al., 2000; Chuab et al., 2004; Murphy et al., 2008) and alpha-1 antitrypsin deficiency (Song et al., 2001; Flotte et al., 2004). The first commercial gene therapy product with AAV vector was Glybera that was approved by EMA in treatment of lipoprotein lipase deficiency in 2012 (table 1.1). Luxturna is another AAV-based gene therapy product, was approved by FDA in clinical use to treat retinal dystrophy (table 1.1).

In 1967, gene therapy was firstly suggested and was described as "genetic surgery" by Marshall Nirenberg in Science (Nirenberg, 1967). He also mentioned "the technical problems that must be overcome are formidable". However, six commercial products of gene therapy have already been authorized in the last two decades worldwide, and three of them were approved in recent years (table 1.1). Besides the approved gene therapy products, gene therapy also has shown great potentials in pre-clinical treatment of various diseases in animal experiments or early-phase clinical trials, which give reasons to expect a good prospect of gene therapy.

\begin{tabular}{|c|c|c|c|c|}
\hline Tradename (proper name) & Date of approval & Approving agency & Indication & Manufacturer \\
\hline Gendicine & October 2003 & $\begin{array}{l}\text { State Food and Drug } \\
\text { Administration of China }\end{array}$ & $\begin{array}{l}\text { Head and neck squamous } \\
\text { cell carcinoma }\end{array}$ & $\begin{array}{l}\text { Shenzhen SiBiono GeneTech } \\
\text { (Shenzhen, China) }\end{array}$ \\
\hline Glybera $^{(3)}$ (alipogene tiparvovec) & November 2012 & $\begin{array}{l}\text { European Marketing } \\
\text { Authorization (EMA) }\end{array}$ & Lipoprotein lipase deficiency & $\begin{array}{l}\text { uniQure (Amsterdam, } \\
\text { Netherlands) }\end{array}$ \\
\hline Strimvelis ${ }^{T M}$ & June 2016 & EMA & $\begin{array}{l}\text { Adenosine deaminase deficiency } \\
\text { (ADA-SCID) }\end{array}$ & $\begin{array}{l}\text { GlaxoSmithKline } \\
\text { (Middlesex, United } \\
\text { Kingdom) }\end{array}$ \\
\hline Kymriah $^{T M}$ (tisagenlecleucel) & August 2017 & $\begin{array}{l}\text { Food and Drug } \\
\text { Administration (FDA) }\end{array}$ & Acute lymphoblastic leukaemia & $\begin{array}{l}\text { Novartis Pharmaceuticals } \\
\text { (Basel, Switzerland) }\end{array}$ \\
\hline $\begin{array}{l}\text { Yescarta }^{m M} \text { (axicabtagene } \\
\text { ciloleucel) }\end{array}$ & October 2017 & FDA & B-cell lymphoma & $\begin{array}{l}\text { Kite Pharma, Incorporated } \\
\text { (Santa Monica, California, } \\
\text { USA) }\end{array}$ \\
\hline $\begin{array}{l}\text { Luxturna }{ }^{T M} \text { (voretigene } \\
\text { neparvovec-rzyl) }\end{array}$ & December 2017 & FDA & $\begin{array}{l}\text { Retinal dystrophy (biallelic } \\
\text { RPE65 mutation) }\end{array}$ & $\begin{array}{l}\text { Spark Therapeutics, Inc. } \\
\text { (Philadelphia, Pennsylvania, USA) }\end{array}$ \\
\hline
\end{tabular}

Table 1.1 Approved gene therapy products. REF: Ginn et al., 2018.

\subsubsection{Gene therapy for Parkinson's disease}

Although no commercial product of gene therapy in PD treatment is available yet, 
many positive results have been reported (Jiao et al., 1993; Kaplitt et al., 2007; LeWitt et al., 2011; Cheng et al., 2018). Generally, treatment effects were achieved by viral vector-mediated expression of specific proteins, and the methods can be simply fitted into two categories by the expressed protein, i.e. growth factors or neurotransmitter-synthesizing enzymes.

Glial cell line-derived neurotrophic factors (GDNF) has been proven to promote the survival and differentiation of dopaminergic neurons and to prevent apoptosis of motor neurons in in vitro experiments (Airaksinen et al., 2002). Its neuroprotective and neurorestorative functions also have been tested in the 6-OHDA PD model in rats to restore rotation behavior and in MPTP treated monkeys to treat trembling. Delivered by AAV or lentivirus vectors, expression of GDNF demonstrated treatment effect in preclinical studies (Beal et al., 2001; Cheng et al., 2018). Neurturin is another growth factor that had shown neuroprotection and neurorestoration in MPTP-trated monkeys (Kordower et al., 2006). The safety of AAV-mediated expression of neurturin was demonstrated in clinical trials, but no clinical benefit was shown in the randomized clinical trials. (Bartus et al., 2017a; Bartus et al., 2017b). By post-mortem examination, expression of neurturin was only observed in relatively few cells surrounding the injection tracts, thus limiting neurturin's potential of neurorestoration (Bartus et al., 2017a; Bartus et al., 2017b). With improvement of technologies, it is likely that more clinical trials concerning gene therapy with growth factors will be attempted in the future.

Another strategy of PD gene therapy is delivery of key enzymes in the dopamine synthesis pathway. Tyrosine hydroxylase with cofactors (e.g. tetrahydrobiopterin) and aromatic L-amino acid decarboxylase (AADC) were delivered by AAV or lentiviral vectors into striatum of PD patients to genetically modify cells producing and releasing dopamine, with published safety reports (Mittermeyer et al., 2012; Palfi et al., 2014). Although no data have been published yet to report efficacy of this treatment in PD patients, relief of dopamine deficiency-dependent motor symptoms was shown in a nonhuman primate model of PD (Bjoerklund et al., 2009). AAV mediated delivery of glutamate decarboxylase was tested to induce 
GABAergic inhibition of subthalamic nucleus firing in PD patients, a significant improvement in unified Parkinson's disease rating scale (UPDRS) was demonstrated in the sham-surgery-controlled phase II trial (LeWitt et al., 2011).

\subsubsection{AAV vectors and regulated gene expression system}

As the major tools of this $\mathrm{PhD}$ project, $\mathrm{AAV}$ vectors and the regulated gene expression system, GeneSwitch, are introduced here. Wild-type adeno-associated virus was firstly identified in 1965 (Atchison et al., 1965). AAV tends to remain quiescent in the absence of a helper virus (e.g. adenovirus, herpes virus). Even in the presence of a helper virus, it does not appear to cause any disease in humans. These two features have driven the idea that AAV can be used for safe and stable gene delivery. Replication protein (Rep), one of the viral proteins in wild-type $A A V$, is a key component in establishing a latent integration into host cell genome at a specific site in the human chromosome 19. Therefore, $A A V$ vectors were modified from wild-type virus by deleting the gene of Rep protein to avoid integrating into human genome (Carter, 2004). Although AAV vectors have been considered safe and less immunogenic than other vectors (e.g. lentivirus), accumulating data from human trials and experiments in animals have shown that both innate and adaptive immune responses can be elicited against AAV capsid (Cap) proteins. Thus, immunogenicity of AAV vectors could be reduced by medication of the capsid or selection of an AAV serotype which is not be blocked by neutralizing antibodies already present in the putative patients. Without integrating into genome of the host cell, modified AAV vectors still can persist in an extrachromosomal state in both dividing and quiescent cells (Deyle et al., 2009). First recombinant AAV vectors were described in 1984 (Hermonat et al., 1984; Tratschin et al., 1984), and were firstly applied in a human clinical trial in 1996 to express cystic fibrosis transmembrane conductance regulator (CFTR) to treat cystic pulmonary fibrosis (Flotte et al., 1996).

AAV entry is determined by its interactions with specific surface glycans and a 
proteinaceous receptor. Nowadays, 12 serotypes of AAV have been isolated from various tissue samples and more than hundred capsid variants have been prepared. AAV-1, AAV-4 and AAV-7 to -12 were discovered from nonhuman primate tissues, AAV-2, AAV-3, AAV-5 and AAV- 6 were isolated from human cells. These serotypes of AAV vector bring various tissue tropisms of the virus such as muscle-biased AAV-1 and liver-biased AAV-8, and the tissue specificity can be strengthened or be weakened by changing the promoter (Guenzel et al., 2014). The various tissue tropisms make AAV ideally suited to development into various human gene therapies to different diseases.

Most viral vector based gene therapy trials applied viral vectors to constitutively express specific proteins with putative treatment effects. The advantage of the constitutive expression is the achievement of durable expression of target protein by a single virus application. However, the level of expression cannot be adjusted according to the progressive conditions of disease, and the expression cannot be terminated in case of side effects. To solve these problems and increasing the safety of the developed gene therapy methods, regulated gene expression systems were employed in many studies, and the systems can be divided to three categories by their activators: small ligands, physical agents and endogenous stimulus.

Tetracycline-controlled transcriptional activation systems (Tet-On or Tet-Off) are the two most commonly used inducible expression systems. A tetracycline transactivator (tTA) protein, which consists of a tetracycline repressor, TetR, and an activation domain, VP16, is used in the Tet-off system to control expression of a gene. The tTA protein can bind with DNA at specific TetO operator sequences which are placed upstream of a minimal promoter. Several repeats of TetO sequences and the minimal promoter are together called a tetracycline response element (TRE), because it responds to the binding of tTA by increasing expression of the gene located downstream. Tetracycline or its derivatives (e.g. doxycycline) can bind with the ITA protein, and relased the tTA protein from binding with Tet response element. Then the activation effect from VP16 of the ITA protein could be suppressed, which prevented transactivation of the gene in 
downstream of TRE. In a Tet-On system, the rtTA protein is capable of binding the operator only if bound by tetracycline or its derivatives, which is a mechanism opposite to the Tet-Off system (Wanka et al., 2016). Performed in either AAV vector or lentiviral vector, Tet-On and Tet-Off systems have been widely used in different trials including delivery of GDNF into the brain (Johansen et al., 2002; Manfredsson et al., 2009; Wang et al., 2006; Wang et al., 2013). The bacterial origin of the components of Tet systems, however, comes at the risk of triggering immunological response in clinical trials. For instance, the host immune system was triggered by the TetR in the macaque skeletal muscle (Le Guiner et al., 2014). However, application of the systems in immune-privilege sites (e.g. retina) has been proven safe in non-human primates and lack of immune response to the TetR (Han et al.,2012).

Ecdysone, a steroidal prohormone of the major insect molting hormone 20-hydroxyecdysone, was used to control another regulated gene expression system. A truncated ecdysone receptor (EcR) was fused with a VP16 activation domain, ecdysone application induces EcR binding with the ecdysone responsive element (EcRE) and then VP16 activation domain can initiate the expression of the cDNA downstream of EcRE (No et al., 1996). Major advantage of the system is the low level of background expression due to the absent of responses to mammalian hormones. However, the non-mammalian elements of the system limits its application in human trials by the potential risk of triggering immunological responses. Another formidable problem of this system is that the inducer, ecdysone, has not been approved for human application.

Rapamycin, also known as sirolimus, is a legal medicine in US to be mainly used in preventing organ transplant rejection. It can dimerize two proteins that are consisted by a hybrid zinc finger DNA binding domain (ZFHD) with Fk506 binding domain and by the $\mathrm{C}$-terminus of $\mathrm{p} 65$ activation protein with a FKBP rapamycin binding domain, respectively. The dimerized proteins can bind with ZFHD1 binding sequence, then the C-terminus of p65 activation protein can initiate the expression of downstream cDNAs/genes (Robbins et al., 1998). Advantages of the system are the approved inducer and its entire human components to avoid 
immunological response. The drawback is the strong immune-suppressor activity of rapamycin. It can be overcome by using analogs (Ye et al., 1999), however, the analogs of rapamycin are not approved medicines, and thus cannot be used in clinical applications to date.

Given that avalable regulated gene expression systems are unlikely to be available for clinical use, alternatives have to e developed. Thus, in this PhD project, a background-free inducible gene expression system, called the GeneSwitch, was applied in an AAV vector to deliver neurotrophic factor GDNF into striatum of rats. The GeneSwitch (GS) system was developed in 1994 as a steroid-based regulated gene expression system (Wang et al., 1994). The system is formed by 3 elements: a regulation cassette, a responsive cassette and the small molecule inducer Mifepristone, a clinically approved synthetic steroid. 5 years ago, a study published by my colleagues reported successful neuroprotection and neurorestoration with regulated GDNF expression in a two -vector GeneSwitch system in an animal model of PD. Relatively low background expression of GDNF was observed in the two-vectors system, and the rate of induction of GDNF expression was only moderate (Tereshchenko et al., 2014). In this $\mathrm{PhD}$ project, an advanced single vector design was used with capability to express high-level of GDNF and absence of any non-induced background expression. (Fig. 1.2).

In the regulation cassette, GS expression is driven by a promoter which can be designed with cell-specificity (e.g. hSYN as the neuron-specific promoter). The expressed GS protein is a fusion protein consisting of a human p65 activation domain (p65), a truncated human progesterone receptor (dPR) and part of the yeast Gal4 DNA binding domain (DBD). The GS protein stays inert until binding to the inducer, a clinically approved synthetic steroid mifepristone. After mifepristone-induced dimerization, GS binds to a minimal promoter containing Gal4 binding sites, thereby inducing expression of the gene downstream of this Gal4-TATA-promoter.

In the responsive cassette, the promoter is constituted by a Gal4 upstream 
activating sequence (UAS) that consists of four repetitions of DBD binding site and a TATA box sequence (Lillie et al., 1989). The cDNA of GDNF is located downstream of the UAS-TATA promoter. A synthetic transcription blocker (TB) is placed between the regulation cassette and the responsive cassette to reduce the background expression (Fig. 1.2).

The inducer of the system, mifepristone, also known as RU-486, is an approved medicine normally used in terminating early pregnancy (Spitz et al., 1998). By its low toxicity in long-term administration, mifepristone is considered as a good candidate to be used as the inducer in regulated gene expression system (Grunberg et al., 2006). After mifepristone-induced dimerization, GS proteins bind to a minimal promoter containing Gal4 binding sites (UAS-TATA) by their Gal4 binding domains, and then p65 activation domain can initiate expression of the gene located downstream. As a consequence, regulated expression of GDNF can be achieved by adjusting the application of mifepristone.

No regulated gene therapy system has advanced into clinical applicability so far, mainly due to immunological problems caused by the regulatory machinery (e.g. Tet-operon) or the not approved inducing drug (e.g. ecdysone) or the serious side effect of the inducing drug (e.g. rapamycin). The GeneSwitch system with an approved medicine as the inducer is considered as a good candidate to overcome these problems. 


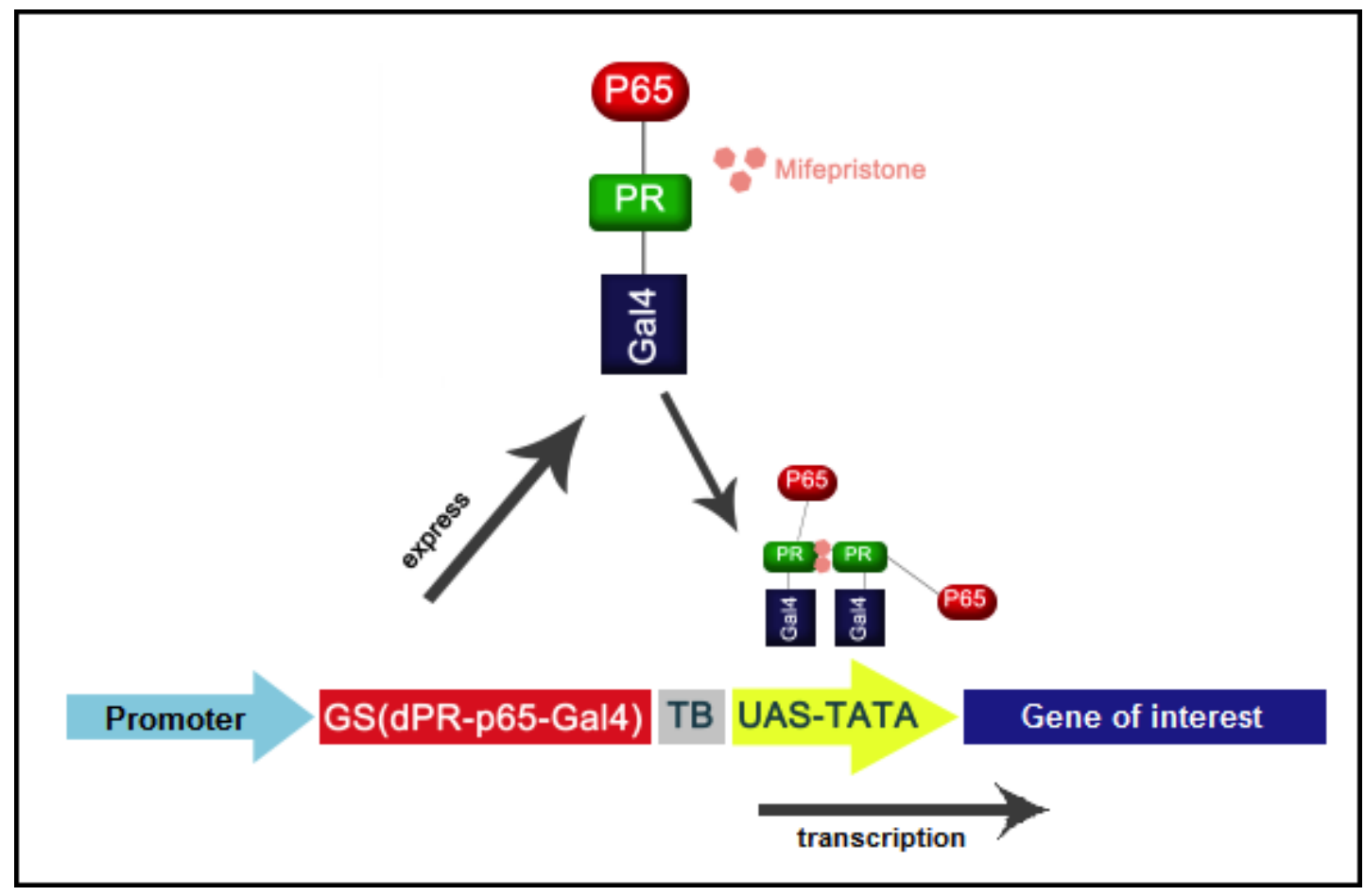

Figure 1.2 Mechanism of the GeneSwitch (GS) system.

The GeneSwitch protein is a fusion protein consisting of a truncated progesterone receptor (dPR), a p65 activation domain (p65) and part of Gal4 DNA binding domain. It is expressed from a tissue-specific promoter in target cell, and stays inert until binding to the inducer steroid, mifepristone . After mifepristone-induced dimerization, GS binds to a minial TATA promoter with 6 upstream Gal4 binding sites, then the p65 activation domain initiates the transcription of therapeutic transgene GS: GeneSwitch; dPR: truncated progesterone receptor; TB: synthetic transcription blocker; UAS-TATA: minimal TATA promoter with 6 upstream Gal4 binding sites.

\subsection{Mifepristone metabolism in rats or human}

A positive correlation has been demonstrated between the plasma concentration of mifepristone (Mfp) and level of expression of GDNF (Cheng et al., 2018). Divergent pharmacokinetics of Mfp in humans versus rats have been reported in the literature (Deraedt et al., 1985; Heikinheimo et al., 2003; Chen et al., 2018). As the main difference, the clearance rate of Mfp in rats is roughly 130-fold higher than it in human (Deraedt et al., 1985). Mfp plasma clearance in humans differs 
from all other species due to tight binding to a plasma carrier protein. . Alpha-1-acid glycoprotein (AAG), an acute phase plasma glycoprotein, exists in most mammals, however, only human AAG has binding affinity for antiprogesterons. The binding of Mfp with the carrier protein might retards the metabolism of Mfp in human plasma. Other possible reason for the difference is assumed to the different activities of metabolizing enzyme of Mfp in various species. Understanding Mfp pharmacokinetics is thus obligatory to apply proper control of the GeneSwitch system.

\subsubsection{Mifepristone pharmacokinetics}

Mfp acts as antagonist to progesteron and glucocorticoid functions. To be used in terminating pregnancy, it is normally applied orally with roughly $70 \%$ absorption rate from the gut, however, the first-pass metabolism in liver decreases its bioavailability to approximately $40 \%$ in human or rats and to about $15 \%$ in monkeys (Heikinheimo et al., 1989; Sartor et al., 1996). By first-pass metabolism in rats or human, approximately $60 \% \mathrm{Mfp}$ is metabolized to three metabolites: mono-demethylated (RU-42633, metapristone), di-demethylated (RU-42848) and hydroxylated (RU-42698) metabolite.

While bioavailability of Mfp in humans and rats are equivalent, there are robust differences in pharmacokinetics due to the plasma carrier AAG, that only in humans, but not in all other species, binds Mfp. Alpha-1 acid glycoprotein (AAG or Orosomucoid, ORM) is an acute phase plasma alpha-globulin glycoprotein, functions as the carrier of basic drugs, steroid and protease inhibitors (Urien et al., 1991; Herve et al., 1996; Colombo et al., 2006). The binding between the carrier protein and Mfp changes the metabolism rate of Mfp: In human beings, peak plasma Mfp concentration is reached within 1-2 $\mathrm{h}$ after oral administration and maintained at relatively high level up to 48 or $72 \mathrm{~h}$ depending on the ingested dose (Sarkar, 2002). In rats, the Mfp plasma concentration reached the peak within $6 \mathrm{~h}$ after oral administration and decreased to almost undetectable level in 
24h (Chen et al., 2018). The clearance rate of Mfp in human is $0.55 \mathrm{~L} / \mathrm{kg} / \mathrm{day}$, and it is $71 \mathrm{~L} / \mathrm{kg} /$ day in rats (129-fold higher than it in human) (Deraedt et al., 1985). The distribution of Mfp is also greatly altered by AAG binding. Without carrier binding, $28 \%$ of the concentration of Mfp measured in serum can be determined in brains of rats (Heikinheimo et al., 1994). In human, with carrier binding, a limited tissue availability and low volume of distribution have been reported (Heikinheimo et al., 2003). No literature reported the proportion of Mfp entering brain after oral administration in human to date. It did not attract attention of the scientists studying its common use, terminating pregnancy. However, it is a very important factor to the GeneSwitch system, as it might greatly affect the expression of GDNF in human. Therefore, generation of a humanized rat AAG model should be helpful to calculate the necessary dose of Mfp to induce the GeneSwitch system in human brain.

\subsubsection{CYP3A enzymes and their inhibitors}

In rats and human, Mfp is mainly metabolized by the cytochrome P-450 monooxygenase 3A (CYP3A) enzymes (Chasserot et al., 1989; Jang et al., 1996). CYP3A is a family of oxidizing enzymes, mainly found in liver and intestine. Being monooxygenases, the main function of members of the enzymes family is catalyzing reactions including metabolism of approximately $60 \%$ of all clinically used medicines and synthesis of lipids components (e.g. steroids) (Lehmann et al., 1998). CYP3A enzymes have more than one active site, which allow them to bind with few substrates at a time to perform oxidizing detoxification in the metabolism of endogenous and exogenous compounds. The chemical alterations include epoxidation of olefins, hydroxylation, aromatic oxidation, $\mathrm{N}$ - and O-dealkylation reactions, heteroatom oxidations, aldehyde oxidations, aromatase activity and dehydrogenation reactions (Schmiedlin et al., 1997; Shahrokh et al., 2012). Several other members of CYP3A family are also involved in drug metabolism, but CYP3A4 is the most common one, it is the main enzyme in 
first-pass metabolism of roughly $30 \%$ of all clinically used medicines (Zanger et al., 2013).

Sex-specific CYP3A activity in rats was suggested (Kato et al., 1992). The sex-specific CYP3A activity was ascribed as the reason for the gender-dependent pharmacokinetics of Mfp in rats (Chen et al., 2018). Pharmacokinetics(such as enhanced maximum concentration and prolonged half-life of the drug) of drugs metabolized by CYP3A4 can be greatly changed by an inhibitor of CYP3A4 (Lehmann et al., 1998). The influence of inhibitors of CYP3A4 in pharmacokinetics of Mfp or in the GeneSwitch system has never been reported in literatures to date.

\subsubsection{Alpha-1 acid glycoprotein and its binding affinity for Mfp}

Alpha-1 acid glycoprotein (AAG) or orosomucoid (ORM) is a $41-43 \mathrm{kDa}$ acute phase plasma alpha-globulin glycoprotein with a pl of 2.8-3.8 and is expressed by two polymorphic genes (ORM 1 and ORM 2). Expression of the AAG is adjusted by a combination of few regulatory mediators that include glucocorticoids, tumor necrosis factor- $\alpha$ (TNF $\alpha$ ), a cytokine network involving mainly interleukin-1 $\beta$ (IL-1ß), interleukin-6 (IL-6) and IL-6 related cytokines. The peptide moiety is a single chain of 183 amino acids (human) or 187 amino acids (rat) with two and one disulfide bridges in humans and rats, respectively (Fournier et al., 2000). Five complex-type N-liked glycans make up $45 \%$ of the total carbohydrate modifications of the petides (Van et al., 1995). It was firstly described in 1950 and since then, numerous articles were devoted to the physiological function of AAG, which, however, remains unknown yet (Schmid, 1950; Weimer et al., 1950). The only established function of AAG is acting as a carrier of basic and neutrally charged lipophilic compounds such as steroid hormones (Olson et al., 1996). The normal concentration of $A A G$ in human plasma is between $0.6-1.2 \mathrm{mg} / \mathrm{ml}$, and is approximately $0.2 \mathrm{mg} / \mathrm{ml}$ for rats (Fournier et al., 2000). As one of the major acute phase proteins in humans, rats, mice and most other species, the plasma 
concentration of AAG increases several-fold during acute-phase reactions that can be induced by burns, pregnancy, several medicines and certain diseases (Colombo et al., 2006).

In human plasma, AAG proteins are presented as a mixture of AAG1 and AAG2 proteins in a molar ratio of 3:1. Expression of AAG1 proteins are controlled by the ORM1 locus which is high polymorphic, and AAG1 proteins are divided into three variants, $A A G 1{ }^{*} F 1, A A G 1{ }^{*} F 2$ and $A A G 1{ }^{*} S$. Expression of $A A G 2$ protein is encoded by another gene, ORM2. AAG1* $\mathrm{F} 1, A A G 1{ }^{*} S$ and $A A G 2$ are observed worldwide, $A A G 1{ }^{*} \mathrm{~F} 2$ is only common in European populations. Taking Mfp binding affinity into consideration, $A A G 1{ }^{*} \mathrm{~F} 1$ and $A A G 1{ }^{*} S$ have been shown a high binding affinity with Mfp, while this is fairly low in AAG1*F2 and AAG2. The F1 variant and $S$ variant have roughly the same binding properties towards Mfp (Escallon et al., 1987; Weidinger et al., 1987; Yuasa et al., 1986, 1987, 1993, 1997). As a conclusion, to build the "humanized" AAG rat model, a cDNA of $A A G 1{ }^{*} F 1$ or $A A G 1{ }^{*} S$ should be inserted into the plasmid of $A A V$ vector, and a stable expression of hAAG should be achieved by the AAV virus application in rats. The concentration of hAAG should reach a similar level as in human plasma: $0.45-0.9 \mathrm{mg} / \mathrm{ml}$ (calculated as: the total concentration of AAG variants $\times 75 \%$, proportion of AAG1 in total $A A G)$.

\subsection{Aim of the project}

No regulated gene therapy system has advanced into clinical trials so far, mainly due to immunological problems caused by the regulatory machinery (Tet-operon) or the inducing small molecule drugs (rapamycin). Thus, there is a pressing demand for development of alternatives, and the project aims to optimize the "GeneSwitch" for tightly regulated expression of neurotrophic factors. To facilitate approval of the vector system by authorities, a novel one-vector system, carrying both GS gene and GDNF gene in only one recombinant genome, has been constructed by my colleagues in the lab. The project functionally verifies this 
one-vector system: Firstly, various dosages and application regimes of the inducer, Mfp, are evaluated. Secondly, the project studies the relationship between GDNF expression level and dosage of Mfp. Thirdly, the project functionally tests the treatment effect of the system in 6-OHDA PD models.

Except for the functional tests, the project also aims to optimize the gene therapy method by additional means: Levels of GDNF expression in male and female rats are studied. A CYP3A inhibitor, norvir, is tested to enhance the level of expression of GDNF, and its effects on GDNF expression in different genders are studied also. Lastly, the project aims to build a "humanized" AAG rats model, aiming to evaluate Mfp dosages that are useful for patients in which the regulated gene therapy will be applied. 


\section{Materials}

\subsection{Animals and cells}

Wistar rats: Janvier

HEK 293 cells: Stratagene

Sure E. Coli strain: SURE Electroporation-Competent Cells, Agilent

\subsubsection{Ethical approval of animal experimentations}

All procedures (including anesthesia and euthanasia) were carried out in accordance with approved experimental animal licenses (16/2074) issued by the responsible animal welfare authority (Niedersächsisches Landesamt für Verbraucherschutz und Lebensmittelsicherheit, LAVES) and controlled by local animal welfare committee and veterinarians of University Medical Center Göttingen.

\subsubsection{Rats}

Adult female or male rats ( 8 weeks old, body weight: 210 to $240 \mathrm{~g}$ ) were purchased from Janvier Labs. Throughout their life, all the rats were group-housed, ranging from 2 to 5 rats per cage. The cages were maintained on a 12-h dark/light cycle and kept in a temperature-regulated room, with free access to food and water. 


\subsection{Chemicals and drugs}

AKos: metapristone

Applichem: agarose for gels, ampicillin, calcium chloride $\left(\mathrm{CaCl}_{2}\right), \mathrm{D}-(+)$ glucose, cumaric acid, dimethyl sulfoxide (DMSO), EDTA, ethanol absolute, glycerol, potassium chloride $(\mathrm{KCl})$, LB Agar, LB media, Magnesium sulfate $\left(\mathrm{MgSO}_{4}\right)$, methanol, mifepristone, paraformaldeide (PFA), phosphate buffered saline (PBS), potassium chloride $(\mathrm{KCl})$, sodium azide, sodium chloride $(\mathrm{NaCl})$, Sodium dodecyl sulfate (SDS), TRIS, Triton X.

Bayer: bepanthene.

Calbiochem: sodium citrate.

Braun: Braunol.

Fermentas: Hind III Lambda DNA.

Fluka: TWEEN 20.

Medistar: Ketamine.

Merck: fat milk, HPLC water, hydrogen peroxide $\left(\mathrm{H}_{2} \mathrm{O}_{2}\right)$, magnesium chloride $\left(\mathrm{MgCl}_{2}\right)$, Perchloric acid $\left(\mathrm{HClO}_{4}\right)$, trichloroacetic acid $\left(\mathrm{C}_{2} \mathrm{HCl}_{3} \mathrm{O}_{2}\right)$.

New England Biolabs (NEB): 2-Log DNA marker, dNTPs.

Norbrook: rimadyl

Novagen: benzonase.

PAA the cell culture company: fetal calf serum (FCS), newborn goat serum (NGS), PS (penicillin/streptomycin), Trypsin for HEK 293 cells.

Riemser: xylazin.

Roche: glycerol, protease inhibitor cocktail (Complete mini).

Roth: citric acid monohydrate, sodium acetate. 
Sigma: acetonitrile, ammonium peroxide sulfate (APS), ascorbic acid, Bactotryptone, Dithiothreitol (DTT), 6-Hydroxydopamine (6-OHDA), mineral oil, Ritonavir (Norvir) TEMED, transferrin.

Teclapharm: apomorphine.

\subsection{Solutions}

4\% PFA in PBS: for 2 liters preparation dissolve $80 \mathrm{~g}$ of PFA and $19.10 \mathrm{~g}$ of PBS in 1.8 litres of bi-distilled water; add few drops of $1 \mathrm{M} \mathrm{NaOH}$ and heat the mixture to $60^{\circ} \mathrm{C}$ under stearing till it is clear. Cool it down on ice, $\mathrm{pH}$ at 7.4 , bring the volume to 2 liters with bi-distilled water and filter with through Whatman $5951 / 2$ folded filters. Store at $4^{\circ} \mathrm{C}$.

$30 \%$ sucrose: for 1 liter preparation dissolve $300 \mathrm{~g}$ of sucrose in 0.8 litres of PBS. Mix it, bring the volume to 1 liter. Store at $4^{\circ} \mathrm{C}$. $(0.88 \mathrm{~mol} / \mathrm{l})$

ASV solution: for $100 \mathrm{ml}$ preparation dissolve $0.9 \mathrm{~g}(0.15 \mathrm{~mol} / \mathrm{l}) \mathrm{Nacl}, 0.5 \mathrm{~g}$ carboxymethyl-cellulose MW 250.00, $0.4 \mathrm{~g}(3.05 \mathrm{mM} / \mathrm{l})$ polysorbate 80 in $90 \mathrm{ml}$ distilled water. $0.9 \mathrm{ml}$ benzyl alcohol was added and bring the solution to $100 \mathrm{ml}$ by distilled water.

Anesthetics: $95 \mu \mathrm{l}$ ketamine mixed with $25 \mu \mathrm{l}$ xylarien, which can be used to anesthetize rat with $100 \mathrm{~g}$ body weight.

DNA loading buffer (6x): 15\% Ficoll 400 DL, 100 mM LiCl, 2\% glycerol, $100 \mathrm{mM}$ EDTA, pH 8.0; 0.6\% SDS, 0.03\% BPB in $\mathrm{H} 2 \mathrm{O}$.

HPLC buffer for dopamine determination (1 L): in 0.8 I HPLC water add 6.973 $\mathrm{g}(85 \mathrm{mM} / \mathrm{l})$ sodium acetate, $7.36 \mathrm{~g}(35.02 \mathrm{mM} / \mathrm{l})$ citric acid monohydrate, $0.105 \mathrm{~g}$ $(0.49 \mathrm{mM} / \mathrm{l})$ sodium octasulfonic acid, $0.048 \mathrm{~g}(0.16 \mathrm{mM} / \mathrm{l})$ EDTA. The $\mathrm{pH}$ was adjusted to 4.3 by citric acid. Add $105 \mathrm{ml}$ methanol and bring volume to 1 I with HPLC water, filter and degas. 
HPLC buffer for mifepristone determination (1 L): to $280 \mathrm{ml} \mathrm{HPLC}$ water add $250 \mathrm{ml}$ methanol and $470 \mathrm{ml}$ acetonitrile.

Lysis buffer for ELISA (1 I ): $8 \mathrm{~g}(0.14 \mathrm{~mol} / \mathrm{l}) \mathrm{NaCl}, 2.42 \mathrm{~g}(19.98 \mathrm{mM} / \mathrm{l})$ Tris, 0.17 $\mathrm{g}(1 \mathrm{mM} / \mathrm{l})$ PMSF, $0.01 \mathrm{~g}$ aprotinin, $0.001 \mathrm{~g}$ leupeptin and $0.09 \mathrm{~g}(0.49 \mathrm{mM} / \mathrm{l})$ sodium vanadate were dissolved in $800 \mathrm{ml}$ distilled water. $10 \mathrm{ml} \mathrm{NP} 40,100 \mathrm{ml}$ glycerol were added to the solution, bring the solution to $1 \mathrm{I}$ by distilled water.

Lysis buffer for HPLC (1 I): $10.05 \mathrm{~g}(0.1 \mathrm{~mol} / \mathrm{l})$ perchloric acid was dissolved in $900 \mathrm{ml}$ distilled water, bring the solution to 1 I by distilled water.

PBS: $9.55 \mathrm{~g} / \mathrm{l}$ PBS was added in bi-distilled water. The solution was filtered and autoclaved.

Soc++ media: $2 \%$ bacto-tryptone, $0.5 \%$ yeast extract, $10 \mathrm{mM} \mathrm{NaCl}, 2.5 \mathrm{mM} \mathrm{KCl}$, $10 \mathrm{mM} \mathrm{MgCl}$, $10 \mathrm{mM}$ MgSO4, $20 \mathrm{mM}$ glucose $\mathrm{pH}$ 7.0) Add Glucose after autoclaving the solution with the remaining ingredients.

TBE buffer (10X 1l): $108 \mathrm{~g}(0.89 \mathrm{~mol} / \mathrm{l})$ Tris, $55 \mathrm{~g}(0.89 \mathrm{~mol} / \mathrm{l})$ boric acid and $9.3 \mathrm{~g}$ (31.82 mM/l) EDTA was dissolved in 900 distilled water, bring the solution to $1 \mathrm{I}$ by distilled water, filter and antoclave.

TBS: $150 \mathrm{mM} \mathrm{NaCl}, 10 \mathrm{mM}$ Tris- $\mathrm{HCl}, \mathrm{pH} 9.0$ (for antigen retrieval).

TE buffer: $10 \mathrm{mM}$ Tris-HCl, 1mM EDTA, pH 8.0.

\subsection{Kits}

AAG ImmunoAssay System: R and D systems

DNA gel extraction kit: Quiagen

GDNF ImmunoAssay System: Promega

DNA miniprep kit: Quiagen

PCR purification kit: Quiagen 


\subsection{Enzymes}

DNA polymerase I large klenow fragment + Klenow buffer: New England Biolabs

DNAse I + buffer: New England Biolabs

Phusion high fidelity DNA polymerase + buffer: Finnzymes

Restriction enzymes + buffers + BSA: New England Biolabs

T4 DNA ligase + ligation buffer: New England Biolabs (NEB) 


\section{Methods}

\subsection{Stereotaxic injection of AAV vectors into rat striatum}

A glass capillary was prepared before the surgery. The capillary was filled with mineral oil in the top, a small air bubble in the middle and $1 \mu \mathrm{l}$ of PBS in the bottom. The glass capillary was connected with a micro-injector (maximum injection volume: $9.999 \mu \mathrm{l}$ ), which will be used to inject AAV vector.

9 weeks old female Wistar rats, between $220 \mathrm{~g}$ and $250 \mathrm{~g}$, were used for the surgery. All surgical operations were processed under anesthesia by $10 \%$ ketamine and $2 \%$ xylazine $(95 \mu \mathrm{l} / 25 \mu \mathrm{l}$ per $100 \mathrm{~g})$. After anesthesia, rats were shaved and fixed by ear bars and a jaw holder in a stereotaxic frame (kopf instrument). Bephantene was applied to the rat eyes to protect the eyes from strong light and dry. Rat head was disinfected with braunol. A longitudinal cut was made on the disinfected region of the head by a scalpel. To reduce pain of the rat, a smaller cut is preferred, however, the cut has to be big enough to expose both the bregma and the lambda. Tissue on top of the skull was removed by scalpel gently. Touching the bregma and lambda by the bottom of the capillary, the heights were measured to set flat of the skull by putting the bragma and lambda at the same height. The coordinates of bregma were measured as the "zero" point, the coordinates of the injections were calculated with the "zero" point by the Praxinos and Watson atlas. A small mark on the skull was made by a micro driller with $0.8 \mathrm{~mm}$ tip, a small hole was drilled around the mark. A fine tweezers were used to remove the small piece of bone of the small hole. The skull and the exposed dura were cleaned by a cotton bud with PBS.

The glass capillary sucked with $2 \mu \mathrm{AAV}$ vectors was injected to the required height to touch the target position. After 3 minutes waiting, the AAV vectors were injected as $500 \mathrm{nl} / \mathrm{min}$. Other 3 minutes were waited to minimize the reflux. The 
capillary was retracted slowly to avoid reflux. Clean the surface of brain and skull again by PBS. The wound then can be surgically sewn. Covered the rats with soft paper to keep them warm until they waked up. $10 \mathrm{mg} / \mathrm{kg}$ of rymadil were injected in the next 3 days to reduce pain. Leave the rats in individual cages until the second day after surgery and then put them together in a bigger cage as maximally 5 rats/cage.

The coordinates of the left striatum injection as follows: AP: $+0.05, \mathrm{ML}:+0.21$, DV (from dura): $-0.5 \mathrm{~cm}$ and AP: $-0.05, \mathrm{ML}:+0.38$, DV (from dura): $-0.5 \mathrm{~cm}$. AAV-5-GS-GDNF was injected at a total titre of $1 \times 10^{9} \mathrm{vg} / \mathrm{rat}$. To build PD model, $5 \mu \mathrm{g} 6$-OHDA in $0.02 \%$ ascorbic acid was injected at the same coordinates 3 weeks before virus injection.

\subsection{Drugs application to rats}

For intraperitoneal (i.p.) injection of mifepristone, mifepristone was dissolved in DMSO as $20 \mathrm{mg} / \mathrm{ml}$, papered freshly. Control animals received only DMSO. For oral administration of mifepristone, mifepristone was suspended by ASV solution or sesame oil, or dissolved in $10 \%$ ethanol as $50 \mathrm{mg} / \mathrm{ml}$. Control animals received only ASV solution, sesame oil or $10 \%$ ethanol. The oral administration of mifepristone was applied by gavage. To initiate AAV-GS-GDNF expressing GDNF, mifepristone was applied in 3 consecutive days.

For intraperitoneal injection of the CYP3A4 inhibitor, Norvir was dissolved in DMSO as $30 \mathrm{mg} / \mathrm{ml}$. Control rats received only DMSO. The Norvir i.p. application was performed 20 minutes before mifepristone application. For oral administration of Norvir, it was suspended by ASV solution. The oral administration of Norvir was processed 1 hour before mifepristone application. Control rats received only ASV solution.

For rotational behavior test, rats were injected intraperitoneally with $0.4 \mathrm{mg} / \mathrm{kg}$ apomorphine. 


\subsection{Transcardial perfusion and processing on rats brains}

Rats were sacrificed by $\mathrm{CO}_{2}$ inhalation with slow flow to avoid suffering of rats. The rats were fixed on cystosepiments by needles impaled feet. The abdominal cavity and thoracic cavity were opened to expose the heart. A small cut was made on the left ventricle. A blunt-ended catheter inserted through the left ventricle and atrium into the aorta, and was fixed by clamping. The abdominal aorta was clamped to restrict the perfusion to the upper part of the body. The nose was cut to give a way out for the blood and PBS. PBS was pumped as flow rate of 18 $\mathrm{ml} / \mathrm{min}$. After the flowing from nose came clean from red, the PBS pumping can be switched to $4 \%$ PFA pumping. The efficiency of PFA perfusion can be checked by the rigidity of the neck. After approximately $20-30$ minutes, the neck was fairly rigid, which means the perfusion of PFA was sufficient.

The head was cut and the brain was collected by a clamp. The brain was left in $4 \%$ PFA for post fixation, $4{ }^{\circ} \mathrm{C}$ over night. Then the brain was soaked in $30 \%$ sucrose for 3-5 days at $4^{\circ} \mathrm{C}$ until it sank in the solution. The brain then was dried by soft paper and stored at $-80^{\circ} \mathrm{C}$.

For sectioning, brains were embedded in a cryomatrix and sliced by a LEICA cryostat as $30 \mu \mathrm{m}$ thick coronary section. Sections were directly mounted on microscope slides.

\subsection{Tissue preparation for dopamine and GDNF quantification}

The amount of expressed GDNF was tested by ELISA. Dopamine, DOPAC and HVA were measured by HPLC. $2 \mathrm{ml}$ micro-tubes (SARSTEDT) were filled with 0.5 $\mathrm{g}$ of Precellys ceramin beads (Peqlab, $1.4 \mathrm{~mm}$ ) and pre-cooled in $-80^{\circ} \mathrm{C}$. The 
tubes were marked and weighted before collection of brain. Rats were sacrificed by $\mathrm{CO}_{2}$ inhalation. Without any perfusion, the brains were collected and striatums of both hemispheres were isolated immediately on a cooled plate. Each striatum was separated to 2 roughly equal parts (one for GDNF ELISA and other for dopamine HPLC testing). The samples of brain were collected in the $2 \mathrm{ml}$ micro-tubes, temporarily stored in dry ice. The tubes were weighted, and net weights of brain samples were calculated by the difference of the tubes' weight before and after brain sample collection. The samples were stored in $-80^{\circ} \mathrm{C}$.

HPLC samples were lysed with $0.1 \mathrm{M}$ perchloric acid (50 $\mu \mathrm{l} / \mathrm{mg}$ tissue). After centrifugation with $13000 \mathrm{~g}$ for $10 \mathrm{~min}$ at $4{ }^{\circ} \mathrm{C}$, the supernatant was injected onto a C8 reverse-phase Acclaim 120 column (ESA, Bedford, MA). Dopamine and the two metabolites of dopamine, 3,4-dihydroxyphenylacetic acid (DOPAC) and homovanillic acid (HVA), were quantified by electrochemical detection. The mobile phase consisted of $85 \mathrm{mM}$ sodium acetate, $0.2578 \mathrm{mM}$ EDTA, $70 \mathrm{mM}$ citric acid, $0.8962 \mathrm{mM}$ octane sulfonic acid and $10.5 \%$ methanol, the $\mathrm{pH}$ was adjusted to 4.3 by citric acid. Flow rate was $0.4 \mathrm{ml} / \mathrm{min}$.

The pieces of brain using for GDNF ELISA were lysed in the GDNF ELISA lysis buffer (137 mM NaCl, $20 \mathrm{mM}$ Tris ( $\mathrm{pH} 8.0$ ), 1\% Nonidet P40, 10\% glycerol and protease inhibitor cocktail (Complete mini, Roche)). After centrifugation with $10000 \mathrm{~g}$ for $3 \mathrm{~min}$ at $4{ }^{\circ} \mathrm{C}$ the supernatant was centrifuged other $10 \mathrm{~min}$ with $13000 \mathrm{~g}$ at $4{ }^{\circ} \mathrm{C}$, the supernatant was used for GDNF ELISA. The GDNF ELISA was performed following the protocol from the ELISA kit (Promega, cat. nr.: G7621).

\subsection{Fluorescence microscopy}

To check whether the coordinates of AAV virus injection targeted correct position, AAV-6-EGFP was applied by stereotaxic injection. The expression of EGFP was tested by fluorescence microscopy. Brain sections were mounted directly on 
microscope slides, stored at $-20^{\circ} \mathrm{C}$. Slides were dried by incubating them at $37^{\circ} \mathrm{C}$ for 30 min and rehydrated by putting them in PBS for few seconds. Slides were then incubated in DAPI (50000-fold dilution by PBS) for $10 \mathrm{~min}$ and washed 3 times with PBS. The slips were covered with cover slips mounted by Mowiol and left at $4{ }^{\circ} \mathrm{C}$ over night to dry.

Slices then can be used for imaging by a Zeiss Axioplan 2 microscope equipped with a CCD camera and axiovision rel 4.7 software. The green fluorescence was detected in a green channel, and DAPI was observed in a blue channel. Images were optimized with ImageJ.

\subsection{Motor functional test}

The treatment effect of the developed gene-therapy method can be confirmed by a behavioral test. 6-OHDA application in unilateral striatum causes a progressive loss of dopaminergic neurons in the injected hemisphere. Apomorphine is a dopamine agonist, stimulating the dopamine receptors. The unilateral 6-OHDA injection induced unbalance of dopamine receptors in the two hemispheres, with stimulation from apomorpphine, the unbalance induced the rat to rotate contralateral to the lesion. The number of contralateral turns can be used to evaluate the size of the lesion and then the treatment effect of the developed method.

$10 \mathrm{mg} / \mathrm{ml}$ apomorphine was diluted to $0.5 \mathrm{mg} / \mathrm{ml}$ by saline solution and $0.5 \mathrm{mg} / \mathrm{kg}$ body weight apomorphine was applied to rats by i.p. injection. Rat was then placed in a cylinder (height: $20 \mathrm{~cm}$, diameter: $30 \mathrm{~cm}$ ). A digital camera was used to record the movement of the rat for 1 hour. The number of contralateral turns in the hour was counted. Number of the contralateral turns per hour was used to evaluate the size of lesion with or without treatment. 


\subsection{Molecular biology}

To build human alpha 1-acid glycoprotein rats model, a proper AAV vector carrying correct cDNA is required. AAG in human plasma is separated to 4 variants, $A A G 1{ }^{*} F 1, A A G 1{ }^{*} F 2, A A G 1{ }^{*} S$ and $A A G 2$. Only $A A G 1{ }^{*} F 1$ and $A A G 1{ }^{*} S$ variants have high binding affinity for antiprogestogens, which are roughly $75 \%$ of the total AAG concentration in human plasma. Firstly, the CDNA of EWB in pAAV-HBA-EWB plasmid was digested by restriction enzymes, and the site was inserted by the $c D N A$ of $h A A G 1^{*} S$. Then the second step was to replace the HBA promoter by a liver specific promoter, LP1 promoter. The cDNA of hAAG1*S was ordered from PlasmID Repository at Harvard Medical School. LP1 promoter and pAAV-HBA-EWB plasmid were kindly provided by Dr. Sebastian Kügler. Kind support was acquired from Dr. Sebastian Kügler to package the plasmid to AAV-1/2 or AAV-8 virus.

\subsubsection{PCR amplification}

To amplify the desired DNA fragment, a Phusion High-Fidelity DNA polymerase (Finnzymes) was applied to ensure high fidelity.

$\begin{array}{lrlrr}\text { PCR mix } & & \text { PCR program } & & \\ 5 \mathrm{x} \text { Phusion Buffer HF } & 10 \mu \mathrm{l} & \text { Cycle step } & \text { Temp. } & \text { Time } \\ \text { primer seq }(10 \mu \mathrm{M}) & 2.5 \mu \mathrm{l} & \text { Initial denaturation } & 98^{\circ} \mathrm{C} & 1^{\prime} \\ \text { primer rev }(10 \mu \mathrm{M}) & 2.5 \mu \mathrm{l} & \text { Denaturation } & 98^{\circ} \mathrm{C} & 30^{\prime \prime} \\ \text { dNTP }(4 \mathrm{mM}) & 2.5 \mu \mathrm{l} & \text { Annealing } & 60^{\circ} \mathrm{C} & 30^{\prime \prime} \\ \text { Template } 0.6(\mathrm{ng} / \mu \mathrm{l}) & 2 \mu \mathrm{l} & \text { Extension } & 72^{\circ} \mathrm{C} & 3^{\prime} \\ \text { Phusion Polymerase HF } & 0.5 \mu \mathrm{l} & \text { Final extension } & 72^{\circ} \mathrm{C} & 30^{\prime \prime} \\ \left.\mathrm{DMSO}^{\prime}+/-\right) & 1.5 \mu \mathrm{l} & \text { End } & 4{ }^{\circ} \mathrm{C} & / \\ \mathrm{MgCO}_{2}(+/-) & 1 \mu \mathrm{l} & & \\ \mathrm{H}_{2} \mathrm{O} & \text { Add to } 50 \mu \mathrm{l} & & & \end{array}$

$1 \mu \mathrm{l} \mathrm{PCR}$ product was tested by agarose gel electrophoresis. If the product is correct, it can be purified by the PCR purification kit. 


\subsubsection{Digestion by restriction enzymes}

To generate compatible ends on the CDNA of hAAG1*S or LP1 promoter for directional insertion into the pAAV-HBA-EWB plasmid, restriction enzyme digestion was performed following the manufacturer's instruction. The reaction system was incubated at $37{ }^{\circ} \mathrm{C}$ for 1 hour, and the reaction was stopped by putting the samples on ice. The digested DNA fragments were separated using $1 \%$ or $1.5 \%$ agarose gel, and desired bands were excised under a UV transillumination system. Then the enzyme digestion products were recovered from the excised gels by a DNA gel extraction kit, which will be introduced later.

$\begin{array}{lr}\text { Restriction enzymes digestion } \\ \text { DNA } & 5 \mu \mathrm{g} \\ \text { Cut Smart buffer (10 x) } & 5 \mu \mathrm{l} \\ \text { Restriction enzyme 1 } & 2 \mu \mathrm{l} \\ \text { Restriction enzyme 2 } & 2 \mu \mathrm{l} \\ \mathrm{H}_{2} \mathrm{O} & \text { Add to } 50 \mu \mathrm{l}\end{array}$

\subsubsection{Agarose gel electrophoresis}

Agarose gel electrophoresis was performed for either recovery of DNA fragments or qualitative check of DNAs. One to two percent agarose gel was prepared depending on the size of the target fragments, higher concentration of agarose for small size DNA. The agarose was added in TBE buffer and dissolved by heating with a microwave. $1 \mu \mathrm{l}$ of ethidium bromide per $50 \mathrm{ml}$ of solution was added. The warm agarose solution was then poured into a horizontal gel tray, and a proper comb was inserted to make sample chambers. Waited few minutes at room temperature to cool down and to polymerize the gel. The gel with gel tray was then placed in an electrophoresis chamber and immersed in TBE buffer. DNA 
samples pre-mixed with DNA loading buffer and DNA marker were loaded into the chambers and were electophoresed for 60-120 min under constant voltage (70-100 V). A Gel Documentation 2000 UV-transilluminator coupled with a computer with the Quantity One software (BioRad) was used to visualize DNA bands.

\subsubsection{Gel extraction kit for DNA}

Digested DNA fragments were recovered by a gel extraction kit. Firstly, an agarose gel electrophoresis was performed to separate the DNA fragments. The desired DNA fragment was recognized by the size which was predicted by silicio and cut from the gel by a scalpel. The DNA was isolated and purified from the gel piece by a Quiagen gel extraction kit (Quiagen). The gel piece was weighted and dissolved in the dissolving buffer. To dissolve the gel, the mixture was placed in $50{ }^{\circ} \mathrm{C}$ water bath for $10 \mathrm{~min}$. The liquid was loaded to an ion exchange column in high salt condition which allows the binding of the DNA fragment to the silica column. After washing steps, the DNA was eluted with 10-50 $\mu$ l of elution buffer.

\subsubsection{PCR purification}

To purify desired DNA fragment from oligonucleotides smaller than $40 \mathrm{bp}$ or to isolate a linearized DNA, a Quiagen PCR purification kit was used. Similar with gel extraction kit, the PCR reaction mixture was diluted in loading buffer and was loaded to an ion exchange column in high salt condition to allow binding. After few times wash, the desired DNA was eluted in 10-50 $\mu$ of elution buffer. 


\subsubsection{Ligation}

Desired DNA fragments were ligated into the PAAV vector backbone using a molar ratio of 3:1. The insert and the backbone were mixed with T4 DNA ligase and ligation buffer. The mixture was incubated for $20 \mathrm{~min}$ at room temperature. A negative control was made by omitting addition of the insert. The ligation was stopped by putting the mixture on ice. The mixture can be used for bacteria transformation directly. The typical ligation reaction has been shown as follow:

$\begin{array}{lrr}\text { Ligation reaction } & \text { ligation } & \text { control } \\ \text { Backbone } & 2 \mu \mathrm{l} & 2 \mu \mathrm{l} \\ \text { Insert } & 0.9 \mu \mathrm{l} & 0.9 \mu \mathrm{l} \\ \text { T4 buffer } 10 \mathrm{x} & 2 \mu \mathrm{l} & 2 \mu \mathrm{l} \\ \text { T4 ligase } & 1 \mu \mathrm{l} & 1 \mu \mathrm{l} \\ \mathrm{H} 2 \mathrm{O} & 14.1 \mu \mathrm{l} & 15 \mu \mathrm{l}\end{array}$

\subsubsection{Transformation}

$1 \mu \mathrm{l}$ of the ligation product was added to $70 \mu \mathrm{l}$ of thawed electrocompetent bacteria. The mixture was transferred to a pre-cooled electroporation cuvette. The cuvette immediately was subjected to a electroshock pulse procedure at Bio-rad Gene Pulser II (Voltage: $1800 \mathrm{~V}$ ). The solution was added into $1 \mathrm{ml}$ of pre-warmed $\mathrm{SOC}++$ media. Then the mixture was incubated for $45 \mathrm{~min}$ at $37^{\circ} \mathrm{C}$ on a shaker with $200 \mathrm{rpm}$. $500 \mu \mathrm{l}$ of bacteria were seeded on LB agar plate containing ampicillin $\left(100 \mu \mathrm{g} / \mathrm{ml}\right.$, Applichem). Plates were left at $37^{\circ} \mathrm{C}$ over-night to cultivate colonies. Single colony was then picked by a $200 \mu$ pipette tip and was added into $10 \mathrm{ml}$ of LB media. The culture was left at $37^{\circ} \mathrm{C}$ with $200 \mathrm{rpm}$ shaking over night, at least 14 hours. $2 \mathrm{ml}$ bacteria culture was added in a $2 \mathrm{ml}$ tube. A Quiagen PCR purification kit was used to purify DNA from the bacteria culture.

To prepare LB agar plates, $40 \mathrm{~g} / \mathrm{l}$ of LB-Agar was dissolved with distilled water. The LB-Agar solution was autoclaved and then cooled down to roughly $60^{\circ} \mathrm{C} .100$ $\mathrm{mg} / \mathrm{l}$ ampicillin and $50 \mathrm{mg} / \mathrm{l}$ kanamycin were added into the mixture. The mixture 
was then added in $10 \mathrm{~cm}$ plates as $25 \mathrm{ml}$ per plate and let to polymerize.

To prepare LB media, $100 \mathrm{mg} / \mathrm{l}$ ampicillin and $50 \mathrm{mg} / \mathrm{l}$ kanamycin were added into $25 \mathrm{~g} / \mathrm{l} \mathrm{LB}$ media.

\subsection{Building hAAG rat model, plasma collection and hAAG quantification}

AAV-LP1-hAAG or AAV-HBA-hAAG were applied to 9 weeks old rats by intravenous injection under anesthesia. Plasma samples were collected 1, 2, 3, 4, 8 weeks post virus application. hAAG concentrations were measured by ELISA. The rats would be considered as proper hAAG rats model when the virus expressed hAAG concentration reaching the range of $0.45-0.9 \mathrm{mg} / \mathrm{ml}$ plasma.

hAAG and mifepristone concentration were tested in the rats plasma samples. To collect rats plasma samples, they were anesthetized, and blood samples were collected by tail vein into $2 \mathrm{ml}$ tubes containing heparin (Sigma). The tubes were centrifuged at $10000 \mathrm{~g}$ for $10 \mathrm{~min}$, the supernatants were collected as plasma samples.

hAAG concentrations were tested in the plasma samples by a Human alpha 1-acid Glycoprotein ELISA kit ( $R$ and D system) and a DuoSet ELISA kit ( $R$ and D system). The experiments were followed the ELISA kit's protocol and hAAG concentration was calculated with a hAAG standard curve. 


\section{Results}

\subsection{Summary}

During the PhD thesis, two projects were carried out. In the first project, an inducible AAV-5 vector for expression of GDNF, under control of the approved small molecule drug mifepristone, was evaluated in rats. GDNF expression could be induced over a wide range up to four hundred-fold over endogenous background, and completely returns to baseline within $3-4$ weeks, without showing any non-induced background expression. Treatment efficacy was evaluated in the 6-OHDA model of PD, where repeated short-term expression of GDNF restored motor capabilities. Pharmacokinetics of Mfp showed unexpected gender-related differences, which were overcome by CYP3A inhibition. In the second project, a "humanized" alpha-1 acid glycoprotein (hAAG) rat model was generated by AAV-1/2-LP1-hAAG intravenous injection. The gene therapy method was tested in the hAAG rat model, and a similar level of expression of GDNF was observed in the model rats and native rats.

\subsection{Kinetics of induced GDNF expression}

Glial cell line-derived neurotrophic factor (GDNF) has a protective effect on dopaminergic neurons, and therefore is considered as a candidate to treat different neuro-degenerative disorders including Parkinson's disease (Barroso-Chinea et al., 2016). However, experiments in rats demonstrated that a decline in tyrosine hydroxylase expression was caused by prolonged GDNF over-expression as a side effect (Barroso-Chinea et al., 2016). The side effects included the reduced expression of enzymes of the dopamine biosynthesis pathway as well as of dopamine transporter activity (Georgievska et al., 2002a; 
Chtarto et al., 2007).

A previous work from the lab demonstrated that pulses of GDNF expression could provide similar neuroprotection effect as a continuous treatment while avoiding TH downregulation (Tereschchenko et al., 2014). In the previous work, the tight regulation of GDNF expression was achieved with a two-vector system: the expression cassettes for GS and for the transgene under control of the induced Gal4-TATA promoter are split up between two individual AAV vectors. This mode allowed for a titration of GS protein: Gal4-TATA promoter in a way that no background expression took place while retaining good induction. Such tightly regulated expression of GDNF with a one-vector configuration has not been reported in the previous works performed by my colleagues: in any case tested, induction rates were low with significant background expression in the non-induced state (Maddalena et al., 2013). Recently, a series of modified vector genomes have been tested by my colleagues, and one vector genome has been selected due to its high induction rate and no background expression (Cheng et al., 2018). In this single-vector genome, all necessary elements have been incorporated into a single AAV vector genome. The one-vector layout is supposed as a facilitation of approval of the gene therapy method by authorities.

The first task of the PhD project was to evaluate the single-vector genome. The kinetics of the induced GDNF expression has been determined. Sufficient expression of GDNF should provide a positive treatment effect to symptoms of PD, and avoid side effects either from over-expression of GDNF or Mfp. The regulated gene-therapy method is easy to be stopped by ceasing application of the inducer, which is considered as a safeguard for the patients. Therefore, it is also important to know the kinetics of GDNF clearance after short-term induction. To test the kinetics of the induced GDNF expression, an experiment was designed as shown in Fig 4.1A. Briefly, $1 \times 10^{9} \mathrm{vg}$ of AAV-5-GS-GDNF was injected into the left striatum of rats, followed by $20 \mathrm{mg} / \mathrm{kg}$ body weight mifepristone was applied intraperitoneally to the rats 3 weeks post virus injection, and GDNF expression was quantified by ELISA at different time points post mifepristone application. As the Fig. 4.1B shows, the highest GDNF expression was observed at 7 days after 
mifepristone intraperitoneal injection and completely decayed to endogenous background level between 28 and 42 days. As a conclusion, the developed AAV-5-GS-GDNF has been proven to be fully reversible in terms of GDNF expression induced by mifepristone. This has never been achieved in previous studies even in a very similar vector, with only difference on the orientation of the two expression cassettes (Cheng et al., 2018).

A
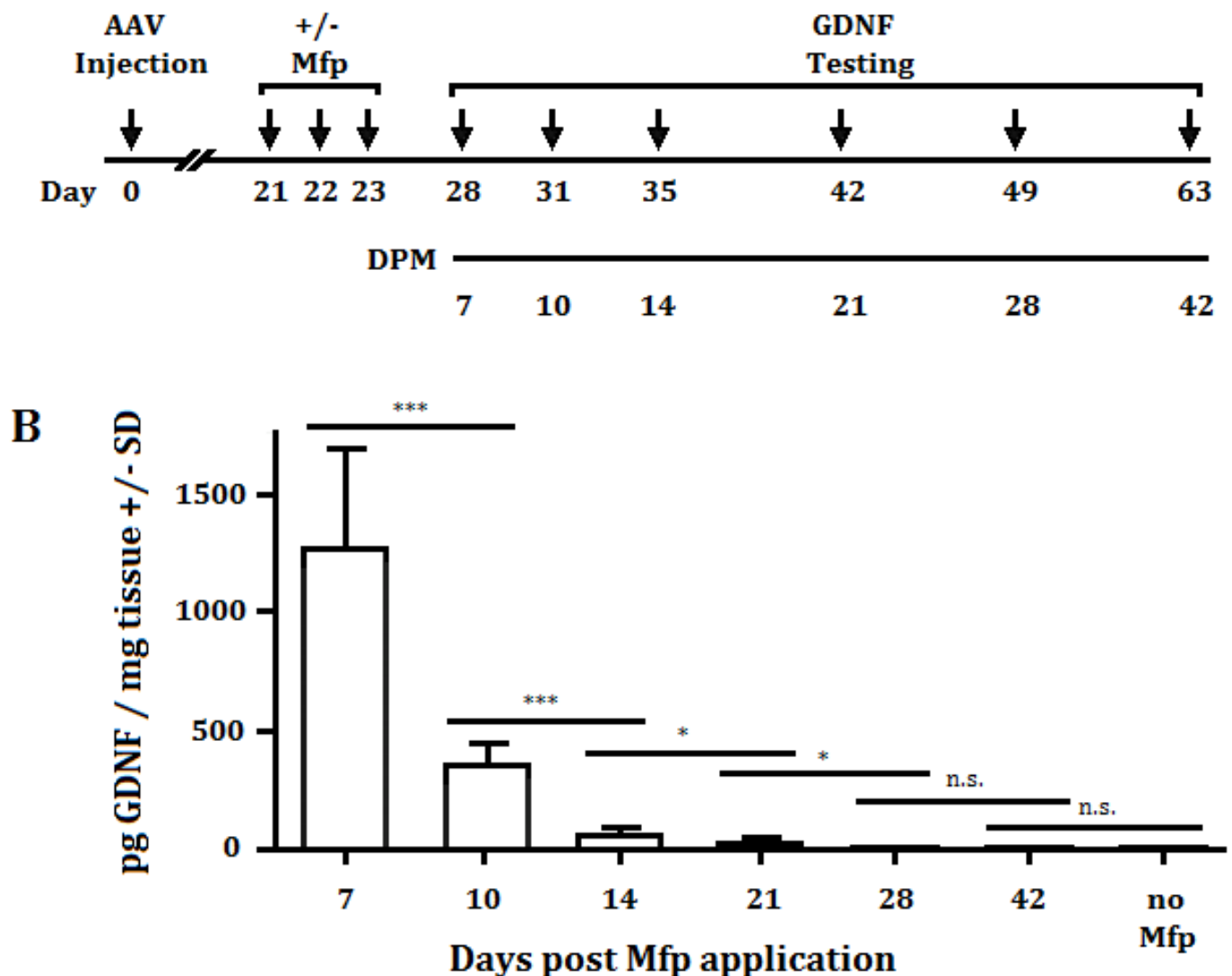

Figure 4.1 Kinetics of the induced GDNF expression.

(A) Schematic representation of experiments determining kinetics of the induced GDNF expression. (B) Decay kinetics of striatal GDNF expression after application of $20 \mathrm{mg} / \mathrm{kg} \mathrm{Mfp} \mathrm{on}$ three consecutive days. GDNF levels in $\mathrm{pg} / \mathrm{mg}$ tissue $\pm \mathrm{SD}$ after injection of $1 \times 10^{9} \mathrm{vg} /$ striatum of AAV-5-GS-GDNF. DPM: days post Mfp application. ${ }^{* \star *} p<0.001$, power (1- $B$ err prob) $=0.99 ;{ }^{*} p<$ 0.05 , power $(1-B$ err prob) $=0.77$. 


\subsection{Evaluations of Mfp dosages and application routes}

In this part of the project, I aimed to elucidate the dynamic range of the AAV-GS-GDNF vectors. To that end, different dosages of Mfp were applied either orally or intraperitoneally. It would be beneficial for the treatments to Parkinson's disease patients in different disease severities. Another aim of the experiments was to determine the minimal dosage of Mfp sufficient to provide therapeutic effects. The safety of Mfp had been reported in literature: $1000 \mathrm{mg}$ single application or one month of $100 \mathrm{mg}$ daily application both did not show any toxic effect in volunteers (Heikinheimo et al., 1987; Heikinheimo et al., 1989; Kawai et al., 2013). However, any potential risks from high dosage application of Mfp or over-expression of GDNF probably can be avoided by a low dosage of Mfp application.

As shown in Fig.4.2A, striatal injections of AAV-5-GS-GDNF were performed at nine weeks old female rats. Three weeks after unilateral striatal vector injection, different dosages of mifepristone were applied to the rats by intraperitoneal injection either for three consecutive days or one day only. Four days after the last application of mifepristone, rat's striata were collected and GDNF expression levels were quantified by ELISA. As shown in Fig.4.2B, a tight control over the GDNF expression was achieved by different dosages of mifepristone application, and $1 \mathrm{mg} / \mathrm{kg}$ mifepristone was sufficient to induce $155 \pm 52 \mathrm{ng}$ GDNF per $\mathrm{mg}$ of tissue. This GDNF level has been demonstrated to be sufficient for successful treatment of a partial striatal 6-OHDA lesion in earlier studies (Tereshchenko et al., 2015).

Comparing with application of Mfp on three consecutive days, a single mifepristone application resulted in proportionally less activation of the GS-GDNF system: while $1600 \pm 500 \mathrm{pg} / \mathrm{mg}$ tissue GDNF was achieved by three consecutive $20 \mathrm{mg} / \mathrm{kg}$ mifepristone applications, $540 \pm 247 \mathrm{pg} / \mathrm{mg}$ tissue GDNF was achieved by single application of $20 \mathrm{mg} / \mathrm{kg}$ mifepristone, which demonstrated another 
strategy to control the system by adjusting mifepristone application frequency.

A
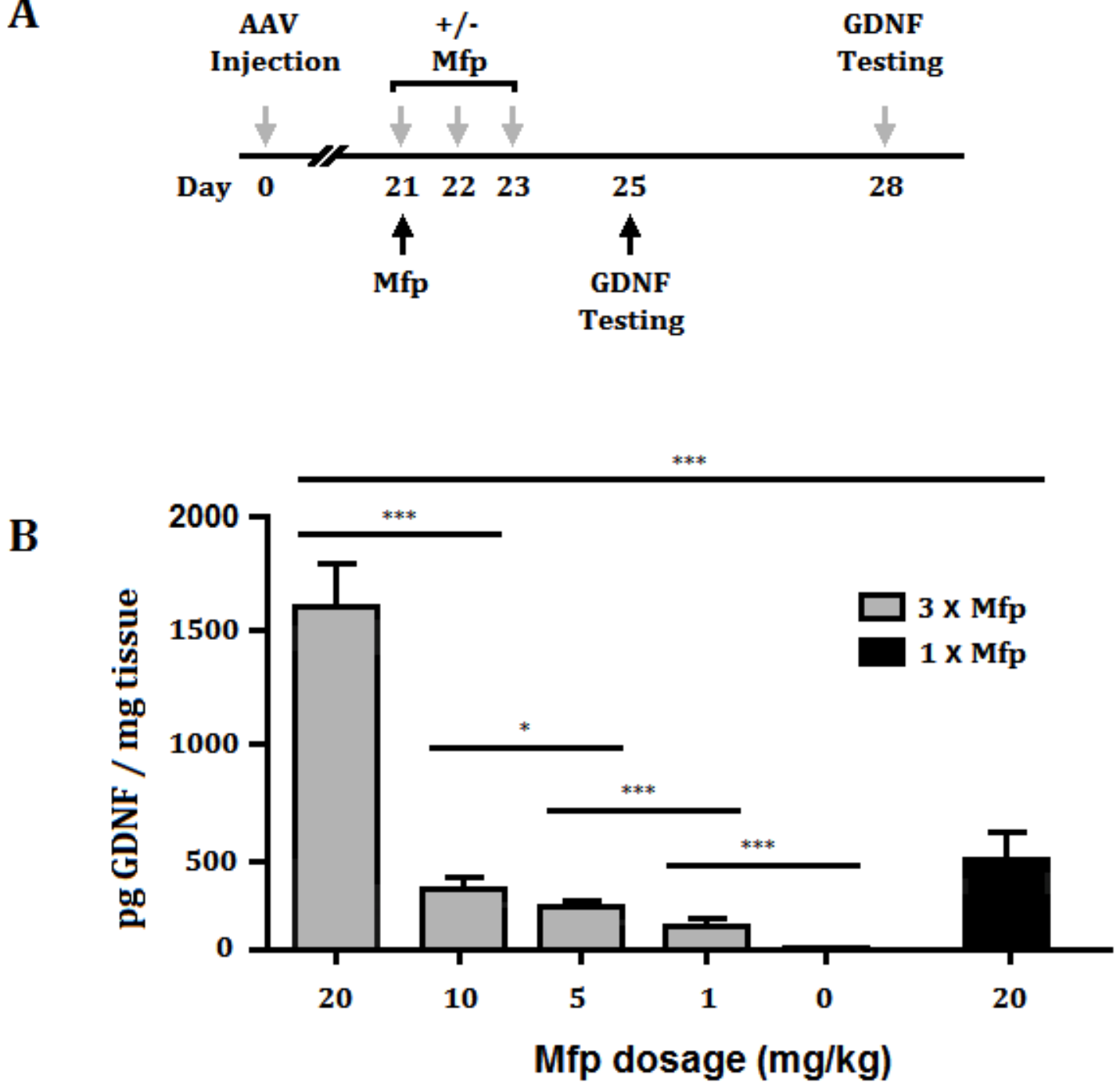

Figure 4.2. Dose responses to i.p. Mfp application.

(A) Schematic representation of experiments comparing Mfp intraperitoneal applications on three consecutive days (grey arrows) with Mfp application on a single day (black arrows). (B) GDNF expression level in $\mathrm{pg} / \mathrm{mg}$ tissue $\pm \mathrm{SD}$ achieved by i.p. injection of different doses of Mfp, dissolved in DMSO. Mfp was either given on three consecutive days $(3 \times$, grey columns, experiments were performed according to schematic representation with grey arrows in A), on one day (1x, black column, experiments were performed according to the schematic representation with black arrows in A) or not at all. For the control group, rats received AAV striatal injection and DMSO intraperitoneal injection. n.s. $=$ no significant difference. $n=7$ animals for each group. ${ }^{*}=p<0.05$, 
${ }^{* * *}=\mathrm{p}<0.001$ in pairwise comparisons of groups with normal distribution and similar variance by non-paired, two-tailed t-tests; Power $(1-\beta$ err prob) $=1$ for all conditions shown, except for the difference between $3 \times 10 \mathrm{mg} / \mathrm{kg}$ i.p and $3 \times 5 \mathrm{mg} / \mathrm{kg}$ i.p., where power (1-ß err prob) $=0.72$.

So far, Mfp was applied intraperitoneally, dissolved in DMSO (Maddalena et al., 2013; Tereshchenko et al., 2014). This application method was considered necessary due to the fact that Mfp is not soluble in aqueous solutions. Furthermore, i.p. application results in bioavailability of drugs similar to i.v. application due to avoidance of the first-pass effect often encountered after oral administration. However, oral drug application is the preferred route for human use. Thus, the pharmacodynamics in terms of induction of GDNF expression was evaluated by either intraperitoneal injection or oral administration of Mfp. Mfp was applied orally, suspended in sesame oil or an aqueous carrier including micelle forming organic compounds (ASV). No obvious difference in levels of GDNF expression was observed (data not shown). Thus, oral administration of Mfp will be performed with suspension by ASV in the further experiments.

As shown in Fig. 4.3A, striatal injections of AAV-5-GS-GDNS were performed in nine weeks old female rats. Three weeks after unilateral striatal vector injection, different dosages of Mfp were applied to the rats by oral administration on either three consecutive days or on one day only. Four days after the last application of Mfp, rats' striata were collected and GDNF expression levels were quantified. Similar with the data in terms of Mfp intraperitoneal applications, a tight control over the GDNF expression was achieved by different dosages of Mfp oral application. However, the efficiency of GDNF induction by oral administration of Mfp is obviously lower as compared to i.p. injection. For instance, roughly five hundred pg GDNF per mg tissue was induced by i.p. injection of $10 \mathrm{mg} / \mathrm{kg} \mathrm{BW}$ Mfp, while $20 \mathrm{mg} / \mathrm{kg} \mathrm{BW} \mathrm{Mfp} \mathrm{oral} \mathrm{application} \mathrm{resulted} \mathrm{in} \mathrm{a} \mathrm{similar} \mathrm{level} \mathrm{of} \mathrm{GDNF}$ expression (Fig. 4.3B). The different pharmacodynamics of Mfp in the two drug application routes were supposed as the reason for the difference. Again, in agreement with data obtained by i.p. injection of Mfp, the GS-GDNF system was proportionally less activated by a single Mfp application as compared to Mfp 
applications on three consecutive days (Fig. 4.3B): $1010 \pm 260 \mathrm{pg} / \mathrm{mg}$ tissue GDNF was achieved by three consecutive $50 \mathrm{mg} / \mathrm{kg}$ mifepristone applications, $525 \pm 198 \mathrm{pg} / \mathrm{mg}$ tissue GDNF was achieved by single application of mifepristone.

As a conclusion, a wide range of GDNF expression in rat's striatum could be achieved by adjustment of dosage, application frequencies or routes of Mfp, ranging from 30 -fold up to 400 -fold over endogenous levels. 
A

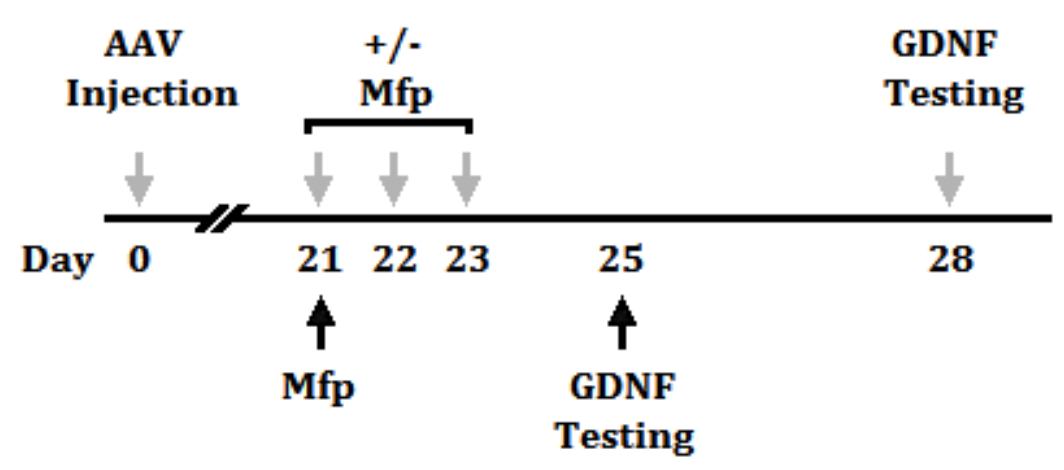

B

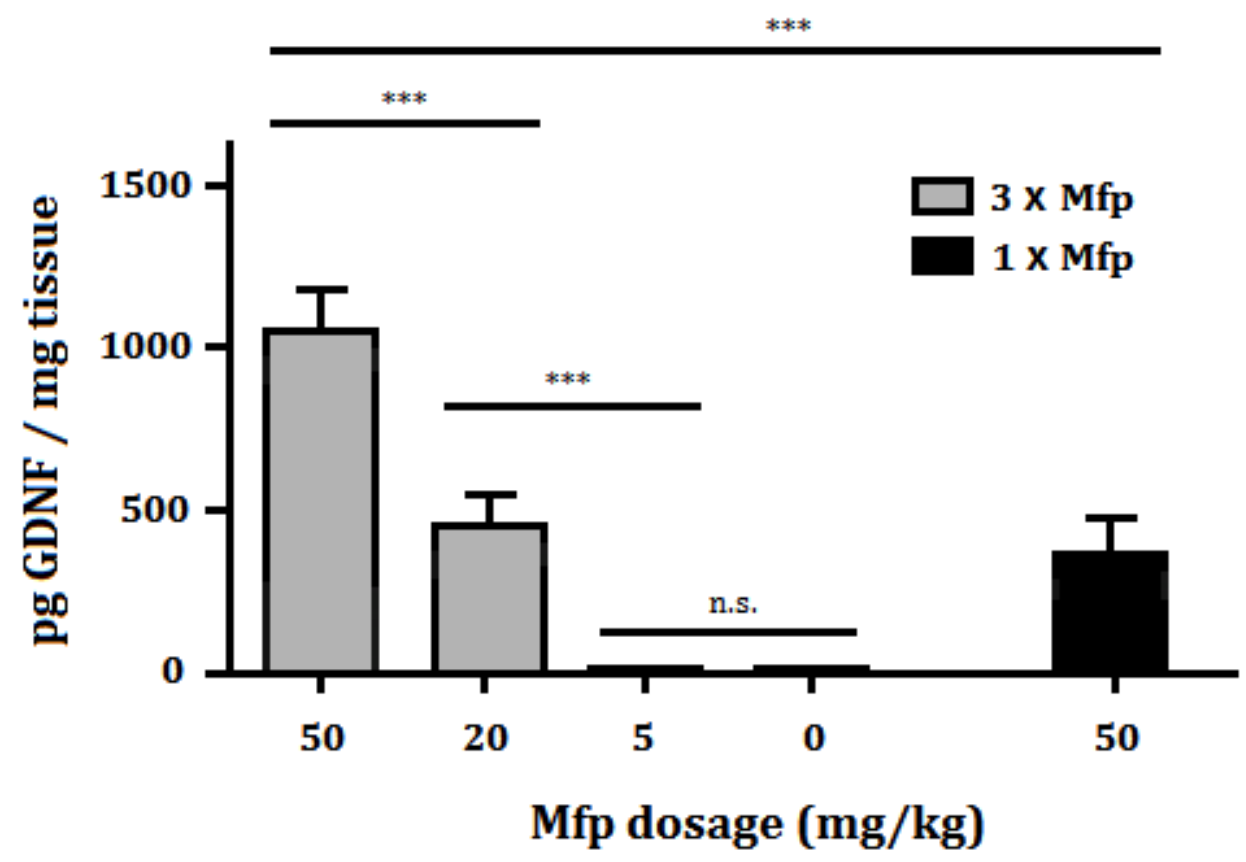

Figure 4.3. Dose responses to oral Mfp application.

(A) Schematic representation of experiments comparing Mfp oral applications on three consecutive days (grey arrows) with Mfp application on a single day (black arrows). (B) GDNF expression levels in $\mathrm{pg} / \mathrm{mg}$ tissue $\pm \mathrm{SD}$ achieved by oral administration of different doses of Mfp, suspended in ASV. Mfp was either given on three consecutive days (3x, grey columns, experiments were performed according to schematic representation with grey arrows in $A$ ), on one day $(1 \times$, black column, experiments were performed according to the schematic representation with black arrows in A) or not at all. For the control group, rats received AAV striatal injection and 
ASV solution gavage. n.s. $=$ no significant difference. $n=7$ animals for each group. ${ }^{*}=p<0.05$, ${ }^{* * *}=\mathrm{p}<0.001$ in pairwise comparisons of groups with normal distribution and similar variance by non-paired, two-tailed t-tests; Power (1- $\beta$ err prob) $=1$ for all conditions shown, except for the difference between $3 \times 10 \mathrm{mg} / \mathrm{kg}$ i.p and $3 \times 5 \mathrm{mg} / \mathrm{kg}$ i.p., where power $(1-\beta$ err prob) $=0.72$.

\subsection{Gender-dependent mifepristone pharmacokinetics and GDNF expression}

So far, the GS-GDNF system was only studied in female rats. In the next part of the project, the GS-GDNF system was evaluated in both male and female rats. An unexpected difference was observed in GDNF expression between male and female rats. Thus, additional experiments were performed to explore the possible reasons of the gender-dependent GDNF expression.

As shown in Fig. 4.4Aa, striatal injections of AAV-5-GS-GDNF were performed in left striata of nine weeks old male and female rats, mifepristone was applied by intraperitoneal injection or gavage on three consecutive days, and levels of striatal GDNF were determined four days after the last mifepristone application. After activating the system with $20 \mathrm{mg} / \mathrm{kg}$ BW Mfp intraperitoneal injections on three consecutive days, about 8-fold higher level of striatal GDNF were determined in brains of female rats as compared to male rats. After activating GDNF expression by $50 \mathrm{mg} / \mathrm{kg} \mathrm{BW}$ oral administrations of Mfp on three consecutive days, the level of GDNF was roughly 5-fold higher in females as compared to males. These results demonstrated a gender-dependent GDNF expression of the system: much higher level of GDNF were achieved in females as compared to males.

The literature suggests that certain AAV vectors have different transduction properties between males and females (Davidoff et al., 2003; Maguire et al., 2013). These different transduction properties were initially supposed as the reason to induce gender-dependent GDNF expression. In order to evaluate this issue further, AAV-5-syn-GDNF, which constitutively expresses GDNF, was 
injected into male and female rats' striatum. Levels of GDNF were determined for both genders 3 weeks post virus application. $8446 \pm 2728$ pg GDNF per mg tissue was determined in male rats, comparing with $8176 \pm 3277$ pg GDNF per mg tissue in females. The variation thus is less than $5 \%$, without a significant difference. Therefore, gender-specific transduction of AAV vectors is not found with our vectors, and cannot be the reason for the gender-dependent GDNF expression.

As a conclusiuon, a gender-dependent pharmacodynamics of Mfp was assumed. To evaluate this, Mfp concentrations in male and female rats' plasma were determined at several time-points after Mfp application. As shown in Fig. 4.4Ab, intraperitoneal injections of $20 \mathrm{mg} / \mathrm{kg}$ BW Mfp were performed in male and female rats on three consecutive days, as time-points " $t=0 h ", ~ " t=24 h "$, and " $t=48 \mathrm{~h}$ ". Plasma concentrations of Mfp were determined before Mfp application, and at 1, 25, 49, 52, 56, 72 and 96 hours after the first application of Mfp. As shown in Fig. $4.4 \mathrm{C}$, one hour after the first intraperitoneal injection of $20 \mathrm{mg} / \mathrm{kg} \mathrm{BW}$, identical mifepristone concentrations in male and female rats' plasma were detected. However, while substantially increased Mfp concentration was observed 1 hour after the second mifepristone application in female rats, this was not observed in male plasma. The increase was improved again by the third Mfp application in females. However, the third application of Mfp did not raise plasma Mfp levels above those achieved with the first injection in males. As a consequence, plasma concentration of Mfp in female rats was robustly higher as compared to males over the intraperitoneal injection of mifepristone, providing the basis for the substantially higher rate of GDNF induction in female striatum. Given that roughly 4-fold lower GDNF expression resulted from lowering the applied Mfp dosage from $3^{*} 20 \mathrm{mg} / \mathrm{kg}$ to $3^{*} 10 \mathrm{mg} / \mathrm{kg}$ (Fig. 4.2B), it seems reasonable to argue that the decreased pharmacodynamic action of Mfp in brains of male rats versus brains of female rats is directly correlated to its reduced absorption or faster metabolic rate in males as compared to female rats. 
A

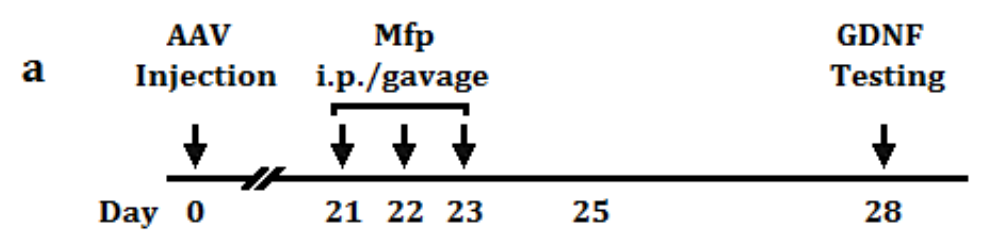

b

Blood samples collection

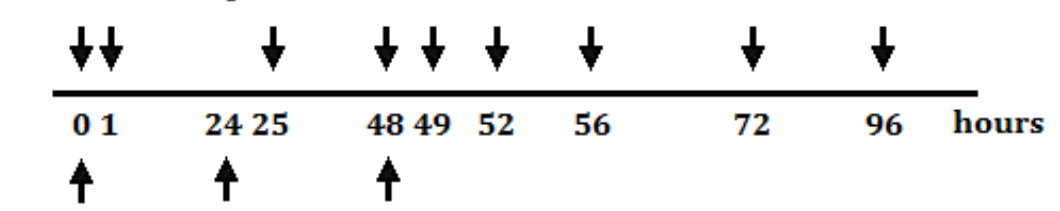

Mfp injection

B

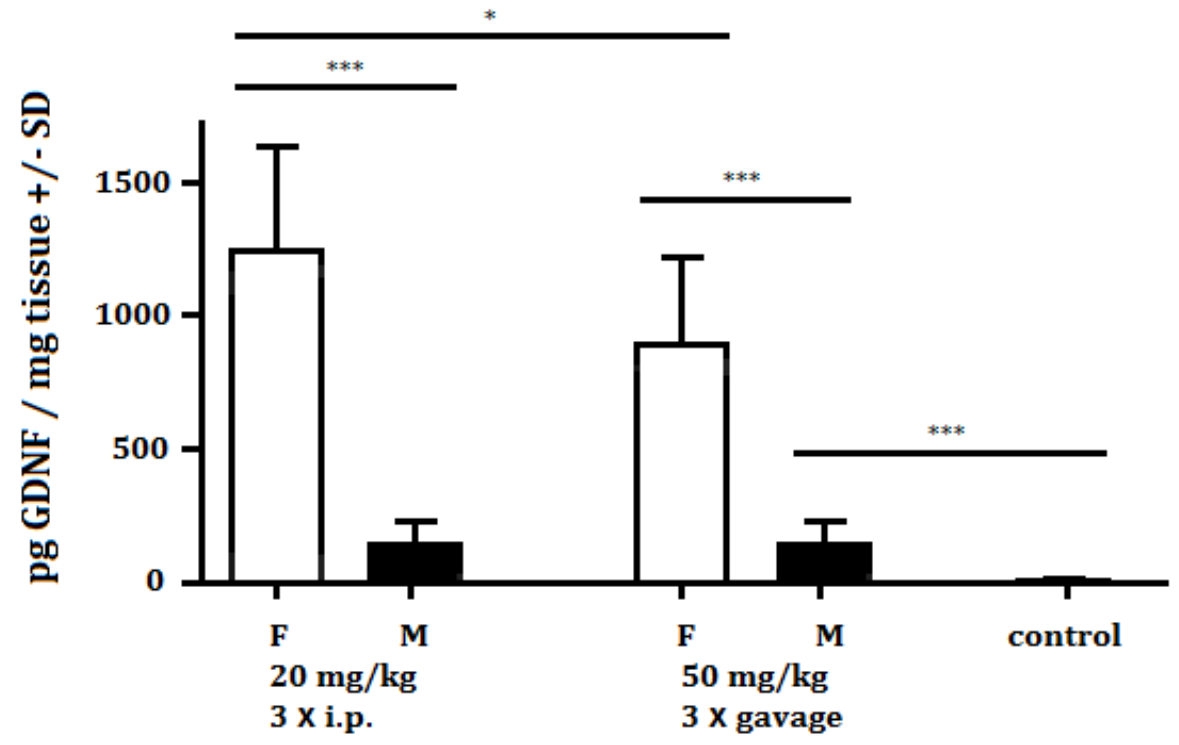

C

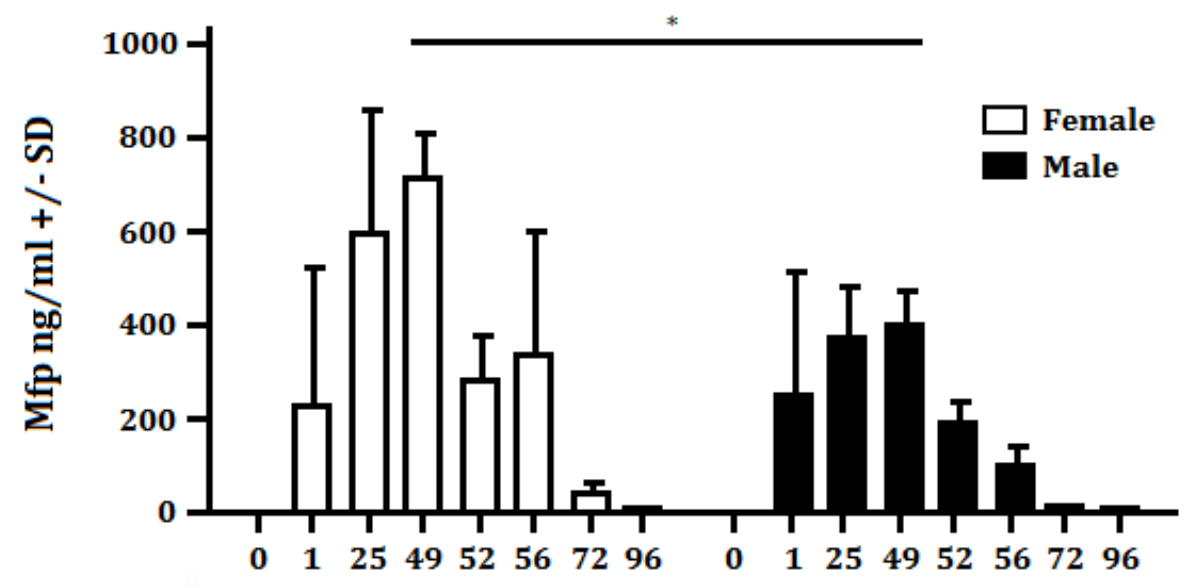

Hours 
Fig. 4.4 Gender-dependent GDNF expression and Mfp pharmacokinetics.

(A) a. Schematic representation of experiments comparing the GS-GDNF system in males with it in female rats; $b$. Time scale of the experiments shown in panel $(C) .(B)$ Level of striatal GDNF induced by intraperitoneal injection or oral administration of mifepristone in male $(M)$ or female $(F)$ rats. ${ }^{*}=p<0.05$ (power $(1-\beta$ err prob) $=0.7) ;{ }^{* *}=p<0.001$ (power $(1-\beta$ err prob) $=0.99)$ in pairwise comparisons of groups with normal distribution and similar variance by non-paired, two-tailed t-tests. $n=7$ animals for each group. (C) Plasma mifepristone concentrations in male and female rats after $3^{*} 20 \mathrm{mg} / \mathrm{kg}$ mifepristone intraperitoneal injections. Mifepristone was applied at time points 0,24 , and $48 \mathrm{~h}$, plasma samples were collected at time points $0,1,25,49,52,56$, 72 and $96 \mathrm{~h}$. Plasma mifepristone concentration are shown for males as black bars and for females as white bars. Statistical analysis by 2 -Way ANOVA with Bonferroni's post hoc test. ${ }^{*}=p$ $<0.05(1-\beta$ err prob) $=0.99$. $n=5$ animals per group .

\subsection{Evalutation of the GS-GDNF vector in the partial striatal 6-OHDA model of PD}

\subsubsection{Functional evaluation of AAV-5-GS-GDNF in the apomorphine - induced motor imbalance test}

Treatment effects of the gene therapy method were evaluated by the restoration of the motor impairments in the 6-OHDA model of Parkinson's disease. As shown in Fig. 4.5A, 6-OHDA was striatally injected into female adult rats at the time point " $\mathrm{t}=0 \mathrm{~d}$ ". Apomorphin-induced rotation behavior was evaluated before and after 6-OHDA application, in order to confirm a successful lesion. Three weeks after 6-OHAD aplication, $1 \times 10^{9} \mathrm{vg}$ AAV-5-GS-GDNF vector or a vector constitutively expressing GDNF were injected into the striata. One group of rats was subjected to Mfp application once at 5 weeks after 6-OHDA lesion (2 weeks after virus injection). Another group received applications of Mfp at 5, 10, 15 and 20 weeks after the lesion (2, 7,12 and 17 weeks after virus application). Without any Mfp applications, a group of AAV-5-GS-GDNF injected rats were considered as the 
negative control. Animals subjected to AAV vectors expressing constitutive GDNF was considered as the group of positive control.

Before lesion by 6-OHDA (time point $0 \mathrm{~d}$ ), all rats showed movements to random directions. Two weeks after the 6-OHDA application, roughly 200 contralateral turns per hour were observed in all animals. An obvious decline in contralateral turns was observed in the positive group: contralateral turns in an hour decreased to 70 at time point 7 weeks. Although not being statistically significant, an increased trend of the contralateral turns was observed in this group between time point 7 weeks and time point 31 weeks: rotations increased to 100/h at time point 31 (Fig. 4.5B).

For the negative control group, without mifepristone induction, GDNF expression should be the same as the background level (Fig. 4.2). As expected, no treatment effect can be found in this group as the contralateral turns persisted at roughly 200 turns per hour from time point 7 to 31 weeks (Fig. 4.5B).

Contralateral turns decreased from $200 / \mathrm{h}$ to roughly $110 / \mathrm{h}$ in the rats with only one mifepristone application, which demonstrated a positive treatment effect by this short pulse of GDNF expression. However, the contralateral turns increased moderately following at later times, resulted in an obvious difference between time point 7 and 31 weeks (Fig. 4.5B). Given that an unabiding treatment effect was provided by the single activation of the system, frequent GDNF expressions induced by periodical mifepristone applications probably can keep the treatment effect durable.

In contrast to the rats with one Mfp application, a stable rotation behavior was observed in the group with four consecutive Mfp aplications, from two weeks after the first time of Mfp application until the last time point (Fig. 4.5B). Comparing to the group of positive control, although GDNF expression was initiated two weeks later in this group, no significantly different rotation behavior was observed in the two groups (Fig. 4.5B). 
A
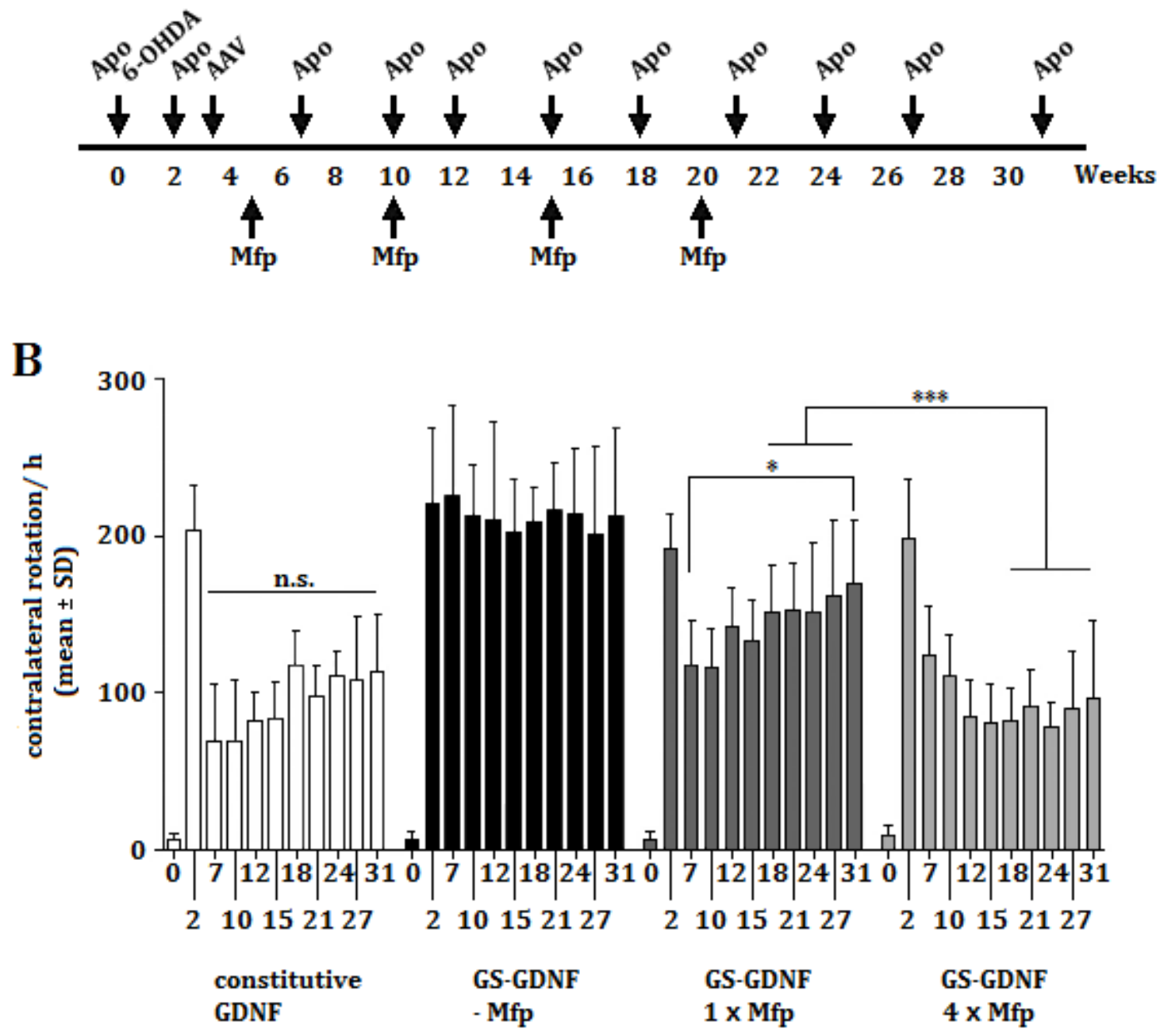

Fig. 4.5 Restoration of motor impairments in the 6-OHDA model of PD.

(A) Schematic represent of the experiments. APO: apomorphine induced rotation behavior; 6-OHDA: 6-OHDA striatal injection; AAV: AAV-5-GS-GDNF striatal injection; Mfp: $20 \mathrm{mg} / \mathrm{kg}$ BW mifepristone intraperitoneal injection on three consecutive days. (B) Rotation behavior counted by the contralateral turns in rats injected with AAV-5-syn-GDNF (constitutive GDNF expression) as the positive control (white bars), in rats injected with AAV-5-GS-GDNF but without mifepristone application as the negative control (black bars), in rats injected with AAV-5-GS-GDNF and once mifepristone application (dark gray bars), and in rats injected with AAV-5-GS-GDNF and 4 times mifepristone applications (light gray bars). The contralateral turns of rotation behavior were counted at $0,2,7,10,12,15,18,21,24,27$ and 31 weeks after 6 -OHDA application. The contralateral turns per hour were counted and shown as mean \pm standard deviation. Statistical analysis by 1 - way ANOVA with Tukey's post hoc test. ${ }^{*}=p<0.05 ;{ }^{* *}=p<0.001 ;$ n.s. $=$ not 
significant. Power ( 1 - $B$ err prob) $>0.98$ for all shown comparisons. $n=5-7$ rats/group at the latest time point of the experiment.

Prolonged GDNF over-expression causes several side-effects in rodents and monkeys (Georgievska et al., 2002a; Chtarto et al., 2007; Su et al., 2009; Barroso-Chinea et al., 2016). A main side effect of prolonged GDNF expression is diminished body weight gain due to stimulation of corticotrophin releasing hormone release from hypothalamic neurons (Su et al., 2009). Body weights of rats in the four groups were recorded until the endpoint of the experiment. Body weight gains in all groups were not statistically different. However, comparing with other three groups, about $10 \%$ less body weight was observed in the animals with constitutive expression of GDNF at the endpoint. The diminished gain of body weight was aggravating since 7 weeks after 6-OHDA lesion, but the body weight recording could not be continued due to the loss of animals during the experiments. Still, the $10 \%$ body weight loss suggests a subtle negative effect of constitutive GDNF expression on body weight gain, which can be avoided by pulsed GDNF expressions (Fig. 4.6). 


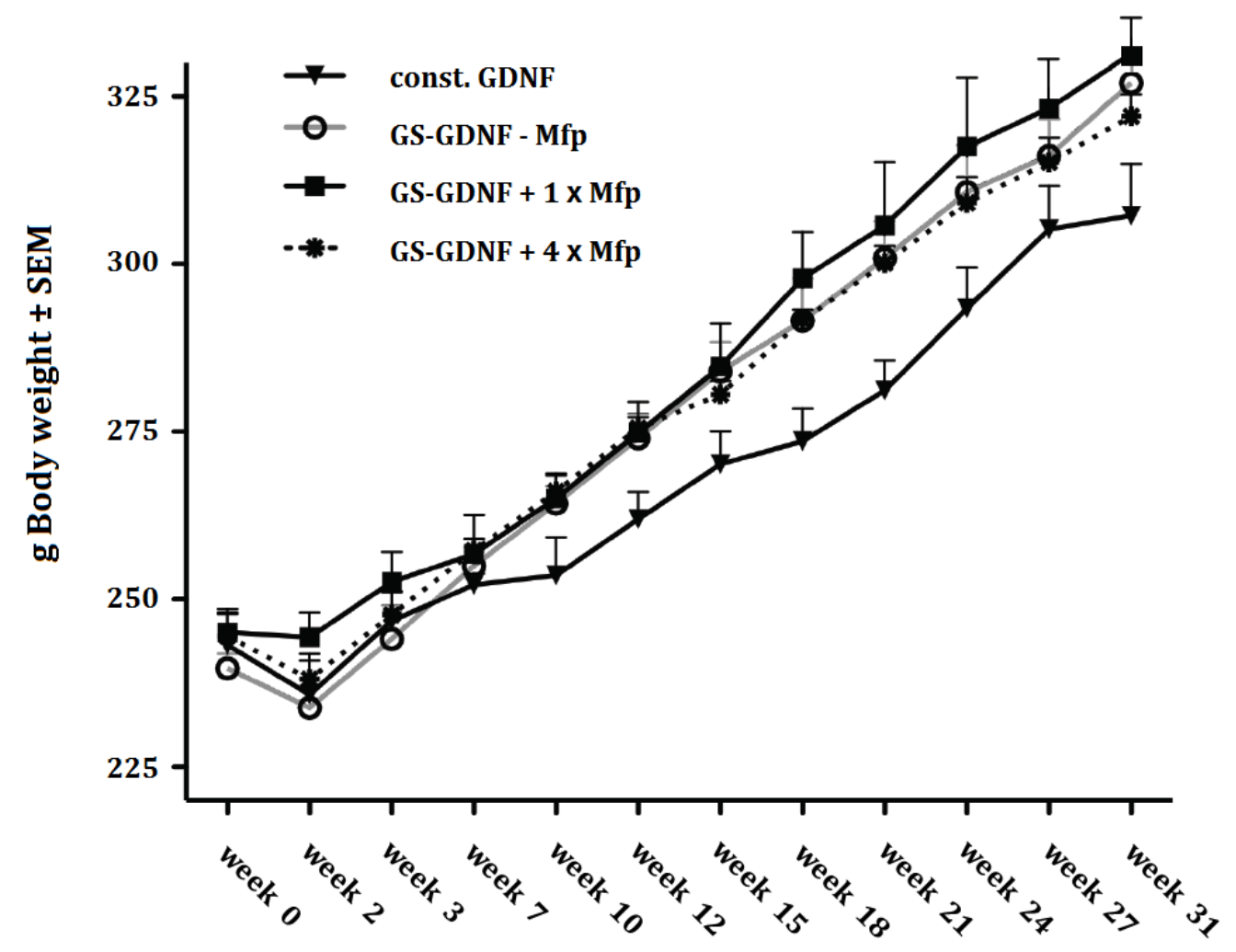

Fig. 4.6 Body weight gain for the rats over the time course of motor experiments

Body weights of the rats at different time points are shown as mean \pm SEM. Statistical analysis by 1 -way ANOVA with Tukey's post hoc test. ${ }^{*}=\mathrm{p}<0.05 ;{ }^{* * *}=\mathrm{p}<0.001$; Power $(1-B$ err prob) $>$ 0.98 for all shown comparisons. $n=5-7$.

The assessment of motor imbalances had to be stopped at 31 weeks after 6-OHDA application, due to the animal loss induced by experimental operation or age induced disease (e.g. tumor). In some groups, only five rats survived to that time. Thus, with the residual animals, the ability of the GS-GDNF system to become reactivated after long-term inactivity was evaluated. Therefore, one more mifepristone application was performed at time point 45 weeks. Induced level of GDNF expression was quantified, and the protecting effect to dopaminergic neurons was determined by measurement of dopamine metabolism. 


\subsubsection{Reactivation of the GS-GDNF vector after long-term inactivation}

As shown in Fig. 4.7A, animals that already received four inductions of GDNF expression were subjected to an additional Mfp application at week 42 after virus injections ( 25 weeks after the last activation of the system). Thus, the GeneSwitch system was reactivated after roughly half a year of inactivity, in rats older than 12 months. One week after the fifth Mfp application, approximately 10000 pg GDNF per mg tissue was determined in the ipsilateral striata. Interestingly, the level of GDNF was about 8-fold higher than the level of GDNF induced by one Mfp application in $2-3$ month old rats. This high GDNF expression even resulted in "leakage" to the contralateral striata (Fig. 4.7). An age - dependent pharmacodynamics of Mfp was suggested to be responsible for this result, and was supposed as the reason for the higher level of expression of GDNF in aged animals. The age - dependent pharmacodynamics of Mfp should be proved by further experiments in quantification of Mfp concentration in plasma of young and aged animals.

As shown in Fig. 4.7, the background level of GDNF was determined in the groups injected vectors with GS-GDNF but without the fifth Mfp activation. A tight control over the system was demonstrated: without Mfp induction, the AAV-5-GS-GDNF stays absolutely background-free for extended periods of time; with mifepristone activation, the system can be turned to ON-state even after long time inactivity. 
A

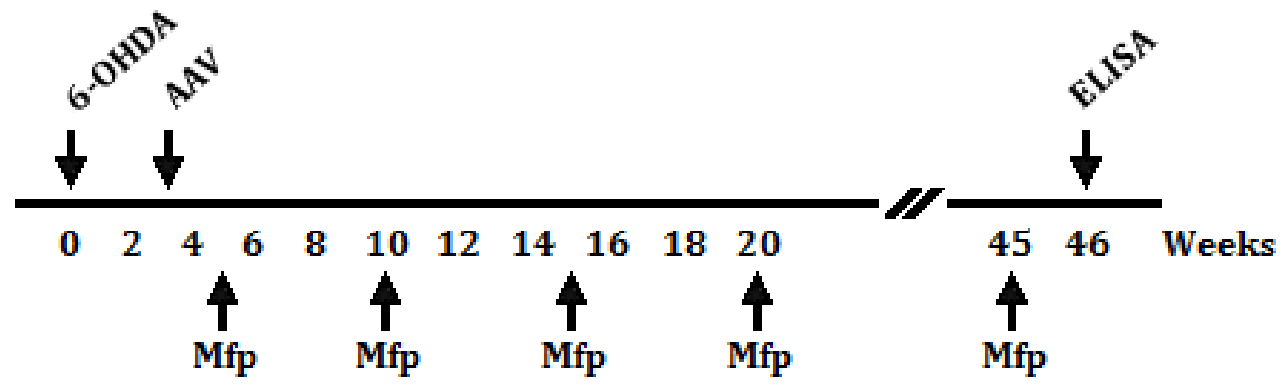

B

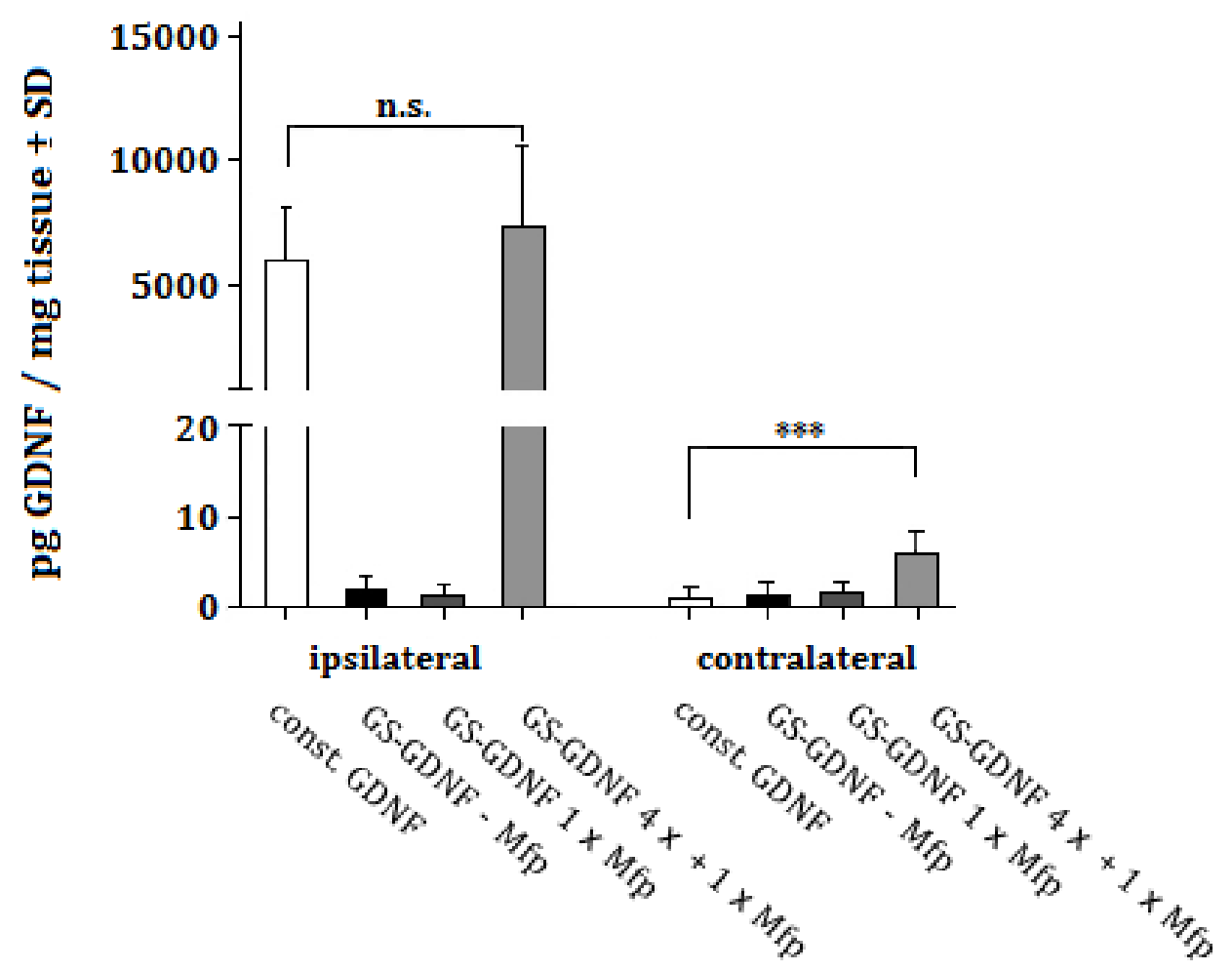

Fig. 4.7 GDNF expression induced by repetitive Mfp applications

Forty-two weeks after injections of AAV vectors, Mfp was re-applied in the rats that had received four times Mfp applications and had been performed behavior tests. Level of GDNF expression in striatum was determined one week after the last mifepristone application. Half striatum was collected for ELISA to quantify GDNF level and other half was collected for determination of dopamine and its metabolites. The amounts of GDNF are shown as pg GDNF/mg tissue \pm SD. Statistical analysis by 1 -way ANOVA with Tukey's post hoc test. ${ }^{* * *}=p<0.001$; n.s. $=$ not significant. Power (1-B err prob) $>0.98$ for all shown comparisons. $n=5-7$. 


\subsubsection{Effects of GDNF expression from AAV-GS-GDNF on dopamine metabolism}

The literature shows that GDNF supports growth and survival of dopaminergic neurons (Choi-Lundberg et al., 1997). As a manifestation of the survival of dopaminergic neurons, levels of dopamine and its metabolites DOPAC anf HVA were determined to verify the neuro-protective effect of the system. As shown in Fig. 4.8, constitutively expressed GDNF greatly prevented decline of the level of dopamine: the level of dopamine in the hemisphere injected with 6-OHDA did not show a significant difference comparing with the none-injection hemisphere. In the animals that received one Mfp application, level of dopamine was equal to those rats that were treated with any GDNF expression. This result demonstrated that the short-term expression of GDNF was not sufficient to provide a long time treatment effect to against persistent lesion from 6-OHDA.

In the rats that were repeatedly induced to express GDNF, the level of dopamine was significantly higher than in animals without GDNF induction. The dopamine level, however, was significantly lower than it in rats with consecutive expression of GDNF. It needs to be mentioned that expression of GDNF from the regulated system was initiated two weeks later as compared to consecutive expression of GDNF. The dopamine levels well reflect the results of the behavior tests, giving a reasonable explanation in molecular mechanism. 
A
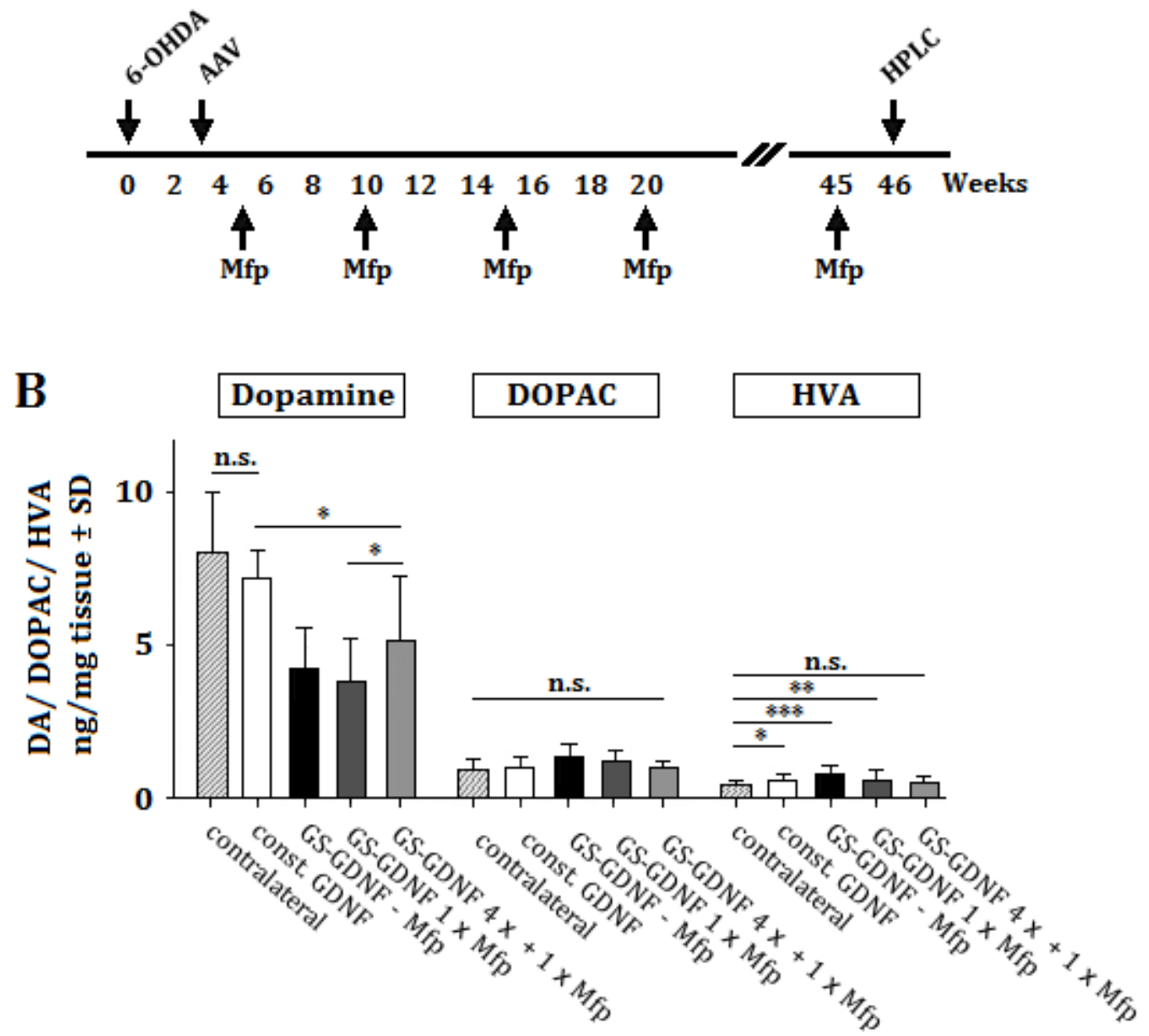

Fig. 4.8 Effect of the system to dopamine metabolism

Forty-two weeks after 6-OHDA lesion, dopamine (DA) and its two main metabolites, 3, 4 dihydroxyphenylacetic acid (DOPAC) and homovanillic acid (HVA), were quantified in striatum of the rats that had been performed behavior tests with different treatments. Half striatum was collected for HPLC to determine concentrations of DA, DOPAC and HVA. Other half striatum had been used for quantification of GDNF. DA, DOPAC and HVA concentration are shown as $\mathrm{ng} / \mathrm{mg}$ tissue \pm SD. Statistical analysis was performed by 1 - way ANOVA with Tukey's post hoc test. ${ }^{*}=p$ $<0.05 ;{ }^{* \star}=p<0.01 ;{ }^{* \star *}=p<0.001 ;$ n.s. $=$ not significant. $n=5-7$. striated bars: contralateral striatum; white bars: AAV-5-syn-GDNF (constitutive GDNF expression); black bars: AAV-5-GS-GDNF without mifepristone application; dark gray bars: AAV-5-GS-GDNF with once mifepristone application; light gray bars: AAV-5-GS-GDNF with $4+1$ times mifepristone applications. 


\subsection{Effect of CYP3A inhibition on Mfp pharmacokinetics}

Age-dependent and gender-dependent GDNF expression are new challenges for development of the GS-GDNF vector for human patients, since the level of GDNF could be very divergent in individuals of different genders and different ages. A method enabling equal levels of GDNF expression in different individuals would be helpful for application of the method in humans. Divergent rates of Mfp metabolism were supposed as a possible reason for the age- or gender-dependent GDNF expression. Equalization of the rates of Mfp metabolism in different genders or ages was considered as a strategy to equal the level of GDNF in individuals. Therefore, the effect of an inhibitor of Mfp metabolism on the gene therapy method was studied.

In rats, Mfp is metabolized by CYP3A in hepatocytes (Chasserot-Golaz et al., 1989). In human liver, it is mainly metabolized by CYP3A4, a member of the CYP3A family (Jang et al., 1996). I speculated that the different pharmacodynamics of Mfp were induced by different CYP3A activities. In agreement with this assumption, divergent activities of CYP3A in male and female rodents have been suggested in the literature (Chen et al., 2017; Chen et al., 2018). To eliminate or to decrease the effect of CYP3A on the GDNF expression, a CYP3A inhibitor, norvir, was used. Norvir (or chemical name: Ritonavir) is an approved medicine that was originally developed to treat HIV by its inhibition on HIV protease. However, nowadays, it is rarely used in treatment of HIV, but remains widely used as a CYP3A inhibitor (Zeldin et al., 2004). In this part of the project, norvir was tested to decrease the effect of CYP3A on metabolism of Mfp, and equaling the levels of GDNF expression in different genders and ages.

AAV-5-GS-GDNF was striatally injected into nine weeks old male and female rats.

Three weeks later, $5 \mathrm{mg} / \mathrm{kg}$ BW Mfp was injected intraperitoneally. Twenty minutes before the Mfp applications, animals in one group received intraperitoneal injections of $30 \mathrm{mg} / \mathrm{kg} \mathrm{BW}$ norvir, dissolved in DMSO. Rats in other group were subjected to intraperitoneal injections of DMSO as controls. Without 
norvir, four days after the last Mfp application, roughly 4-fold higher level of GDNF expression was determined in female rats comparing with male rats (Table 4.1). In contrast, with the CYP3A inhibitor the same level of GDNF expression was quantified in male and female rats. The results proved that different CYP3A activities were the main reason for the gender-dependent GDNF expression. Another effect that needs to be mentioned is the general increase of GDNF expression by norvir: roughly 8 -fold increase in females and 30 -fold increase in males (Table 4.1). Thus, with norvir, less Mfp could induce sufficient expression of GDNF, which avoids potential risks of frequent high-dosage Mfp applications.

\begin{tabular}{|l|l|l|}
\hline Gender & $\begin{array}{l}\mathbf{3 0} \mathbf{~ m g} / \mathbf{k g} \text { BW Norvir } \\
(20 \mathrm{~min} \text { before } 5 \mathrm{mg} / \mathrm{kg} \mathrm{BW} \text { Mfp, 3*) }\end{array}$ & $\begin{array}{l}\text { GDNF amount } \\
(\mathrm{pg} \text { GDNF/mg tissue } \pm \text { SD) }\end{array}$ \\
\hline \multirow{3}{*}{ Female } & With Norvir & $4518.9 \pm 2635.4$ \\
\cline { 2 - 3 } & Without Norvir & $546.4 \pm 399.9$ \\
\hline \multirow{2}{*}{ Male } & With Norvir & $4277.5 \pm 1621.5$ \\
\cline { 2 - 3 } & Without Norvir & $138.3 \pm 35.4$ \\
\hline
\end{tabular}

Table 4.1 The influence of CYP3A inhibiting effect of norvir on GDNF expression. $n=5$

Studying age-dependent GDNF expression, 9 weeks old female rats were considered as "young rats", and 54 weeks old female rats were used as "old rats" (table 4.2). Given that roughly 4-fold higher GDNF expression was determined in 54 weeks old rats comparing with 9 weeks old rats (Fig. 4.7), it seems reasonable to argue that CYP3A activity is stronger in young animals than in aged animals. Therefore, the CYP3A inhibitor was applied with Mfp in young rats that had been applied AAV-5-GS-GDNF. The GDNF expression in the animals that received norvir was compared with levels in young and aged rats that only received Mfp applications. As shown in table 4.2, three-fold higher level of GDNF expression was induced in aged rats as compared with young rats by only Mfp application. Three-fold higher level of GDNF expression was induced by Mfp and norvir applications in young rats comparing with it induced by only Mfp application in 
aged animals. The results demonstrated that aged rats still had the ability to metabolize Mfp, but the activity is lower than young rats. Thus, the age-dependent CYP3A activities were the main reason for the age-dependent GDNF expression.

\begin{tabular}{|l|l|}
\hline Experimental subjects & $\begin{array}{l}\text { GDNF amount } \\
\text { (pg GDNF/mg tissue } \pm \text { SD) }\end{array}$ \\
\hline young rats without Norvir & $546.4 \pm 399.9$ \\
\hline aged rats without Norvir & $1234.0 \pm 445.9$ \\
\hline young rats with Norvir & $4518.9 \pm 2635$ \\
\hline
\end{tabular}

Table 4.2 Age-dependent GDNF expression activated by $3 \times 5 \mathrm{mg} / \mathrm{kg}$ BW Mfp i.p. injection. $\mathrm{n}$ $=5$.

\subsection{Generation of a humanized rat model to study pharmacokinetics of Mfp}

Human alpha-1-acid glycoprotein (hAAG) or Orosomucoid (ORM) is an acute phase plasma alpha-globulin glycoprotein, being synthesized primarily in hepatocytes (Colombo et al., 2006). The only known function of hAAG is working as a carrier of neutrally and basic charged lipophilic compounds. It can bind with basic medicines, protease inhibitors and steroids, including mifepristone (Urien $S$ et al., 1991). A hypothesis is proposed in the project: the binding between hAAG and Mfp might changes pharmacokinetics and pharmacodynamics of Mfp, and thus might impact on GDNF expression in the gene therapy method either. Only human alpha-1-acid glycoprotein has a high affinity for Mfp, while in almost all other mammalian species alpha-1-acid glycoprotein is present but does not bind Mfp. This means that no animal can be used as a human-like model with similar pharmacokinetics of Mfp yet (Heikinheimo et al., 1990) to test the GS-GDNF system.

Before clinical trials of the system in patients, several questions need to be 
studied in an animal model: firstly, whether hAAG bound Mfp can pass the blood-brain barrier and initiate GDNF expression? Secondly, what is the proper frequency to apply Mfp in the animals with hAAG in plasma? The binding between hAAG and Mfp might prolong the half-life of mifepristone. As a result, a lower frequency of Mfp application could achieve a durable GDNF expression. Thirdly, if hAAG-bound Mfp cannot pass blood-brain barrier, what is the concentration of Mfp to achieve saturation of hAAG? Therefore, as a first step towards a humanized evaluation system, the establishment of a hAAG rats model was carried out.

AAV vectors expressing hAAG were intravenously injected to 9 weeks old female rats. One, two, three and four weeks after the virus application, blood samples were collected, and the expressed hAAG concentrations were quantified by ELISA. With $1 \times 10^{10} \mathrm{vg}$ AAV-1/2-HBA-hAAG application, hAAG level displayed a tendency rising at the beginning and declining later, the highest concentration was $17.2 \pm 8.7 \mathrm{ng} / \mathrm{ml}$ at two weeks after virus injection (Fig. 4.9). With $1 \times 10^{11} \mathrm{vg}$ AAV-1/2-HBA-hAAG application, the highest hAAG amount was $72.9 \pm 17.7 \mathrm{ng} / \mathrm{ml}$ at the first time point, and since then, a declining trend of concentration of hAAG was demonstrated (Fig. 4.9). Only background level of hAAG expression were achieved in the AAV-5-HBA-hAAG group (Fig. 4.9). By these results, better hAAG expression ability was observed in AAV-1/2-HBA-hAAG than AAV-5-HBA-hAAG, therefore, AAV-1/2 serotype will be used in further experiments to establish the model. The highest level of hAAG was achieved by $1 \times 10^{11} \mathrm{vg}$ AAV-1/2-HBA-hAAG application, the concentration was $72.9 \pm 17.7 \mathrm{ng} / \mathrm{ml}$ which is still 10,000-fold lower than it in human plasma. Due to the declining trend, it is meaningless to test the virus in higher titer. Given that a declining trend of hAAG expression was observed, animal immunoreaction was supposed as a possible reason to induce the low and descending hAAG expression.

To prove the hypothesis and to avoid the immunoreaction, four strategies were used: firstly, the HBA promoter, a non-organ specific promoter, was replaced by a liver-specific promoter, because the liver-restricted expression could partly avoid activation of the immune system against the human protein. Secondly, 
recombinant virus was applied to neonatal rats to enable their immune system tolarence to the vector and hAAG protein. Thirdly, lower titer $\left(3 \times 10^{10} \mathrm{vg}\right)$ virus had been applied to neonatal rats to develop tolerance of immune system to AAV virus and hAAG protein, higher titer $\left(1 \times 10^{11} \mathrm{vg}\right)$ virus was applied to the rats one month after the lower titer virus application. Fourthly, AAV-8 expressed hAAG was tested to avoid immune reaction due to the liver-specific transduction and biodistribution of AAV-8 serotype (Paneda et al., 2009).

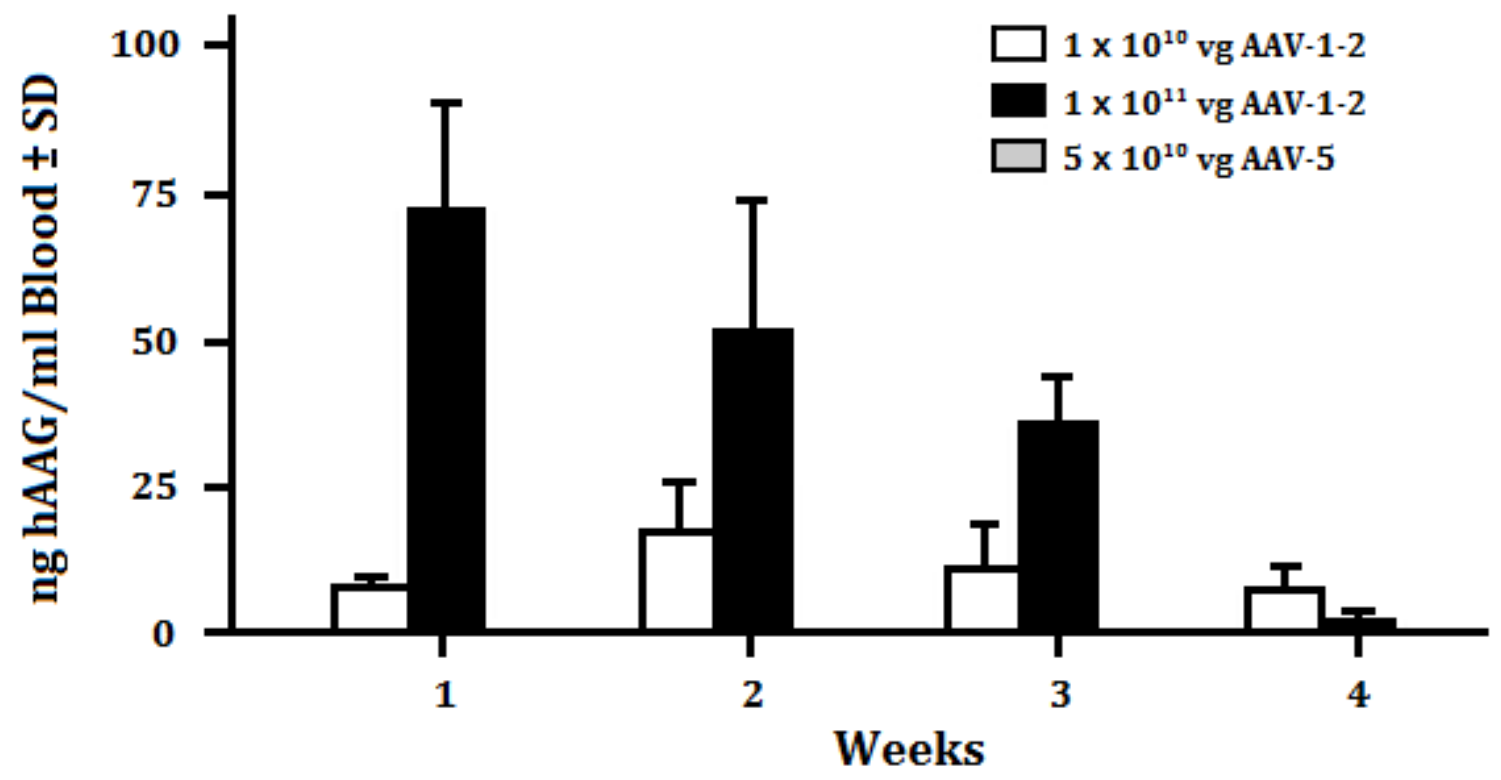

Fig. 4.9 Levels of Human-AAG expression in rats blood with various virus applications

$1 \times 10^{10} \mathrm{vg}$ or $1 \times 10^{11} \mathrm{vg}$ AAV-1/2-HBA-hAAG or $5 \times 10^{10} \mathrm{vg}$ AAV-5-HBA-hAAG was intravenously injected to nine weeks old female rats. One, two, three and four weeks after virus application, levels of hAAG expression were determined in blood of the rats. Human AAG concentration is shown as $\mathrm{ng} / \mathrm{ml}$ blood $\pm \mathrm{SD}$. white bars: $1 \times 10^{10} \mathrm{vg} \mathrm{AAV-1/2-HBA-hAAG;} \mathrm{black} \mathrm{bars:} 1 \times 10^{11} \mathrm{vg}$ AAV-1/2-HBA-hAAG; gray bars: $5 \times 10^{10} \mathrm{vg}$ AAV-5-HBA-hAAG. $\mathrm{n}=5$.

As shown in table 4.3, AAV-1/2-LP1-hAAG was applied in three routes: firstly, $1 \times$ $10^{11} \mathrm{vg}$ AAV-1/2-LP1-hAAG was applied to two days old neonatal rats (P2) by liver injection. The level of hAAG expression was declining in the month after virus 
injection, which is probably induced by a rapid body weight gainduring the month, resulting in dilution of the episomal vector genomes during cell divisions. Secondly, $1 \times 10^{11} \mathrm{vg} \mathrm{AAV-1/2-LP1-hAAG}$ was applied to nine weeks old adult rats (P67) by intravenous injection. The concentration of hAAG was increasing in the month after vector application, which demonstrated the durability of this route of virus application. Thirdly, $3 \times 10^{10} \mathrm{vg} \mathrm{AAV-1/2-LP1-hAAG} \mathrm{was} \mathrm{applied} \mathrm{to} \mathrm{one} \mathrm{day} \mathrm{old}$ rats by liver injection and $1 \times 10^{11} \mathrm{vg} \mathrm{AAV-1/2-LP1-hAAG} \mathrm{was} \mathrm{intravenously}$ reapplied to the rats when they were one month old $(\mathrm{P} 1+\mathrm{P} 31)$. One month after the higher titer virus injection, 14.2 and $17.1 \mu \mathrm{g} / \mathrm{ml}$ hAAG were determined in male and female rats. The hAAG concentration achieved by the third route was higher than it in the another two methods. However, a sharp decline of hAAG concentration was observed only one month later (Table. 4.3). Considering both high level and durability of hAAG expression, application of the virus to adult rats is the best way in the three tested routes of virus application.

\begin{tabular}{|c|c|c|c|}
\hline \multirow{2}{*}{$\begin{array}{c}\text { Time of } \\
\text { applicaiton }\end{array}$} & $\begin{array}{c}\text { Titer of AAV virus } \\
(\mathbf{v g})\end{array}$ & \multicolumn{2}{|c|}{$\begin{array}{c}\text { hAAG concentration } \\
\text { (male/female, } \boldsymbol{\mu g} / \mathrm{ml})\end{array}$} \\
\cline { 3 - 4 } & $1 \times 10^{11}$ & $2.6 / 2.5$ & $1.4 / 1.7$ \\
\hline P2 & $1 \times 10^{11}$ & $1.7 / 3.8$ & $2.5 / 4.3$ \\
\hline P67 & & $14.2 / 17.1$ & $5.7 / 9.4$ \\
\hline P1 + P31 & $3 \times 10^{10}+1 \times 10^{11}$ & month \\
\hline
\end{tabular}

Table 4.3 Establishment of hAAG rats model with AAV-1/2-LP1-hAAG applications

AAV-1/2-LP1-hAAG was applied to rats at different time points as different methods: P2: $1 \times 10^{11}$ vg AAV-1/2-LP1-hAAG was applied to two days old neonatal rats by liver injection; P67: $1 \times 10^{11}$ vg AAV-1/2-LP1-hAAG was injected intravenously to nine weeks old adult rats; P1 + P31: $3 \times 10^{10}$ vg AAV-1/2-LP1-hAAG was injected to livers of one day old neonatal rats and $1 \times 10^{11} \mathrm{vg}$ AAV-1/2-LP1-hAAG was applied intravenously to them one month later. Mean hAAG concentration is shown as $\mu \mathrm{g} / \mathrm{ml}$ plasma. $\mathrm{n}=5-9$.

Given that the liver-specific transduction of AAV-8 serotype (Paneda et al., 2009) might partly avoid clearance by immune system, AAV-8-LP1-hAAG was expected 
to express higher level of hAAG than AAV-1/2 vectors. However, results opposite to this expectation were observed: by applying vectors by the three routes, hAAG expression levels were all much lower than achieved by AAV-1/2 vectors (table 4.3 and table 4.4). Other strategy to enhance the level of hAAG expression was application of a stronger promoter in the vectors. Comparing with other liver-specific promoter, LP1 promoter, with a transcriptional enhancer, is already a very effective promoter. Due to the high transcription rate of HBA promoter, ability of hAAG expression of AAV-1/2-HBA-hAAG was compared with the vectors with LP1 promoter. Even though the HBA promoter is not an organ specific promoter, the possible immunoreaction from rats could be avoided by vectors application in neonatal rats or by the the "P1 + P31" route. No gender-specific expression of hAAG was observed (table 4.3 and table 4.4), therefore, it is not necessary to compare the concentrations of hAAG in males and females further. So, only female rats were tested in next experiments of establishment of the model.

\begin{tabular}{|c|c|c|c|}
\hline \multirow{2}{*}{$\begin{array}{c}\text { Time of } \\
\text { application }\end{array}$} & \multirow{2}{*}{ Titer $(\mathbf{v g})$} & \multicolumn{2}{|c|}{ hAAG concentration $(\boldsymbol{\mu g} / \mathbf{m l})$} \\
\cline { 3 - 4 } & & $\mathbf{1}$ month & $\mathbf{2}$ month \\
\hline $\mathrm{P} 2$ & $1 \times 10^{11}$ & $0.005 / 0.006$ & $0.007 / 0.008$ \\
\hline $\mathrm{P} 67$ & $1 \times 10^{11}$ & $0.007 / 1.1$ & $0.01 / 1.3$ \\
\hline $\mathrm{P} 1+\mathrm{P} 31$ & $3 \times 10^{10}+1 \times 10^{11}$ & $0.009 / 0.005$ & $0.007 / 0.004$ \\
\hline
\end{tabular}

Table 4.4 Establishment of hAAG rats model with AAV-8-LP1-hAAG applications

AAV-8-LP1-hAAG was applied to rats at various time points as different methods: P2: $1 \times 10^{11} \mathrm{vg}$ AAV-8-LP1-hAAG was applied to two days old neonatal rats by liver injection; P67: $1 \times 10^{11} \mathrm{vg}$ AAV-8-LP1-hAAG was injected intravenously to nine weeks old adult rats; P1 + P31: $3 \times 10^{10} \mathrm{vg}$ AAV-8-LP1-hAAG was injected to livers of one day old neonatal rats and $1 \times 10^{11} \mathrm{vg}$ AAV-8-LP1-hAAG was applied intravenously to them one month later. Mean hAAG concentration is shown as $\mu \mathrm{g} / \mathrm{ml}$ plasma. $\mathrm{n}=5-9$.

A stable hAAG expression was achieved with $1 \times 10^{11} \mathrm{vg} \mathrm{AAV-1/2-HBA-hAAG}$ application in two days old neonatal rats, and the levels of hAAG expression were higher than them expressed by virus with LP1 promoter either one month or two 
month after virus application (table 4.3 and table 4.5). The higher concentration of hAAG in neonatal rats demonstrated that the HBA promoter is more effective than LP1 promoter. However, a lower concentration of hAAG was observed in the "P1 + P31" group. The tolerance established by lower titer virus application in neonatal rats probably was not strong enough to absolutely avoid the immune response.

Until then, two routes to establish the hAAG model were available: one method was application of vectors with LP1 promoter in adult rats. The other route was application of vectors with HBA promoter in neonatal rats. Given that AAV application in neonatal rats might immunizes the rats to AAV-5-GS-GDNF, applying AAV-1/2-LP1-hAAG in adult rats was preferred. Then the next step was to enhance the concentration of hAAG by increasing the titer of intravenously injected AAV-1/2-LP1-hAAG.

\begin{tabular}{|c|c|c|c|}
\hline \multirow{2}{*}{$\begin{array}{c}\text { Time of } \\
\text { application }\end{array}$} & \multirow{2}{*}{ Titer $(\mathbf{v g})$} & \multicolumn{2}{|c|}{ hAAG concentration $(\boldsymbol{\mu g} / \mathbf{m l})$} \\
\cline { 3 - 4 } & & 1 month & 2 month \\
\hline P2 & $1 \times 10^{11}$ & 7.2 & 5.0 \\
\hline P67 & $1 \times 10^{11}$ & 0.002 & 0.0006 \\
\hline P1 + P31 & $3 \times 10^{10}+1 \times 10^{11}$ & 2.7 & 2.0 \\
\hline
\end{tabular}

Table 4.5 Establishment of hAAG rats model with AAV-1/2-HBA-hAAG applications

AAV-1/2-HBA-hAAG was applied to rats at various time points as different methods: P2: $1 \times 10^{11}$ vg AAV-1/2-HBA-hAAG was applied to two days old neonatal rats by liver injection; P67: $1 \times 10^{11}$ vg AAV-1/2-HBA-hAAG was injected intravenously to nine weeks old adult rats; P1 + P31: $3 \times 10^{10}$ vg AAV-1/2-HBA-hAAG was injected to livers of one day old neonatal rats and $1 \times 10^{11} \mathrm{vg}$ AAV-1/2-HBA-hAAG was applied intravenously to them one month later. Mean hAAG concentration is shown as $\mu \mathrm{g} / \mathrm{ml}$ plasma. $\mathrm{n}=5-9$.

In human plasma, the normal concentration of hAAG is between $0.6-1.2 \mathrm{mg} / \mathrm{ml}$ (Colombo et al., 2006). However, this concentration included both AAG1 and AAG2. The Mfp binding affinity was only observed in AAG1 which constitutes $75 \%$ of total AAG concentration (Yuasa et al., 1997). So the target concentration of 
hAAG in the model animals should be $0.45-0.9 \mathrm{mg} / \mathrm{ml}$. To achieve this hAAG plasma concentration, increasing titres of $1 \times 10^{11}, 5 \times 10^{11}, 1 \times 10^{12}$ and $2 \times 10^{12}$ vg AAV-1/2-LP1-hAAG were intravenously injected to nine weeks old female rats. Plasma samples were collected one and two months after the virus application, and their hAAG concentrations were determined by ELISA. As shown in table 4.5, an increasingly significant hAAG concentration was observed following enhancement of titer of the virus. One month after the virus application, an aproximately human-level concentration of hAAG was achieved by the $1 \times 10^{12} \mathrm{vg}$ virus application: $0.425 \mathrm{mg} \mathrm{hAAG}$ per $\mathrm{ml}$ plasma was determined. If doubling the titer, the hAAG concentration was $1.0 \mathrm{mg} / \mathrm{ml}$ that is higher than the maximum of range of the normal hAAG1 concentration (table 4.5). One month later, the hAAG concentrations slightly declined in all groups, however, more than $90 \%$ concentration of hAAG was still quantified in the group with $1 \times 10^{12} \mathrm{vg}$ vector application, which demonstrated the durable expression of hAAG. Summarily, an animal model with stable human level of hAAG was established by $1 \times 10^{12} \mathrm{vg}$ AAV-1/2-LP1-hAAG intravenous injection in adult rats.

\begin{tabular}{|c|c|c|}
\hline \multirow{2}{*}{$\begin{array}{c}\text { Titer } \\
(\mathbf{v g})\end{array}$} & \multicolumn{2}{|c|}{ hAAG concentration $(\boldsymbol{\mu g} / \mathrm{ml})$} \\
\cline { 2 - 3 } & $\mathbf{1}$ month & 2 month \\
\hline $1 \times 10^{11}$ & 2.5 & 1.7 \\
\hline $5 \times 10^{11}$ & 48.9 & 42.9 \\
\hline $1 \times 10^{12}$ & 425.2 & 383.0 \\
\hline $2 \times 10^{12}$ & 1003.4 & 979.7 \\
\hline
\end{tabular}

Table 4.6 Tuning titer of AAV-1/2-LP1-hAAG to establish the hAAG rats model.

Different titer of AAV-1/2-LP1-hAAG was intravenously injected to nine weeks old female rats. Plasma was collected on one and two months after the virus application. Mean hAAG concentration is shown as $\mu \mathrm{g} / \mathrm{ml}$ plasma. $\mathrm{n}=3-5$ 


\subsection{Evaluation of the GS-GDNF system in the hAAG rats model}

After the hAAG rats model had been established, the GS-GDNF system was evaluated in this model. Induced levels of GDNF were compared with those obtained in native rats. Establishing the hAAG model rats, $1 \times 10^{12} \mathrm{vg}$ AAV-1/2-LP1-hAAG was injected intravenously to nine weeks old female rats. One hour after AAV-1/2-LP1-hAAG application, $1 \times 10^{9} \mathrm{vg} \mathrm{AAV-5-GS-GDNF}$ was injected into left striatum. One month later, the plasma concentrations of hAAG were quantified, and the concentrations in all animals reached human plasma level (data not shown). Then $20 \mathrm{mg} / \mathrm{kg}$ body weight Mfp was intraperitoneally injected on three consecutive days to activate the GS-GDNF system. In case the hAAG-binding limits brain entry of Mfp and reduces the level of GDNF expression, norvir was applied to decrease the reduction by restriction of the metabolism of Mfp. For norvir application, $30 \mathrm{mg} / \mathrm{kg}$ body weight norvir was intraperitoneally applied 20 minutes before Mfp application. As shown in table 4.7, almost identical levels of GDNF expression were determined in the hAAG model and in native rats. This finding demonstrates that hAAG-binding might did not limit the passage of Mfp through the blood-brain barrier, as it was suggested in the literature (Jolliet-Riant et al., 1998). With norvir application, the level of GDNF expression was increased roughly two-fold in both the hAAG model rats and in the native rats. The similar level of GDNF expression with norvir application in the model rats and native rats again demonstrated that hAAG did not affect the activation of the system in striatum by Mfp. Another possible reason for the scarce effect of hAAG-binding on the GS-GDNF system is that Mfp did not bind with hAAG in rats plasma by some unclear reasons. To verify the bind between hAAG and Mfp, different pharmacokinetics of Mfp in the hAAG model rats and native rats need to be proven in future experiments. 


\begin{tabular}{|c|c|c|c|}
\hline \multicolumn{2}{|c|}{ Experiment setup } & \multicolumn{2}{c|}{ GDNF (pg/mg tissue) } \\
\cline { 3 - 4 } & Mfp & $2770 \pm 678$ & $8 \pm 2$ \\
\hline \multirow{2}{*}{ hAAG-model rats } & Norvir + Mfp & $5460 \pm 1800$ & $7 \pm 2$ \\
\cline { 2 - 4 } & Mfp & $2220 \pm 964$ & $7 \pm 3$ \\
\hline \multirow{2}{*}{ native rats } & Norvir + Mfp & $4891 \pm 2039$ & $7 \pm 2$ \\
\cline { 2 - 4 } & & & \\
\hline
\end{tabular}

\section{Table 4.7 Levels of GDNF expression in hAAG-model rats vs. native rats}

All animals received $1 \times 10^{9} \mathrm{vg}$ AAV-5-GS-GDNF striatal injection when they were nine weeks old. To establish hAAG-model rats, $1 \times 10^{12} \mathrm{vg} \mathrm{AAV-1/2-LP1-hAAG}$ was intravenously injected to the rats one hour before AAV-GS-GDNF application. Mfp: three weeks after AAV-GS-GDNF application, $20 \mathrm{mg} / \mathrm{kg}$ BW Mfp was intraperitoneally injected to the rats on three consecutive days. Norvir: $30 \mathrm{mg} / \mathrm{kg}$ BW Norvir was applied by intraperitoneal injection 20 minutes before mifepristone application. Four days after the last Mfp application, striatum was collected and levels of GDNF were determined by ELISA. GDNF amount is shown as $\mathrm{pg} / \mathrm{mg}$ tissue $\pm \mathrm{SD}$. $n=3$. 


\section{Discussion}

\subsection{Neurotrophic factor gene therapy for PD: failures and prospects}

The etiology of Parkinson's disease remains largely unknown, and the symptomatics of PD are very divergent. Probably no singular treatment approach is able to halt or even prevent the progression of this multifaceted disease. Thus, neuotrophic factors, which can trigger a relative wide variety of neuroprotective and neuro-restorative processes, are considered as appropriate candidates for development of novel treatment options for PD.

Glial cell line-derived neurotrophic factor has been proven to have a protective effect on dopaminergic neurons. GDNF signal via receptors that consist of a member of the GDNF receptor alpha (GRFa) family and the RET (rearranged during transfection) tyrosine kinase receptor. Activation of the receptors induced Ret phosphorylation that caused activation of several intracellular pathways (e.g. phosphatidylinositol 3 kinase) and neurorestorative effects. The biological effects of activation of the intracellular pathways are still unknown (Sole et al., 1999). In a small open-label trial, the protein was injected into the putamen of PD patients. One year after the GDNF infusion, there were a 39\% improvement in the off-medication motor sub-score of the Unified Parkinson's Disease Rating Scale (UPDRS) and a $61 \%$ improvement in the activites of daily living sub-score (Gill et al., 2003). However, no clinical benefit was observed in a larger placebo-controlled trial with the GDNF injections (Lang et al., 2006). Failure from the clinical trials with the protein injections did not deter other scientists from testing a gene therapy that expressed neurturin, a member of the GDNF family. The sequence of amino acids of neurturin is highly homologic to the amino acid sequence of GDNF. They, both, signal through the RET receptor, however, GDNF binds to GFRa1 and neurturin prefers GFRa2 (Dass et al., 2007). Neurturin was 
delivered by AAV-mediated gene transfer, and AAV-neurturin significantly improved 1-methyl-4-phenyl-1,2,3,6-tetrahydropyridine-induced motor impairments by 80 to $90 \%$ (Kordower et al., 2006). The vector expressed neurturin was injected into putamen or both putamen and substantia nigra in PD patients. The AAV-mediated expression of neurturin has been proven safe, however, no clinical benefit was observed in the patients (Bartus et al., 2017a; Bartus et al., 2017b). Histological examination of post-mortem brains reveals that the expression of neurturin was only located surrounding the injection tracts, and neuroprotective effect of neurturin was limited in the small area (Bartus et al., 2017a; Bartus et al., 2017b). Except the bad tissue penetrance of AAV vectors, neurturin transport from putamen to substantia nigra was prevented by the advanced neurodegeneration in advanced PD patients (Bartus et al., 2015).

\subsection{Precise control of the GeneSwitch system}

GDNF promoted the survival and morphological differentiation of dopaminergic neurons and increased their high-affinity dopamine uptake, which suggests that it can be considered as a candidate to treat the progressive degeneration of dopaminergic neurons in PD (Gill et al., 2003). Even after the failing of the clinical trials of neurturin gene therapy (Bartus et al., 2017a; Bartus et al., 2017b), GDNF is still considered as a good candidate for PD treatment. Because, the failure was attributed to the developing technologies of gene therapy. The neuroprotective and neurorestorative effects of GDNF are still considered to be effective in the multifaceted symptoms of PD. An advanced gene therapy method, which could express GDNF in a wide area of brain, might provide sufficient treatment effect on PD.

GDNF could induce sprouting of dopaminergic termini, however, it cannot increase total neuron or astrocyte numbers (Lin et al., 1993), which means that a GDNF treatment should be applied to PD patients with sufficient remain of dopaminergic neurons. Post-mortem examination demonstrated that, only five 
years after PD diagnosis, residual dopaminergic termini in striata are gone (Kordower et al., 2006). In the first five years after PD diagnosis, L-DOPA still can deliver good treatment effect. Thus, convincing early PD patients to accept an intracerebral injection of AAV virus, especially if the treatment cannot be halted, might be difficult. That is why a precise control of the regulated gene expression system is fairly important for the development of the GDNF gene therapy into clinical trials in the future.

Firstly, the level of GDNF expression in non-induced state of the regulated GDNF construct was as same as the endogenous level (2-4 pg/mg tissue), which demonstrated that the background expression of GDNF was from the rat gene, not from the vector. One week after three times i.p. injections of $20 \mathrm{mg} / \mathrm{kg} \mathrm{BW} \mathrm{Mfp}$, the level of GDNF can be increased 400 to 600 -fold as compared to endogenous level of GDNF, demonstrating the high level of induction of the system. The level of GDNF decreased to background level about one month after the Mfp applications (Fig. 4.1), proving the system can be terminated efficiently. With these characteristics, the GS-GDNF system has been proven to possess no non-induced background expression, high level of induction and ability to return to background level of expression.

Secondly, to satisfy different requirements of individuals, higher level of GDNF expression can be achieved by increased dosage of applied Mfp and vice versa (Fig. 4.2 and Fig. 4.3). Therefore, an external pharmacological control over the dosage of the therapeutic gene product has been demonstrated in the project, which could not be achieved in the vectors constitutively expressed the gene product. The external pharmacological control of the expression of GDNF might help to recruit more patients for GDNF gene therapy in the future. If patients face side-effect from overexpression of GDNF, the expression can be absolutely terminated by termination of Mfp application or be fine-adjusted by regulating dosage of Mfp. Following advancement of severity of PD, the level of GDNF expression can be enhanced by increasing dosage of Mfp application.

Thirdly, the system can be kept in activated state for extended periods of time by 
repeated Mfp applications, and can be readily re-activated after long-term off-status (Fig. 4.7). This demonstrated the potential of the method to achieve long-term treatment effect in PD by a single surgery to apply the recombinant vector, followed by frequent Mfp applications.

PD patients very early after diagnosis benefit for a few years from the convenient method, oral administration of L-DOPA, however, it appears that during the years patients' dopaminergic output into caudate/putamen ceases thoroughly, which leaves no opportunity for any restoration of the dopaminergic projection (Ebert et al., 2010). With these advantages of the method and its potential life-time treatment effect, PD patients in early stages might can be easily convinced to accept this novel gene therapy rather than taking the impermanent treatment with L-DOPA.

\subsection{Treatment effect of the developed gene therapy method}

A slowly progressive degeneration of nigral dopaminergic neurons and nigro-striatal projection could be achieved by striatal injections of 6-OHDA (Sauer and Oertel, 1994), which mimics the progressive degeneration of dopaminergic neurons in PD. 6-OHDA application in unilateral striatum causes a progressive loss of dopaminergic neurons in the injected hemisphere. Apomorphine is a dopamine agonist, stimulating the dopamine receptors. The unilateral 6-OHDA injection induced unbalance of dopamine receptors in the two hemispheres, with stimulation from apomorphine, the unbalance induced the rat to rotate contralateral to the lesion. Therefore, the rat 6-OHDA model is a well accepted model of PD. Although the toxin was applied only once, degeneration progressed for 3 - 4 months (Sauer and Oertel, 1994). Without any GDNF induction, the contralateral turns stabilized around 200 turns per hour in the 6-OHDA injected rats more than 7 months, which demonstrated that the degeneration of 
dopaminergic neurons was irreversible (Fig. 4.5).

A single short-term expression of GDNF was beneficial to the motor restoration, however, the motor restoration was only kept for a short-term (Fig. 4.5). Thus, a repeated dosing of Mfp is necessary. The restoration in behavior was kept by the repeated inductions of GDNF expression for more than 6 months and until the last experimental time-point (Fig. 4.5). A tendency towards increased rotation phenotype over time was found in the group with constitutive vector, which might be due to TH-down regulation, which is not seen with the regulated vector. These data fully confirms a previous study in the lab with a previous version of the regulated vector used as a split vectors system, and thus demonstrates excellent robustness of the vector system.

As a conclusion, the regulated system with background-free expression of GDNF and long-lasting activation state has been proven long-term efficacy in motor restoration by the intermitted activation of the vector.

\subsection{Optimization of pharmacodynamics: CYP3A} inhibition

A gender- and age-dependent GDNF expression was observed in the project (Fig. 4.4 and Table. 4.2). Thus dosage of Mfp has to be varied according gender and ages of the patients. As shown in Fig. 4.4, gender-specific pharmacokinetics of Mfp was ascribed as the major reason for the gender-dependent GDNF expression. The different pharmacokinetics of Mfp might also be the main cause of the age-dependent GDNF expression. In rats and human, Mfp is mainly metabolized by the cytochrome P-450 monooxygenase 3A (CYP3A) enzymes (Chasserot et al., 1989; Jang et al., 1996). I proposed a hypothesis that various activities of CYP3A depending on age and gender induced the different pharmacokinetics of Mfp which leads to the gender- and age-dependent GDNF expression in the GS system. Thus, pharmacological CYP3A4 inhibition appeared 
to be a reasonable next step to improve Mfp bioavailability, but only approved human drugs could be considered for this purpose.

Norvir is an antiretroviral medication originally developed to treat HIV by its inhibiting effect on HIV protease (Deeks et al., 1997). However, it is now rarely used for its antiviral activity, but widely used as an inhibitor of particular liver enzymes, CYP3A (Zeldin et al., 2004). It was patented in 1989 and came into medical use in 1996, and was evaluated as "the most effective and safe medicines needed in a health system" by World Health Organization's List of Essential Medicines in 2015 (World Health Organization, 2016). To be used as a pharmacokinetic booster, low dosage is sufficient and no side effect has been reported (rxlist.com). Theoretically, if applying Mfp and norvir concurrently, the $\mathrm{C}_{\max }$ and half-life of Mfp in plasma should be enhanced, and then, the transcription of viral vector carried gene should be promoted by the increase of plasma concentration of Mfp.

As shown in Fig. 4.1, equal GDNF levels in both sexes were achieved by co-application of norvir with Mfp. Norvir co-application also showed strong ability to increase the level of expressed GDNF (Table 4.1). By this characteristics, high levels of GDNF expression can be achieved by much lower dosage of Mfp, which avoids the potential side-effect brought by repetitive Mfp applications.

\subsection{Optimizing the application route of Mfp}

In previous studies of our laboratory, Mfp was delivered in DMSO and was applied through intraperitoneal injection (Maddalena et al., 2013; Tereschenko et al., 2014). Frequent intraperitoneal injections are not convenient for patients, and probably will limit the competitiveness of the GS system comparing with oral administration of L-DOPA. A more acceptable method to deliver Mfp was demonstrated in the $\mathrm{PhD}$ project by oral application. An aqueous carrier including micelle forming organic compounds was used to suspend Mfp, and suspended 
Mfp was applied to rats by gavage.

As Fig. 4.3B showed, a tight control over the GDNF expression was achieved by different dosages of mifepristone by oral application. To achieve a similar level of GDNF expression induced by i.p. injection of Mfp, higher dosage of Mfp in oral administration was required, which might be induced by the degradation of Mfp in first-pass effect that many drugs suffer after oral application.

Striatal level of GDNF higher than $120 \mathrm{pg} / \mathrm{mg}$ tissue had been proven restored motor performance in the 6-OHDA model (Tereshchenko et al., 2014). For i.p. injection, $3 \times 1 \mathrm{mg} / \mathrm{kg} \mathrm{BW}$ Mfp was sufficient to induce roughly $150 \mathrm{pg}$ expressed GDNF per mg tissue. The daily Mfp dose corresponds to a dose of $10.5 \mathrm{mg}$ in humans. For oral administration, $3 \times 20 \mathrm{mg} / \mathrm{kg}$ BW Mfp was sufficient to induce roughly 500 pg expressed GDNF per mg tissue. The daily Mfp dose corresponds to a dose of $210 \mathrm{mg}$ in humans. Mfp has been safely applied in daily dosage of 50-200 mg for few months or in single dosage of $1000 \mathrm{mg}$ (Heikinheimo et al., 1987; Heikinheimo et al., 1989; Kawai et al., 2013). Therefore, both dosages used for i.p. injection or oral administration were within acceptable clinical ranges. In addition, co-application of norvir may further reduce Mfp dosages.

\subsection{Comparison of GS-GDNF with other systems for regulated GDNF expression}

No literature quantitatively compared the inducing efficacy of GDNF expression in different vector systems. However, few studies achieved the regulated expression of GDNF in a Tet-ON system, and their GDNF expression can be compared with the novel GS-GDNF vector: a low level of GDNF (roughly $60 \mathrm{pg}$ GDNF per mg tissue) was expressed by Tet-ON AAV vectors (Chtarto et al., 2007; Yang et al., 2009). Roughly 1000 pg GDNF per mg tissue was expressed by a lentiviral vector, however, high level of background GDNF expression of roughly $250 \mathrm{pg}$ GDNF per mg tissue in non-induced state was determined (Georgievska et al., 2004). Up to 
1000 pg GDNF per mg tissue was achieved in a recently developed AAV-Tet-ON-GDNF vector, the background level of GDNF was $75 \mathrm{pg} / \mathrm{mg}$ tissue, which still was 15- to 30-fold higher compared with endogenous GDNF expression (Chtarto et al., 2016). It has to be mentioned that the inducer doxycycline was applied for many days or even weeks in all these studies. In another study, LV vector system depending on stabilization of GDNF fusion proteins coupled to destabilizing domains of E.coli dihydrofolate reductase could express 125 pg GDNF per mg tissue. Still, the level of GDNF in background was $13 \mathrm{pg} / \mathrm{mg}$ tissue, which was still 3- to 6-fold higher comparing with endogenous level of GDNF (Quintino et al., 2013). Without any non-induced background, 450 pg GDNF per mg tissue was expressed by a rapamycin-regulated system, while the dosage of rapamycin was not clinically acceptable (Hadaczek et al., 2011).

These regulated GDNF expression systems have potential to be further optimized. The AAV-GS-GDNF system reported in the project, at least for the time being, represents a superior combination of high-level of GDNF expression, zero expression in non-induced state and treatment efficacy on 6-OHDA lesion with a clinically acceptable dose of the inducer, Mfp.

\section{7 Evaluation of the GS-GDNF system in a "humanized" rat model (hAAG expressing rats).}

Due to the specific existence of a carrier protein for Mfp in human plasma, a fundamentally different pharmacokinetics of Mfp in humans compared with other species was suggested (Heikinheimo et al., 1990). In humans, plasma concentration of Mfp peaked 1 hour after oral administration and stabilized in a relatively high level for 48 to 72 hours (Heikinheimo et al., 2003). In contrast, the Mfp concentration in rat's plasma peaked to maximum 6 hour after gavage and rapidly returned to undetectable level only 24 hour after the Mfp application (Chen et al., 2018). Variation of Mfp pharmacokinetics might change the GDNF 
expression of the system. As shown in table. 4.7, the concentration of GDNF was not affected by the bind between Mfp and hAAG, which means that hAAG binding cannot limit Mfp entering brain and initiating GDNF expression or the binding capability can be easily saturated. However, probably the duration of expression of GDNF could be adjusted by the bind between Mfp and hAAG. 129-fold higher clearance rate of Mfp in rats comparing with it in humans was demonstrated in literature (Heikinheimo et al., 1987). Thus, the longer half-life of Mfp in animals with carrier protein of Mfp might activate the GS-GDNF system for longer time. It should be determined by further experiments. Because a proper frequency of Mfp application is very important for the application of the system in patients.

Another possible cause for the same GDNF expression in native rats and hAAG rats model is that Mfp was not bound by hAAG by some unclear reasons. The bind between hAAG and Mfp has to be verified in further experiments. Without proof of the bind, inaccurate conclusions might be suggested from table 4.7. Due to the unexpected consumption of time during the establishment of hAAG rat model, I do not have sufficient time to determine the pharmacokinetics of Mfp in the hAAG model rats. But the experiments will be finished in the next few months.

\subsection{Outlook}

A close dose-response relationship between induced GDNF expression and dosage of Mfp has been demonstrated in this $\mathrm{PhD}$ project, and the therapeutic treatment effect of the expressed GDNF has been proven. The next step should be testing the system in an animal model more similar to humans. The carrier protein, hAAG, in human plasma can change the pharmacokinetics of Mfp and probably limits Mfp passing the BBB. A hAAG rats model has been established in the PhD project, and the same level of GDNF expression was determined in the hAAG rats model and native rats. The following experiments should focus on the pharmacokinetics of Mfp in the hAAG model rats. If the concentration of Mfp in plasma could be kept in relative high level for longer time (48-72 h, as it in human 
plasma) in the hAAG model rats. Then the binding between Mfp and hAAG in the plasma of model animals could be confirmed, and the gene therapy method would be proven potential effect on humans. 


\section{References}

Airaksinen, M. S., \& Saarma, M. (2002). The GDNF family: signalling, biological functions and therapeutic value. Nature Reviews Neuroscience, 3(5), 383.

Aiuti, A., Roncarolo, M. G., \& Naldini, L. (2017). Gene therapy for ADA-SCID, the first marketing approval of an ex vivo gene therapy in Europe: paving the road for the next generation of advanced therapy medicinal products. EMBO molecular medicine, 9(6), 737-740.

Al Yacoub, N., Romanowska, M., Haritonova, N., \& Foerster, J. (2007). Optimized production and concentration of lentiviral vectors containing large inserts. The journal of gene medicine, 9(7), 579-584.

Allocca, M., Tessitore, A., Cotugno, G., \& Auricchio, A. (2006). AAV-mediated gene transfer for retinal diseases. Expert opinion on biological therapy, 6(12), 1279-1294.

Alton, E. W., Armstrong, D. K., Ashby, D., Bayfield, K. J., Bilton, D., Bloomfield, E. V., ... \& Carvelli, P. (2015). Repeated nebulisation of non-viral CFTR gene therapy in patients with cystic fibrosis: a randomised, double-blind, placebo-controlled, phase $2 \mathrm{~b}$ trial. The Lancet Respiratory Medicine, 3(9), 684-691.

Asokan, A., Schaffer, D. V., \& Samulski, R. J. (2012). The AAV vector toolkit: poised at the clinical crossroads. Molecular Therapy, 20(4), 699-708.

Atchison, R. W., Casto, B. C., \& Hammon, W. M. (1965). Adenovirus-associated defective virus particles. Science, 149(3685), 754-755.

Baev, O. R., Rumyantseva, V. P., Tysyachnyu, O. V., Kozlova, O. A., \& Sukhikh, G. T. (2017). Outcomes of mifepristone usage for cervical ripening and induction 
of labour in full-term pregnancy. Randomized controlled trial. European Journal of Obstetrics \& Gynecology and Reproductive Biology, 217, 144-149.

Barroso-Chinea, P., Cruz-Muros, I., Afonso-Oramas, D., Castro-Hernández, J., Salas-Hernández, J., Chtarto, A., ... \& González-Hernández, T. (2016). Long-term controlled GDNF over-expression reduces dopamine transporter activity without affecting tyrosine hydroxylase expression in the rat mesostriatal system. Neurobiology of disease, $88,44-54$.

Bartus, R. T., \& Johnson Jr, E. M. (2017). Clinical tests of neurotrophic factors for human neurodegenerative diseases, part 1: where have we been and what have we learned?. Neurobiology of disease, 97, 156-168.

Bartus, R. T., \& Johnson Jr, E. M. (2017). Clinical tests of neurotrophic factors for human neurodegenerative diseases, part 2: Where do we stand and where must we go next?. Neurobiology of disease, 97, 169-178.

Bartus, R. T., Kordower, J. H., Johnson Jr, E. M., Brown, L., Kruegel, B. R., Chu, Y., ... \& Herzog, C. D. (2015). Post-mortem assessment of the short and long-term effects of the trophic factor neurturin in patients with a-synucleinopathies. Neurobiology of disease, 78, 162-171.

Baum, C., Modlich, U., Göhring, G., \& Schlegelberger, B. (2011). Concise review: managing genotoxicity in the therapeutic modification of stem cells. Stem Cells, 29(10), 1479-1484.

Beal, M. F. (2001). Experimental models of Parkinson's disease. Nature reviews neuroscience, 2(5), 325.

Birkmayer, W., Riederer, P., Ambrozi, L., \& Youdim, M. B. H. (1977). Implications of combined treatment with'Madopar'and L-deprenil in Parkinson's disease: a long-term study. The lancet, 309(8009), 439-443. 
Bjoerklund, A., Björklund, T., \& Kirik, D. (2009). Gene Therapy for Dopamine Replacement in Parkinson's Disease. Science translational medicine, 1(2), 2ps2-2ps2.

Blömer, U., Naldini, L., Kafri, T., Trono, D., Verma, I. M., \& Gage, F. H. (1997). Highly efficient and sustained gene transfer in adult neurons with a lentivirus vector. Journal of virology, 71(9), 6641-6649.

Bose, A., \& Beal, M. F. (2016). Mitochondrial dysfunction in Parkinson's disease. Journal of neurochemistry, 139, 216-231.

Braak, H., Del Tredici, K., Rüb, U., De Vos, R. A., Steur, E. N. J., \& Braak, E. (2003). Staging of brain pathology related to sporadic Parkinson's disease. Neurobiology of aging, 24(2), 197-211.

Bronstein, J. M., Tagliati, M., Alterman, R. L., Lozano, A. M., Volkmann, J., Stefani, A., .. \& Pahwa, R. (2011). Deep brain stimulation for Parkinson disease: an expert consensus and review of key issues. Archives of neurology, 68(2), 165-165.

Calne, D. B., Burton, K., Beckman, J., \& Martin, W. W. (1984). Dopamine agonists in Parkinson's disease. Canadian Journal of Neurological Sciences, 11(S1), 221-224.

Carter, B. J. (2004). Adeno-associated virus and the development of adeno-associated virus vectors: a historical perspective. Molecular therapy, 10(6), 981-989.

Cenci, M. A. (2014). Presynaptic mechanisms of I-DOPA-induced dyskinesia: the findings, the debate, and the therapeutic implications. Frontiers in neurology, 5, 242.

Chaudhuri, K. R., Healy, D. G., \& Schapira, A. H. (2006). Non-motor symptoms of Parkinson's disease: diagnosis and management. The Lancet Neurology, 5(3), 235-245. 
Chasserot-Golaz, S., Parcollet, P., \& Beck, G. (1989). Interrelationship between RU38486 and the P450 activities in rat liver. Journal of steroid biochemistry, 34(1-6), 473-478.

Chen, W., Xiao, Y., Chen, J., Liu, J., Shao, J., Li, T., ... \& Xu, J. (2017).

Sex-related pharmacokinetic differences and mechanisms of metapristone (RU486 metabolite). Scientific reports, 7(1), 17190.

Chen, W., Cheng, Y., Chen, J., Chen, J., Jiang, K., Zhou, Y., \& Jia, L. (2018). Pharmacokinetic differences of mifepristone between sexes in animals. Journal of pharmaceutical and biomedical analysis, 154, 108-115.

Cheng, S., Tereshchenko, J., Zimmer, V., Vachey, G., Pythoud, C., Rey, M., ... \& Bähr, M. (2018). Therapeutic efficacy of regulable GDNF expression for Huntington's and Parkinson's disease by a high-induction, background-free "GeneSwitch" vector. Experimental neurology, 309, 79-90.

Chirmule, N., Propert, K. J., Magosin, S. A., Qian, Y., Qian, R., \& Wilson, J. M. (1999). Immune responses to adenovirus and adeno-associated virus in humans. Gene therapy, 6(9), 1574.

Choi-Lundberg, D. L., Lin, Q., Chang, Y. N., Chiang, Y. L., Hay, C. M., Mohajeri, H., ... \& Bohn, M. C. (1997). Dopaminergic neurons protected from degeneration by GDNF gene therapy. Science, 275(5301), 838-841.

Chtarto, A., Humbert-Claude, M., Bockstael, O., Das, A. T., Boutry, S., Breger, L. S., ... \& Muller, R. N. (2016). A regulatable AAV vector mediating GDNF biological effects at clinically-approved sub-antimicrobial doxycycline doses. Molecular Therapy-Methods \& Clinical Development, 3, 16027.

Chtarto, A., Yang, X., Bockstael, O., Melas, C., Blum, D., Lehtonen, E., ... \& Velu, T. (2007). Controlled delivery of glial cell line-derived neurotrophic factor by a single tetracycline-inducible AAV vector. Experimental neurology, 204(1), 387-399. 
Chuah, M. K. L., Collen, D., \& Vandendriessche, T. (2004). Preclinical and clinical gene therapy for haemophilia. Haemophilia, 10, 119-125.

Colombo, S., Buclin, T., Décosterd, L. A., Telenti, A., Furrer, H., Lee, B. L., ... \& Eap, C. B. (2006). Orosomucoid (a1-acid glycoprotein) plasma concentration and genetic variants: Effects on human immunodeficiency virus protease inhibitor clearance and cellular accumulation. Clinical pharmacology \& therapeutics, 80(4), 307-318.

Connolly, B. S., \& Lang, A. E. (2014). Pharmacological treatment of Parkinson disease: a review. Jama, 311(16), 1670-1683.

Cotzias, G. C., Papavasiliou, P. S., \& Gellene, R. (1969). Modification of Parkinsonism-chronic treatment with L-dopa. New England Journal of Medicine, 280(7), 337-345.

Dass, B., \& Kordower, J. H. (2007). Gene therapy approaches for the treatment of Parkinson's disease. In Handbook of clinical neurology (Vol. 84, pp. 291-304). Elsevier.

Davidoff, A. M., Ng, C. Y., Zhou, J., Spence, Y., \& Nathwani, A. C. (2003). Sex significantly influences transduction of murine liver by recombinant adeno-associated viral vectors through an androgen-dependent pathway. Blood, 102(2), 480-488.

Deeks, S. G., Smith, M., Holodniy, M., \& Kahn, J. O. (1997). HIV-1 protease inhibitors: a review for clinicians. Jama, 277(2), 145-153.

Deraedt, R., Bonnat, C., Busigny, M., Chatelet, P., Cousty, C., Mouren, M., ... \& Salmon, J. (1985). Pharmacokinetics of RU 486. In The antiprogestin steroid RU 486 and human fertility control (pp. 103-122). Springer, Boston, MA.

Deyle, D. R., \& Russell, D. W. (2009). Adeno-associated virus vector integration. Current opinion in molecular therapeutics, 11(4), 442. 
Dias, V., Junn, E., \& Mouradian, M. M. (2013). The role of oxidative stress in Parkinson's disease. Journal of Parkinson's disease, 3(4), 461-491.

Dickson, D. W. et al. Neuropathological assessment of Parkinson's disease: refining the diagnostic criteria. Lancet Neurol. 8, 1150-1157 (2009).

Dirkx, M. F., den Ouden, H., Aarts, E., Timmer, M., Bloem, B. R., Toni, I., \& Helmich, R. C. (2016). The cerebral network of Parkinson's tremor: an effective connectivity fMRI study. Journal of Neuroscience, 36(19), 5362-5372.

Ebert, A. D., Barber, A. E., Heins, B. M., \& Svendsen, C. N. (2010). Ex vivo delivery of GDNF maintains motor function and prevents neuronal loss in a transgenic mouse model of Huntington's disease. Experimental neurology, 224(1), 155-162.

Engelender, S. (2008). Ubiquitination of a-synuclein and autophagy in Parkinson's disease. Autophagy, 4(3), 372-374.

Escallon, M. H., Ferrell, R. E., \& Kamboh, M. I. (1987). Genetic studies of low-abundance human plasma proteins. V. Evidence for a second orosomucoid structural locus (ORM2) expressed in plasma. American journal of human genetics, 41(3), 418.

Ferreira, J. J., Lees, A., Rocha, J. F., Poewe, W., Rascol, O., \& Soares-da-Silva, P. (2016). Opicapone as an adjunct to levodopa in patients with Parkinson's disease and end-of-dose motor fluctuations: a randomised, double-blind, controlled trial. The Lancet Neurology, 15(2), 154-165.

Flotte, T. R., Brantly, M. L., Spencer, L. T., Byrne, B. J., Spencer, C. T., Baker, D., \& Humphries, M. (2004). Phase I trial of intramuscular injection of a recombinant adeno-associated virus alpha 1-antitrypsin (rAAV2-CB-hAAT) gene vector to AAT-deficient adults. Human gene therapy, 15(1), 93-128.

Flotte, T. R., \& Carter, B. J. (1995). Adeno-associated virus vectors for gene therapy. Gene therapy, 2(6), 357-362. 
Flotte, T., Carter, B., Conrad, C., Guggino, W., Reynolds, T., Rosenstein, B., ... \& Wetzel, R. (1996). A phase i study of an adeno-associated virus-cftr gene vector in adult cf patients with mild lung disease. Johns hopkins children's center, baltimore, maryland. Human gene therapy, 7(9), 1145-1159.

Fournier, T., Medjoubi-N, N., \& Porquet, D. (2000). Alpha-1-acid glycoprotein. Biochimica et Biophysica Acta (BBA)-Protein Structure and Molecular Enzymology, 1482(1-2), 157-171.

Fox, S. H., Katzenschlager, R., Lim, S. Y., Ravina, B., Seppi, K., Coelho, M., ... \& Sampaio, C. (2011). The Movement Disorder Society evidence- based medicine review update: treatments for the motor symptoms of Parkinson's disease. Movement Disorders, 26(S3), S2-S41.

Frankel, J. P., Lees, A. J., Kempster, P. A., \& Stern, G. M. (1990). Subcutaneous apomorphine in the treatment of Parkinson's disease. Journal of Neurology, Neurosurgery \& Psychiatry, 53(2), 96-101.

Freed, C. R., Greene, P. E., Breeze, R. E., Tsai, W. Y., DuMouchel, W., Kao, R., ... \& Eidelberg, D. (2001). Transplantation of embryonic dopamine neurons for severe Parkinson's disease. New England Journal of Medicine, 344(10), 710-719.

Garnett, E. S., Firnau, G., \& Nahmias, C. (1983). Dopamine visualized in the basal ganglia of living man. Nature, 305(5930), 137.

Georgievska, B., Jakobsson, J., Persson, E., Ericson, C., Kirik, D., \& Lundberg, C. (2004). Regulated delivery of glial cell line-derived neurotrophic factor into rat striatum, using a tetracycline-dependent lentiviral vector. Human gene therapy, 15(10), 934-944.

Georgievska, B., Kirik, D., \& Björklund, A. (2002). Aberrant sprouting and downregulation of tyrosine hydroxylase in lesioned nigrostriatal dopamine neurons induced by long-lasting overexpression of glial cell line derived 
neurotrophic factor in the striatum by lentiviral gene transfer. Experimental neurology, 177(2), 461-474.

Gill, S. S., Patel, N. K., Hotton, G. R., O'Sullivan, K., McCarter, R., Bunnage, M., ... \& Heywood, P. (2003). Direct brain infusion of glial cell line-derived neurotrophic factor in Parkinson disease. Nature medicine, 9(5), 589.

Ginn, S. L., Alexander, I. E., Edelstein, M. L., Abedi, M. R., \& Wixon, J. (2013). Gene therapy clinical trials worldwide to 2012-an update. The journal of gene medicine, 15(2), 65-77.

Ginn, S. L., Amaya, A. K., Alexander, I. E., Edelstein, M., \& Abedi, M. R. (2018). Gene therapy clinical trials worldwide to 2017: An update. The journal of gene medicine, 20(5), e3015.

Grunberg, S. M., Weiss, M. H., Russell, C. A., Spitz, I. M., Ahmadi, J., Sadun, A., \& Sitruk-Ware, R. (2006). Long-term administration of mifepristone (RU486): clinical tolerance during extended treatment of meningioma. Cancer investigation, 24(8), 727-733.

Guenzel, A. J., Hillestad, M. L., Matern, D., \& Barry, M. A. (2014). Effects of adeno-associated virus serotype and tissue-specific expression on circulating biomarkers of propionic acidemia. Human gene therapy, 25(9), 837-843.

Hadaczek, P., Beyer, J., Kells, A., Narrow, W., Bowers, W., Federoff, H. J., ... \& Bankiewicz, K. S. (2011). Evaluation of an AAV2-based rapamycin-regulated glial cell line-derived neurotrophic factor (GDNF) expression vector system. PLoS One, 6(11), e27728.

Halliday, G. M., \& McCann, H. (2010). The progression of pathology in Parkinson's disease. Annals of the New York Academy of Sciences, 1184(1), 188-195. 
Halliday, G. M., Holton, J. L., Revesz, T. \& Dickson, D. W. Neuropathology underlying clinical variability in patients with synucleinopathies. Acta Neuropathol. 122, 187-204 (2011).

Han, Y., Chang, Q. A., Virag, T., West, N. C., George, D., Castro, M. G., \& Bohn, M. C. (2010). Lack of humoral immune response to the tetracycline (Tet) activator in rats injected intracranially with Tet-off rAAV vectors. Gene therapy, 17(5), 616.

Harris, J. R. (Ed.). (2012). Protein aggregation and fibrillogenesis in cerebral and systemic amyloid disease (Vol. 65). Springer Science \& Business Media.

Heikinheimo, O. (1990). Antiprogesterone steroid RU486. Pharmacokinetics and receptor binding in humans. Acta obstetricia et gynecologica Scandinavica, 69(4), 357-358.

Heikinheimo, O., Haukkamaa, M., \& Laehteenmaeki, P. (1989). Distribution of RU 486 and its demethylated metabolites in humans. The Journal of Clinical Endocrinology \& Metabolism, 68(2), 270-275.

Heikinheimo, O., Kekkonen, R., \& Lähteenmäki, P. (2003). The pharmacokinetics of mifepristone in humans reveal insights into differential mechanisms of antiprogestin action. Contraception, 68(6), 421-426.

Heikinheimo, O., Laähteenmaäki, P. L. A., Koivunen, E., Shoupe, D., Croxatto, H., Luukkainen, T., \& Laähteenmaäki, P. (1987). Metabolism and serum binding of $\mathrm{RU} 486$ in women after various single doses. Human Reproduction, 2(5), 379-385.

Heikinheimo, O., Pesonen, U., Huupponen, R., Koulu, M., \& Lähteenmäki, P. (1994). Hepatic metabolism and distribution of mifepristone and its metabolites in rats. Human Reproduction, 9(suppl_1), 40-46.

Henderson, C. E., Phillips, H. S., Pollock, R. A., Davies, A. M., Lemeulle, C., Armanini, M., ... \& LC, L. S. (1994). GDNF: a potent survival factor for 
motoneurons present in peripheral nerve and muscle. Science, 266(5187), 1062-1064.

Hermonat, P. L., \& Muzyczka, N. (1984). Use of adeno-associated virus as a mammalian DNA cloning vector: transduction of neomycin resistance into mammalian tissue culture cells. Proceedings of the National Academy of Sciences, 81(20), 6466-6470.

Herve, F., Duché, J. C., d'Athis, P., Marché, C., Barré, J., \& Tillement, J. P. (1996). Binding of disopyramide, methadone, dipyridamole, chlorpromazine, lignocaine and progesterone to the two main genetic variants of human alpha 1-acid glycoprotein: evidence for drug-binding differences between the variants and for the presence of two separate drug-binding sites on alpha 1-acid glycoprotein. Pharmacogenetics, 6(5), 403-415.

Hughes, A. J., Ben-Shlomo, Y., Daniel, S. E., \& Lees, A. J. (1992). What features improve the accuracy of clinical diagnosis in Parkinson's disease: a clinicopathologic study. Neurology, 42(6), 1142-1142.

Hughes, A. J., Daniel, S. E., \& Lees, A. J. (2001). Improved accuracy of clinical diagnosis of Lewy body Parkinson's disease. Neurology, 57(8), 1497-1499.

lacono, D., Geraci-Erck, M., Rabin, M. L., Adler, C. H., Serrano, G., Beach, T. G., \& Kurlan, R. (2015). Parkinson disease and incidental Lewy body disease: just a question of time?. Neurology, 85(19), 1670-1679.

Jang, G. R., Wrighton, S. A., \& Benet, L. Z. (1996). Identification of CYP3A4 as the principal enzyme catalyzing mifepristone (RU 486) oxidation in human liver microsomes. Biochemical pharmacology, 52(5), 753-761.

Jankovic, J. (2008). Parkinson's disease: clinical features and diagnosis. Journal of neurology, neurosurgery \& psychiatry, 79(4), 368-376.

Jankovic, J., \& Poewe, W. (2012). Therapies in Parkinson's disease. Current opinion in neurology, 25(4), 433-447. 
Jiao, S., Gurevich, V., \& Wolff, J. A. (1993). Long-term correction of rat model of Parkinson's disease by gene therapy. Nature, 362(6419), 450.

Jellinger, K. A. (2007). More frequent Lewy bodies but less frequent Alzheimer-type lesions in multiple system atrophy as compared to age-matched control brains. Acta neuropathologica, 114(3), 299-303.

Johansen, J., Rosenblad, C., Andsberg, K., Møller, A., Lundberg, C., Björlund, A., \& Johansen, T. E. (2002). Evaluation of Tet-on system to avoid transgene down-regulation in ex vivo gene transfer to the CNS. Gene therapy, 9(19), 1291.

Jolliet-Riant, P., Boukef, M. F., Duche, J. C., Simon, N., \& Tillement, J. P. (1998). The genetic variant $A$ of human alpha 1-acid glycoprotein limits the blood to brain transfer of drugs it binds. Life sciences, 62(14), PL219-PL226.

Kaplitt, M. G., Feigin, A., Tang, C., Fitzsimons, H. L., Mattis, P., Lawlor, P. A., ... \& During, M. J. (2007). Safety and tolerability of gene therapy with an adeno-associated virus (AAV) borne GAD gene for Parkinson's disease: an open label, phase I trial. The Lancet, 369(9579), 2097-2105.

Kato, R., \& Yamazoe, Y. (1992). Sex-specific cytochrome P450 as a cause of sex-and species-related differences in drug toxicity. Toxicology letters, 64, 661-667.

Katzenschlager, R., Hughes, A., Evans, A., Manson, A. J., Hoffman, M., Swinn, L., ... \& Lees, A. J. (2005). Continuous subcutaneous apomorphine therapy improves dyskinesias in Parkinson's disease: a prospective study using singledose challenges. Movement disorders: official journal of the Movement Disorder Society, 20(2), 151-157.

Kawai, S., Nieman, L. K., Brandon, D. D., Udelsman, R., Loriaux, D. L., \& Chrousos, G. P. (1987). Pharmacokinetic properties of the antiglucocorticoid and antiprogesterone steroid RU 486 in man. Journal of Pharmacology and Experimental Therapeutics, 241(2), 401-406. 
Kay, M. A., Manno, C. S., Ragni, M. V., Larson, P. J., Couto, L. B., McClelland, A., ... \& Arruda, V. (2000). Evidence for gene transfer and expression of factor IX in haemophilia B patients treated with an AAV vector. Nature genetics, 24(3), 257.

Kay, M. A., \& Nakai, H. (2003). Looking into the safety of AAV vectors. Nature, 424(6946), 251.

Kohn, D. B., Sadelain, M., \& Glorioso, J. C. (2003). Occurrence of leukaemia following gene therapy of X-linked SCID. Nature Reviews Cancer, 3(7), 477.

Kordower, J. H., \& Bjorklund, A. (2013). Trophic factor gene therapy for Parkinson's disease. Movement Disorders, 28(1), 96-109.

Kordower, J. H., Herzog, C. D., Dass, B., Bakay, R. A., Stansell, J., Gasmi, M., \& Bartus, R. T. (2006). Delivery of neurturin by AAV2 (CERE-120)-mediated gene transfer provides structural and functional neuroprotection and neurorestoration in MPTP-treated monkeys. Annals of neurology, 60(6), 706-715.

Kotin, R. M., Siniscalco, M., Samulski, R. J., Zhu, X. D., Hunter, L., Laughlin, C. A., ... \& Berns, K. I. (1990). Site-specific integration by adeno-associated virus. Proceedings of the National Academy of Sciences, 87(6), 2211-2215.

Kotterman, M. A., Chalberg, T. W., \& Schaffer, D. V. (2015). Viral vectors for gene therapy: translational and clinical outlook. Annual review of biomedical engineering, 17, 63-89.

Lang, A. E., Gill, S., Patel, N. K., Lozano, A., Nutt, J. G., Penn, R., ... \& Brodsky, M. A. (2006). Randomized controlled trial of intraputamenal glial cell line-derived neurotrophic factor infusion in Parkinson disease. Annals of neurology, 59(3), 459-466.

Lebherz, C., Maguire, A., Tang, W., Bennett, J., \& Wilson, J. M. (2008). Novel AAV serotypes for improved ocular gene transfer. The Journal of Gene Medicine: A 
cross-disciplinary journal for research on the science of gene transfer and its clinical applications, 10(4), 375-382.

Le Guiner, C., Stieger, K., Toromanoff, A., Guilbaud, M., Mendes-Madeira, A., Devaux, M., ... \& Adjali, O. (2014). Transgene regulation using the tetracycline-inducible TetR-KRAB system after AAV-mediated gene transfer in rodents and nonhuman primates. PloS one, 9(9), e102538.

Lehmann, J. M., McKee, D. D., Watson, M. A., Willson, T. M., Moore, J. T., \& Kliewer, S. A. (1998). The human orphan nuclear receptor PXR is activated by compounds that regulate CYP3A4 gene expression and cause drug interactions. The Journal of clinical investigation, 102(5), 1016-1023.

LeWitt, P. A., Rezai, A. R., Leehey, M. A., Ojemann, S. G., Flaherty, A. W., Eskandar, E. N., ... \& Tatter, S. B. (2011). AAV2-GAD gene therapy for advanced Parkinson's disease: a double-blind, sham-surgery controlled, randomised trial. The Lancet Neurology, 10(4), 309-319.

Lillie, J. W., \& Green, M. R. (1989). Transcription activation by the adenovirus E1a protein. Nature, 338(6210), 39.

Limousin, P., Pollak, P., Benazzouz, A., Hoffmann, D., Le Bas, J. F., Perret, J. E., ... \& Broussolle, E. (1995). Effect on parkinsonian signs and symptoms of bilateral subthalamic nucleus stimulation. The Lancet, 345(8942), 91-95.

Lin, L. F., Doherty, D. H., Lile, J. D., Bektesh, S., \& Collins, F. (1993). GDNF: a glial cell line-derived neurotrophic factor for midbrain dopaminergic neurons. Science, 260(5111), 1130-1132.

Lindvall, O., Brundin, P., Widner, H., Rehncrona, S., Gustavii, B., Frackowiak, R., ... \& Marsden, C. D. (1990). Grafts of fetal dopamine neurons survive and improve motor function in Parkinson's disease. Science, 247(4942), 574-577. 
Mahlknecht, P., Hotter, A., Hussl, A., Esterhammer, R., Schocke, M., \& Seppi, K. (2010). Significance of MRI in diagnosis and differential diagnosis of Parkinson's disease. Neurodegenerative Diseases, 7(5), 300-318.

Maguire, C. A., Crommentuijn, M. H., Mu, D., Hudry, E., Serrano-Pozo, A., Hyman, B. T., \& Tannous, B. A. (2013). Mouse gender influences brain transduction by intravascularly administered AAV9. Molecular Therapy, 21(8), 1470-1471.

Manfredsson, F. P., Burger, C., Rising, A. C., Zuobi-Hasona, K., Sullivan, L. F., Lewin, A. S., ... \& Mandel, R. J. (2009). Tight Long-term dynamic doxycycline responsive nigrostriatal GDNF using a single rAAV vector. Molecular Therapy, 17(11), 1857-1867.

Maude, S. L., Frey, N., Shaw, P. A., Aplenc, R., Barrett, D. M., Bunin, N. J., ... \& Mahnke, Y. D. (2014). Chimeric antigen receptor T cells for sustained remissions in leukemia. New England Journal of Medicine, 371(16), 1507-1517.

May, C., Rivella, S., Callegari, J., Heller, G., Gaensler, K. M., Luzzatto, L., \& Sadelain, M. (2000). Therapeutic haemoglobin synthesis in $\beta$-thalassaemic mice expressing lentivirus-encoded human $\beta$-globin. Nature, 406(6791), 82.

Mittermeyer, G., Christine, C. W., Rosenbluth, K. H., Baker, S. L., Starr, P., Larson, P., ... \& Bankiewicz, K. S. (2012). Long-term evaluation of a phase 1 study of AADC gene therapy for Parkinson's disease. Human gene therapy, 23(4), 377-381.

Moguilewsky, M., \& Philibert, D. (1985). Biochemical profile of RU 486. In The antiprogestin steroid $R U 486$ and human fertility control (pp. 87-97). Springer, Boston, MA.

Murphy, S. L., \& High, K. A. (2008). Gene therapy for haemophilia. British journal of haematology, 140(5), 479-487.

Nirenberg, M. W. (1967). Will society be prepared?. Science, 157(3789), 633-633. 
No, D., Yao, T. P., \& Evans, R. M. (1996). Ecdysone-inducible gene expression in mammalian cells and transgenic mice. Proceedings of the National Academy of Sciences, 93(8), 3346-3351.

Olanow, C. W. et al. A double-blind controlled trial of bilateral fetal nigral transplantation in Parkinson's disease. Ann. Neurol. 54, 403-414 (2003).

Olanow, C. W., Kieburtz, K., Odin, P., Espay, A. J., Standaert, D. G., Fernandez, H. H., ... \& Pritchett, Y. (2014). Continuous intrajejunal infusion of levodopa-carbidopa intestinal gel for patients with advanced Parkinson's disease: a randomised, controlled, double-blind, double-dummy study. The Lancet Neurology, 13(2), 141-149.

Olanow, C. W., Obeso, J. A., \& Stocchi, F. (2006). Continuous dopamine-receptor treatment of Parkinson's disease: scientific rationale and clinical implications. The Lancet Neurology, 5(8), 677-687.

Olanow, C. W., Stern, M. B., \& Sethi, K. (2009). The scientific and clinical basis for the treatment of Parkinson disease (2009). Neurology, 72(21 Supplement 4), S1-S136.

Olson, R. E., \& Christ, D. D. (1996). Plasma protein binding of drugs. In Annual reports in medicinal chemistry, 31, 327-336

Orlowski, R. J., Porter, D. L., \& Frey, N. V. (2017). The promise of chimeric antigen receptor T cells (CART s) in leukaemia. British journal of haematology, 177(1), 13-26.

Outeiro, T. F., Koss, D. J., Erskine, D., Walker, L., Kurzawa-Akanbi, M., Burn, D., ... \& Attems, J. (2019). Dementia with Lewy bodies: an update and outlook. Molecular neurodegeneration, 14(1), 5.

Palfi, S., Gurruchaga, J. M., Ralph, G. S., Lepetit, H., Lavisse, S., Buttery, P. C., ... \& Iwamuro, H. (2014). Long-term safety and tolerability of ProSavin, a lentiviral vector-based gene therapy for Parkinson's disease: a dose escalation, open-label, 
phase 1/2 trial. The Lancet, 383(9923), 1138-1146.

Paneda, A., Vanrell, L., Mauleon, I., Crettaz, J. S., Berraondo, P., Timmermans, E. J., ... \& Fontanellas, A. (2009). Effect of adeno-associated virus serotype and genomic structure on liver transduction and biodistribution in mice of both genders. Human gene therapy, 20(8), 908-917.

Paus, S., Brecht, H. M., Köster, J., Seeger, G., Klockgether, T., \& Wülner, U. (2003). Sleep attacks, daytime sleepiness, and dopamine agonists in Parkinson's disease. Movement Disorders, 18(6), 659-667.

Piccini, P., Brooks, D. J., Björklund, A., Gunn, R. N., Grasby, P. M., Rimoldi, O., ... \& Lindvall, O. (1999). Dopamine release from nigral transplants visualized in vivo in a Parkinson's patient. Nature neuroscience, 2(12), 1137.

Poewe, W., \& Antonini, A. (2015). Novel formulations and modes of delivery of levodopa. Movement Disorders, 30(1), 114-120.

Poewe, W., Seppi, K., Tanner, C. M., Halliday, G. M., Brundin, P., Volkmann, J., ... \& Lang, A. E. (2017). Parkinson disease. Nature reviews Disease primers, 3 , 17013.

Politis, M., Wu, K., Molloy, S., G. Bain, P., Chaudhuri, K. R., \& Piccini, P. (2010). Parkinson's disease symptoms: the patient's perspective. Movement Disorders, 25(11), 1646-1651.

Politis, M. (2014). Neuroimaging in Parkinson disease: from research setting to clinical practice. Nature Reviews Neurology, 10(12), 708.

Porter, D. L., Levine, B. L., Kalos, M., Bagg, A., \& June, C. H. (2011). Chimeric antigen receptor-modified $\mathrm{T}$ cells in chronic lymphoid leukemia. New England Journal of Medicine, 365(8), 725-733.

Quintino, L., Manfré, G., Wettergren, E. E., Namislo, A., Isaksson, C., \& Lundberg, C. (2013). Functional neuroprotection and efficient regulation of GDNF using 
destabilizing domains in a rodent model of Parkinson's disease. Molecular Therapy, 21(12), 2169-2180.

Ran, F. A., Hsu, P. D., Wright, J., Agarwala, V., Scott, D. A., \& Zhang, F. (2013). Genome engineering using the CRISPR-Cas9 system. Nature protocols, $8(11)$, 2281.

Rao, G., Fisch, L., Srinivasan, S., D'Amico, F., Okada, T., Eaton, C., \& Robbins, C. (2003). Does this patient have Parkinson disease?. Jama, 289(3), 347-353.

Robbins, P. D., \& Ghivizzani, S. C. (1998). Viral vectors for gene therapy. Pharmacology \& therapeutics, 80(1), 35-47.

Rosenberg, S. A., Aebersold, P., Cornetta, K., Kasid, A., Morgan, R. A., Moen, R., ... \& Merino, M. J. (1990). Gene transfer into humans-immunotherapy of patients with advanced melanoma, using tumor-infiltrating lymphocytes modified by retroviral gene transduction. New England Journal of Medicine, 323(9), 570-578.

Rubí, B., \& Maechler, P. (2010). Minireview: new roles for peripheral dopamine on metabolic control and tumor growth: let's seek the balance. Endocrinology, 151(12), 5570-5581.

Sadelain, M. (2015). CAR therapy: the CD19 paradigm. The Journal of clinical investigation, 125(9), 3392-3400.

Sadelain, M., Rivière, I., \& Riddell, S. (2017). Therapeutic T cell engineering. Nature, 545(7655), 423.

Sarkar, N. N. (2002). Mifepristone: bioavailability, pharmacokinetics and use-effectiveness. European Journal of Obstetrics \& Gynecology and Reproductive Biology, 101(2), 113-120.

Sartor, O., \& Figg, W. D. (1996). Mifepristone: antineoplastic studies. Clinical obstetrics and gynecology, 39(2), 498-505. 
Sauer, H., \& Oertel, W. H. (1994). Progressive degeneration of nigrostriatal dopamine neurons following intrastriatal terminal lesions with 6-hydroxydopamine: a combined retrograde tracing and immunocytochemical study in the rat. Neuroscience, 59(2), 401-415.

Schapira, A. H. V. (2007). Mitochondrial dysfunction in Parkinson's disease. 1261

Schapira, A. H. (2011). Monoamine oxidase B inhibitors for the treatment of Parkinson's disease. CNS drugs, 25(12), 1061-1071.

Schapira, A. H., Fox, S. H., Hauser, R. A., Jankovic, J., Jost, W. H., Kenney, C., ... \& Anand, R. (2017). Assessment of safety and efficacy of safinamide as a levodopa adjunct in patients with Parkinson disease and motor fluctuations: a randomized clinical trial. JAMA neurology, 74(2), 216-224.

Schmid, K. (1950). Preparation and properties of an acid glycoprotein prepared from human plasma. Journal of the american chemical society, 72(6), 2816-2816.

Schmiedlin-Ren, P., Edwards, D. J., Fitzsimmons, M. E., He, K., Lown, K. S., Woster, P. M., ... \& Watkins, P. B. (1997). Mechanisms of enhanced oral availability of CYP3A4 substrates by grapefruit constituents: decreased enterocyte CYP3A4 concentration and mechanism-based inactivation by furanocoumarins. Drug Metabolism and Disposition, 25(11), 1228-1233.

Seidel, K., Mahlke, J., Siswanto, S., Krüger, R., Heinsen, H., Auburger, G., ... \& den Dunnen, W. (2015). The brainstem pathologies of Parkinson's disease and dementia with Lewy bodies. Brain pathology, 25(2), 121-135.

Shahrokh, K., Cheatham III, T. E., \& Yost, G. S. (2012). Conformational dynamics of CYP3A4 demonstrate the important role of Arg212 coupled with the opening of ingress, egress and solvent channels to dehydrogenation of 4-hydroxy-tamoxifen. Biochimica et Biophysica Acta (BBA)-General Subjects, 1820(10), 1605-1617. 
Silva, G., Poirot, L., Galetto, R., Smith, J., Montoya, G., Duchateau, P., \& Pâques, F. (2011). Meganucleases and other tools for targeted genome engineering: perspectives and challenges for gene therapy. Current gene therapy, 11(1), 11-27.

Simuni, T., \& Hurtig, H. (2008). Levodopa: a pharmacologic miracle four decades later. Parkinson's Disease: Diagnosis and Clinical Management, 230.

Soler, R. M., Dolcet, X., Encinas, M., Egea, J., Bayascas, J. R., \& Comella, J. X. (1999). Receptors of the glial cell line-derived neurotrophic factor family of neurotrophic factors signal cell survival through the phosphatidylinositol 3-kinase pathway in spinal cord motoneurons. Journal of neuroscience, 19(21), 9160-9169.

Song, S., Embury, J., Laipis, P. J., Berns, K. I., Crawford, J. M., \& Flotte, T. R. (2001). Stable therapeutic serum levels of human alpha-1 antitrypsin (AAT) after portal vein injection of recombinant adeno-associated virus (rAAV) vectors. Gene therapy, 8(17), 1299.

Spitz, I. M., Bardin, C. W., Benton, L., \& Robbins, A. (1998). Early pregnancy termination with mifepristone and misoprostol in the United States. New England Journal of Medicine, 338(18), 1241-1247.

Stoessl, A. J., Lehericy, S., \& Strafella, A. P. (2014). Imaging insights into basal ganglia function, Parkinson's disease, and dystonia. The Lancet, 384(9942), 532-544.

Surace, E. M., \& Auricchio, A. (2008). Versatility of AAV vectors for retinal gene transfer. Vision research, 48(3), 353-359.

Tereshchenko, J., Maddalena, A., Bähr, M., \& Kügler, S. (2014). Pharmacologically controlled, discontinuous GDNF gene therapy restores motor function in a rat model of Parkinson's disease. Neurobiology of disease, 65, $35-42$. 
Thrasher, A. J., \& Williams, D. A. (2017). Evolving gene therapy in primary immunodeficiency. Molecular Therapy, 25(5), 1132-1141.

Tomlinson, C. L., Stowe, R., Patel, S., Rick, C., Gray, R., \& Clarke, C. E. (2010). Systematic review of levodopa dose equivalency reporting in Parkinson's disease. Movement disorders, 25(15), 2649-2653.

Tratschin, J. D., West, M. H., Sandbank, T. R. A. C. E. Y., \& Carter, B. J. (1984). A human parvovirus, adeno-associated virus, as a eucaryotic vector: transient expression and encapsidation of the procaryotic gene for chloramphenicol acetyltransferase. Molecular and cellular biology, 4(10), 2072-2081.

Urien, S., Bree, F., Testa, B., \& Tillement, J. P. (1991). pH-dependency of basic ligand binding to a1-acid glycoprotein (orosomucoid). Biochemical Journal, 280(1), 277-280.

Urnov, F. D., Rebar, E. J., Holmes, M. C., Zhang, H. S., \& Gregory, P. D. (2010). Genome editing with engineered zinc finger nucleases. Nature Reviews Genetics, 11(9), 636.

Van Dijk, W., Havenaar, E. C., \& Brinkman-Van der Linden, E. C. M. (1995). a 1-acid glycoprotein (orosomucoid): pathophysiological changes in glycosylation in relation to its function. Glycoconjugate journal, 12(3), 227-233.

Vandendriessche, T., Thorrez, L., Acosta- Sanchez, A., Petrus, I., Wang, L., Ma, L., ... \& Collen, D. (2007). Efficacy and safety of adeno- associated viral vectors based on serotype 8 and 9 vs. lentiviral vectors for hemophilia B gene therapy. Journal of Thrombosis and Haemostasis, 5(1), 16-24.

Voges, J., Hilker, R., Bötzel, K., Kiening, K. L., Kloss, M., Kupsch, A., ... \& Pinsker, M. O. (2007). Thirty days complication rate following surgery performed for deepbrain-stimulation. Movement disorders: official journal of the Movement Disorder Society, 22(10), 1486-1489. 
Volpicelli-Daley, L. A., Gamble, K. L., Schultheiss, C. E., Riddle, D. M., West, A. B., \& Lee, V. M. Y. (2014). Formation of $\alpha$-synuclein Lewy neurite-like aggregates in axons impedes the transport of distinct endosomes. Molecular biology of the cell, 25(25), 4010-4023.

Von Moltke, L. L., Durol, A. L. B., Duan, S. X., \& Greenblatt, D. J. (2000). Potent mechanism-based inhibition of human CYP3A in vitro by amprenavir and ritonavir: comparison with ketoconazole. European journal of clinical pharmacology, 56(3), 259-261.

Wang, J. J., Zhang, T., Niu, D. B., Wang, K., Li, K. R., Xue, B., \& Wang, X. M. (2006). Doxycycline-regulated co-expression of GDNF and TH in PC12 cells. Neuroscience letters, 401(1-2), 142-145.

Wang, S., Ren, P., Guan, Y., Zou, C., Fu, L., \& Zhang, Y. (2013). Inducible regulation of GDNF expression in human neural stem cells. Science China Life Sciences, 56(1), 32-39.

Wang, X., \& Rivière, I. (2016). Clinical manufacturing of CAR T cells: foundation of a promising therapy. Molecular Therapy-Oncolytics, 3, 16015.

Wang, Y., O'Malley, B. W., \& Tsai, S. Y. (1994). A regulatory system for use in gene transfer. Proceedings of the National Academy of Sciences, 91(17), 8180-8184.

Wang, Z., Halbert, C. L., Lee, D., Butts, T., Tapscott, S. J., Storb, R., \& Miller, A. D. (2014). Elimination of contaminating cap genes in AAV vector virions reduces immune responses and improves transgene expression in a canine gene therapy model. Gene therapy, 21(4), 363.

Wanka, F., Cairns, T., Boecker, S., Berens, C., Happel, A., Zheng, X., ... \& Meyer, V. (2016). Tet-on, or Tet-off, that is the question: advanced conditional gene expression in Aspergillus. Fungal Genetics and Biology, 89, 72-83. 
Weidinger, S., Müller, T., Schwarzfischer, F., \& Cleve, H. (1987). Three new orosomucoid (ORM) variants revealed by isoelectric focusing and print immunofixation. Human genetics, 77(3), 286-288.

Weimer, H. E., Mehl, J. W., \& Winzler, R. J. (1950). Studies on the mucoproteins of human plasma $V$. Isolation and characterization of a homogeneous mucoprotein. Journal of Biological chemistry, 185(2), 561-568.

Windels, F., Thevathasan, W., Silburn, P., \& Sah, P. (2015). Where and what is the PPN and what is its role in locomotion?. Brain, 138(5), 1133-1134.

World Health Organization (WHO). (2016). WHO Model List of Essential Medicines-19th List. April 2015-Amended November 2015. Acesso em, 23.

Xu, Q., Park, Y., Huang, X., Hollenbeck, A., Blair, A., Schatzkin, A., \& Chen, H. (2010). Physical activities and future risk of Parkinson disease. Neurology, 75(4), 341-348.

Yang, X., Mertens, B., Lehtonen, E., Vercammen, L., Bockstael, O., Chtarto, A., ... \& Sarre, S. (2009). Reversible neurochemical changes mediated by delayed intrastriatal glial cell line-derived neurotrophic factor gene delivery in a partial Parkinson's disease rat model. The journal of gene medicine, 11(10), 899-912.

Ye, X., Rivera, V. M., Zoltick, P., Cerasoli, F., Schnell, M. A., Gao, G. P., ... \& Wilson, J. M. (1999). Regulated delivery of therapeutic proteins after in vivo somatic cell gene transfer. Science, 283(5398), 88-91.

Yuasa, I., Umetsu, K., Suenaga, K., \& Robinet-Levy, M. (1986). Orosomucoid (ORM) typing by isoelectric focusing: evidence for two structural loci ORM1 and ORM2. Human genetics, 74(2), 160-161.

Yuasa, I., Suenaga, K., Umetsu, K., Ito, K., \& Robinet-Levy, M. (1987). Orosomucoid (ORM) typing by isoelectric focusing: evidence for gene duplication of ORM1 and genetic polymorphism of ORM2. Human genetics, 77(3), 255-258. 
Yuasa, I., Umetsu, K., Vogt, U., Nakamura, H., Nanba, E., Tamaki, N., \& Irizawa, Y. (1997). Human orosomucoid polymorphism: molecular basis of the three common ORM1 alleles, ORM1* F1, ORM1* F2, and ORM1* S. Human genetics, 99(3), 393-398.

Yuasa, I., Weidinger, S., Umetsu, K., Suenaga, K., Ishimoto, G., Eap, B. C., ... \& Baumann, P. (1993). Orosomucoid system: 17 additional orosomucoid variants and proposal for a new nomenclature. Vox sanguinis, 64(1), 47-55.

Zanger, U. M., \& Schwab, M. (2013). Cytochrome P450 enzymes in drug metabolism: regulation of gene expression, enzyme activities, and impact of genetic variation. Pharmacology \& therapeutics, 138(1), 103-141.

Zhang, Y., Zhang, F., Li, X., Baller, J. A., Qi, Y., Starker, C. G., ... \& Voytas, D. F. (2013). Transcription activator-like effector nucleases enable efficient plant genome engineering. Plant physiology, 161(1), 20-27.

Zeldin, R. K., \& Petruschke, R. A. (2004). Pharmacological and therapeutic properties of ritonavir-boosted protease inhibitor therapy in HIV-infected patients. Journal of antimicrobial chemotherapy, 53(1), 4-9. 


\section{Annexes}

\subsection{Abbreviations}

6-OHDA: 6-hydroxy dopamine

AAG: alpha-1 acid glycoprotein

Apo: Apomorphine

AUC: Area under the curve

AAV: Adeno Associated Virus

BBB: Blood brain barrier

BW: Body weight

$\mathbf{C}_{\max }:$ Maximal concentration

CNS: Central nervous system

CYP3A: Cytochrome P-450 monooxygenase 3A

CYP3A4: Cytochrome P-450 monooxygenase 3A4

DA: dopamine/dopamiregic

DAT: Dopamine transporter

DOPAC: 3,4-Dihydroxyphenylacetic acid

DPM: Days post mifepristone application

dPR: truncated progesterone receptor 
EDTA: Ethylenediaminetetraacetic acid

EGFP: Enhanced green fluorescence protein

ELISA: Enzyme linked immune sorbent assay

EMA: European marketing authorization

FDA: Food and drug administration

Gal4: Gal4 DNA binding domain

GDNF: Glial cell derived neurotrophic factor

hAAG: human alpha-1 acid glycoprotein

HPLC: High pressure liquid chromatography

hPR-LBD: Human progesterone recptor ligand binding domain

HVA: Homovanillic acid

i.p.: intraperitoneal

Mfp: Mifepristone

P65: P65 activation domain

PBS: Phosphate buffered saline

PCR: Polymerase chain reaction

PD: Parkinson's disease

PFA: Paraformaldehyde

PR: progesterone receptor

REF: Reference

Rpm: rotations per minute 
SD: Standard deviation

SN: Substantia nigra

SV40: Simian virus 40 poli adenilation sequence

TB: Synthetic transcription factor

TH: Tyrosine hydroxylase

UAS-TATA: minimal TATA promoter with 6 upstream Gal4 binding sites

Vg: viral genome 


\subsection{Publications}

\section{PhD study:}

Cheng, S., Tereshchenko, J., Zimmer, V., Vachey, G., Pythoud, C., Rey, M., ... \& Bähr, M. (2018). Therapeutic efficacy of regulable GDNF expression for Huntington's and Parkinson's disease by a high-induction, background-free "GeneSwitch" vector. Experimental neurology, 309, 79-90.

\section{Master study:}

Cheng, S., Zhang, Y. F., Zeng, Z. Q., Lin, J., Zhang, Y. W., Ni, H., \& Li, H. H. (2015). Screening, separating, and completely recovering polyphenol oxidases and other biochemicals from sweet potato wastewater in starch production. Applied microbiology and biotechnology,99(4), 1745-1753. 


\section{Acknowledgment}

I'm very grateful to my dear supervisor, Dr. Sebastian Kügler. Thank you so much for your consistent support. I faced quite a lot of difficulties at beginning of my $\mathrm{PhD}$, I cannot come to this step without your encouragements definitely. It's easy to share happiness with others, but, I came to you with my questions or demands frequently, you always smile and guide me with your abundant knowledge. We solved lots of difficult problem together, I benefited a lot from the process. Your enthusiasm for science will always be an inspiration for me. In my future career, l'll keep it in mind to find the real reason behind surface in scientific research.

I want to thank Prof. Markus Zweckstetter and Prof. André Fischer for being part of my thesis committee. I got lots of invaluable suggestions from them. Thank you for their time devotion in my PhD project. I'm also grateful to Prof. Thomas Dresbach, Prof. Thomas Meyer and Prof. Michael Müller for joining my thesis examination board.

Thank you for all my colleges in the lab. Everyone is very friendly with me and gave me many good advices. Thank you Monika, I'm really enjoy the time to learn experimental techniques with you, you are so patient and your experimental skills are excellent. I also appreciate Maryna, Sonja, Anupam, Sam, Sofia, Kristian, Muzna, Claudia, Grit and Johan for their kindly supports and providing a good lab environment.

I'm thankful for my wife, Biyao Wang. She shared all my experience, when I collected important positive data, she brought me to celebrate; when I was in dilemma, she encouraged me and discussed with me how to solve it. I can't remember how many nights or weekends, she let me throwing myself into experiments even it disorganized her plan, but she always understands me and stays together with me. It's my luckiest to marry you. 
Supports from my parents and grandparents are indispensable for my $\mathrm{PhD}$ study. They raised me and encouraged me to work in science. I feel so sorry that I have to live abroad many years, so far with them. They are always in my first consideration for everything.

I appreciate the innumerable helps from my best friend, Lei Cui. When I faced challenge in my experiments, you gave me lots of invaluable suggestions. When I was a freshman in abroad, I received so many kindly helps from you. I also want to thank Citong Zhang and Dongye Li. We can meet only once every year, but I really enjoy the time and expect for the next meet. Thank you Tianxiang Lu for the interesting beer time and basketball play.

Last but not least, I really appreciate the rats sacrificed for the project. I tried my best to reduce their suffering. I always feel sad for them, but the only thing I can do is to decrease their suffering and planning experiments as careful as I can. More positive results make their generous sacrifice meaningful. 